WSRC-RP- $-92-903$

DE93 005791

\title{
The Comparison of DYNA3D to Approximate Solutions for a Partially-Full Waste Storage Tank Subjected to Seismic Loading (U)
}

M. Zaslawsky and W. N. Kennedy

Westinghouse Savannah River Company

Savannah River Site

Aiken, SC 29808

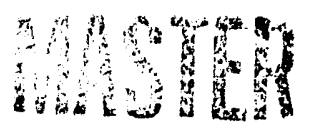

Prepared for the U. S. Lix partment of Energy under contract No. DE-AC09-89SR18035 


\title{
The Comparison of DYNA3D to Approximate Solutions for a Partially-Full Waste Storage Tank Subjected to Seismic Loading
}

\author{
M. Zaslawsky and W.N. Kennedy \\ Westinghouse Savannah River Company \\ Savannah River Site \\ Aiken, SC 29808
}

\section{Introduction}

Mathematical solutions to the problem consisting of a partially-full waste tank subjected to seismic loading, embedded in soil, is classically difficult in that one has to address:

- soil-strusture interaction

- fluid-structure interaction

- non-linear behavior of materials

- dynamic effects

Separating the problem and applying numerous assumptions will yield approximate solutions. Codes such as SASSI, a 3D soil-structure interaction code, do not address the fluid-structure interaction, interaction betrveen the walls and the soil, non-linear effects, and are limited in the size of the problem (i.e. number of interaction nodes).

Computer programs that address many of these problems are DYNA3D or NIKE3D; the former being an explicit code and the latter an implicit code. Attention in this paper will be focused on DYNA3D and specifically the fluidstructure interaction. A paper by Chen, et. al., ${ }^{1}$ has addressed the effect of soil-structure interaction by comparing AFLUSH, CLASSI, and DYNA3D by relating the Cap model in DYNA3D to the Seed and Idriss model.

Validation problems were developed for SASSI as part of the licensing of the Diablo Canyon Reactor and approved by the Nuclear Regulatory Commission (NRC). These validation problems therefore meet the quality assurance requirements of the Department of Energy (DOE), Westinghouse Savannah River Company (WSRC), and the American National Standards Institute (ANSI) NQA-1 and are acceptable for use at the Savannah River Site (SRS) as well as other DOE sites. The sample problems in the Users Manual of DYNA and NIKE are illustrative of the type of problems the cades are capable of addressing and to some extent bow to prepare the input file. A set of validation problems for the Lawrence Livermore National Laboratory (LLNL) codes in general do not exist nor are the users manuals under document control. The Ueers Manual for DYNA3D as well as the pre- and post-processors (INGRID and TAURUS respectively), leave much to the analyst depending on which version of the manual one uses. Commercial codes such as ANSYS and ABAQUS have extensive documentation on their use. The Livermore codes, in contrast, are LLNL/DOE codes, and while in the public domain, have limited documentation compared to the commercial codes. While the Livermore manuals are essentially free, the commencial manuals cost approximately $\$ 300.00$ per manual. In addition, the staffs in the commercial organizations to validate the codes etc., are significantly langer than the Livermore ataff devoted to code development.

DYNA3D was written with the objective of addressing impulsive or explosive type forces and not seismic loading. DYNA would be very appropriate for evaluating the effects of tomadoes on structure. Due to the features of slide surface or slide line capability, developed exclusively at Livermore by John Hallquist, and additional features which include:

- non-linear capability

- pre- and poet-proceseror

- bandwidth minimization

- a valid constitutive relacionship for fluids

- an extensive library of constitutive relationships 
DYNA contains the nucleus of an attractive code to be used to investigate problems where the emphasis is both soil and finid structure interaction. In particular, this investigation was undertaken to determine the effect of viscosity which is in the DYNA model and is not addressed in the approximate methods.

The Livermore manuals occasionally describe a capability that is not available in the current source program. For example, the manual describes the use of an 8 node shell element, but this is a degenerate shell element and the shears and moments are not available. The generation of a parabolic surface while in the INGRID manual was not available. We have been advised by telephone by one of Livermores analysts not to use slice surface capability " 1 " (i.e. pure sliding without friction ) and to use instead slide surface " 3 " (sliding with friction and separation). The consequence, while we can set the friction to "zero", is that we still bave separation. While this is more realistic, it creates diffiralty if one is trying to compare the DYNA solution to approximate solutions which do not permit separation.

Some of the parameters used in the manuals are not engineering accepted terminology and to obtain the actual definition one must go to the author. Since Livermore is basically a Physics laboratory, definitions tend to be based more C2 a physicists approach than an engineering approach. The origins of the codes were physics problems. The parameter $\mathbf{N}_{\mathbf{x x}}$ for example in TAURUS is not defined and is not the $\mathrm{N}$ defined by Haroun and Housner in their paper on Seismic Design of Liquid Storage Tanks. Another example is $V$ in the material model for DYNA where the definition is "relative volume" rather than the "total volume" used in engineering terminology.

A limitation on the applicability to seismic anslysis is the inability of DYNA to respond to a seismic time period of many cycles of reversal of acceleration. After 3 cycles of reaching its peak acceleration, the solution is invalid for the following reasons:

1. The size of the fluid element is incompatible with the frequency content of the time history. Extremely small elements would be required and more nodes needed to define interfaces. This is tractable, but would require more computer time. The calculation for longer time histories becomes much more semsitive and a more refined model is required.

2. The constitutive model of the fluid is not dependent on flow (and time) and is inappropriate for a dynamic calculation.
3. With extensive sloshing, the elements may undergo severe distortion and exceed the capability of the Lagrangian formulation. Eulerian codes are more applicable to problems of this type but are not versatile (i.e., can address simultaneously soil-structure interaction, structure-structure interaction, fluid-structure interaction, as well as structural analyses.

There is no limit to the number of below ground-level nodes that one can have in DYNA3D as diatinct from SASSI. In addition, numeross constants are used in the approximate solution which may not be appropriate or as will be shown, vary according to its autbor. This paper specifically address the validation of Iluid structure internction. DYNA3D is a code capable of addressing the entire problem instead of breaking it up into separate processes and therefore should be considered in solving the waste tank problem. One point that should also be considered is that the Livermore codes are owned by DOE and the source programs are available. Unlike commercial codes there is no cost in procuring the codes or in their use. Modifications to the source program are possible and therefore its capabilities can be extended.

The input file to address the fluid structure interaction problem addressed in this paper could not have been undertaken without the consultation of the Livermore staff. In particular, the authors wish to express their appreciation to Di. Robert Whirley and to Mike Burger of LLNL's engineering staff for their suggestions and assistanse.

The Livermore codes do not have validation problems per NQA-1 as was stated, and the time it has taken to complete this analysis exceeded the DOE schedules. DOE and the Watte tank community selected slternate solutions such as the approximate solutions which have hed wide acceptance and modeling the fluid in SASSI by replecing it with a muss and a spring to represent the reaposse of the fluid. This paper is an attempt to alleviate the validation requirements of the fluid structure interaction portion of the DYNA code as it is applicable to the waste tank problem and to investigate the effect of viscosity which cannot be addressed by either the approximate solution or the "modified" SASSI approach.

The approximete solution is one developed for flexible partially-filled tanks and referred to as the "Modified Housmer Metbod". These results are compared to an approximate filled flexible tank waing the method of Haroun and Housner. DYNA3D calculations were run for a rigid tank, flexible tank, and a Alexible tank where only the viscosity has been varied. The DYNA3D results for a rigid and flexible tank partially filled are consistent with the approximate solutions. 
Additional calculations were performed with DYNA to evaluate the effect of continued sloshing and distortion of the elements. DYNA3D is limited in that it can only be run for several cycles as was stated. When the number of cycles become greater than 3, the solution does not converge (i.e., the fluid tends to climb the tank walls). Whenever the physical limits are exceeded, the solution also degenerates. The case was run where the top was removed and the walls extended ten feet; this resulted in an unreasonable solution. A slide surface could be inserted between the top of the tank and the top of the fluid surface, but the solution after contact would not be reasonable because of the distortion of the elements after that time.

\section{Problem Description}

The problem we are addressing is the waste tank resting on the ground (embedment is not considered) subjected to a borizontal seismic acceleration and gravity. While there are approximate solutions to address two borizontal and one vertical acceleration plus gravity and there is a method to perform the identical calculation using DYNA3D, we chose the single borizontal motion plus gravity. Basically, both the approximate method and the DYNA calculation produce results based on the square root of the sum of the squares of each motion. The model both for the approximate method as well as the computer solution is presented in Figure 1.

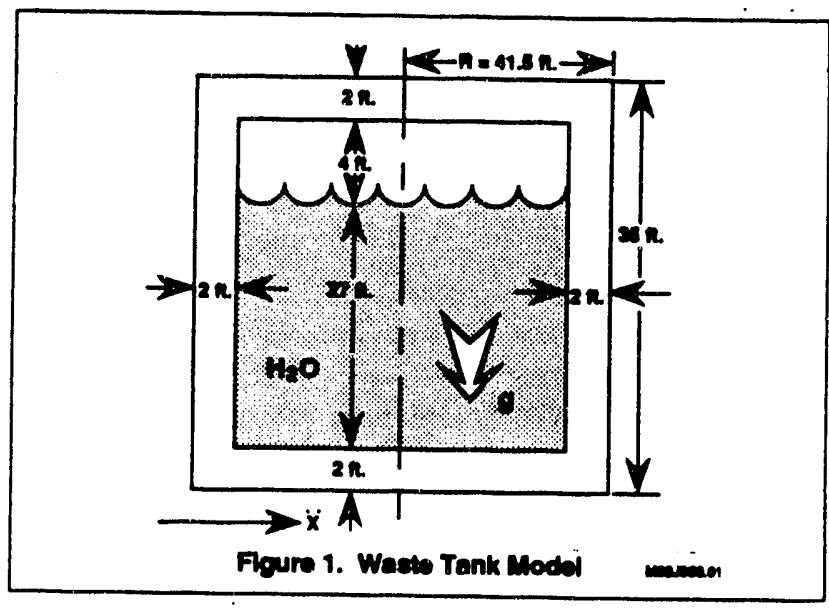

Note When considering the flexible case the wall thickness is reduced to $0.052 \mathrm{ft}(5 / 8 \mathrm{in}$.) and the radius is increased to $\mathbf{4 2 . 5} \mathrm{ft}$.
The seismic load is $\ddot{x}$ based on R. G. 1.60 scaled to $0.2 \mathrm{~g}$ at $3 \%$ damping. The time history is an artificial time history using the computer program SIMQKE. ${ }^{2}$ The model considers the walls and base rigid. The walls, top, and bottom plates, must be modeled as four node shell elements in order to capture the moments and shears. Unlike GEMINI or SAP4 the rotation about the axis normal to the shell surface does not have to be constrained in DYNA or NIKE.

In the case of the top and bottom plates, the normal is the global $z$ axis. In the case of the walls, the normal is always changing and in GEMINI this would be a major effort. In DYNA3D the constraint is automatically addressed once the element is defined as a four node shell element.

While an aspect ratio of $1: 1$ is preferred, the aspect ratio selected is $<5: 1$. More accurate and stable results would be obtained with a 1:1 aspect ratio. However, running time on the computer for a 1:1 aspect ratio would be considerably increased.

Since appropriately, a fluid model is used in DYNA, the standard method of applying gravity cannot be used. Each section of the DYNA3D Manual applied to this problem will be discussed along with its features that are not in the 1989 Manual; this aspect is not addressed in the companion paper on this subject that has been submitted for publication to the American Nuclear Society (ANS). The code INGRID was used to generate the model in Figure 1. The graphics output from INGRID includes node location and identification of slip placies as shown in the attachment. Shell elements were generated by making the walls very thin. In this way an eight node brick repeats with the same initial four nodes for each element. By editing, the second set of four nodes are then deleted. A slide surface is included between the bottom of the fluid and the tank, the sides of the fluid and the tank walls, and between the walls and the top and bottom plates. However, in the case of the walls and the top and bottom plates, we tie shell edge to shell surface (option 7 in the Sbell Interface Definitions in the DYNA Manual).

For the purposes of validation the fluid is modeled as water with all the appropriate properties. The model for the fluid is not the same between the approximate solution and the DYNA3D solution and each will be described under the following appropriate sections. 


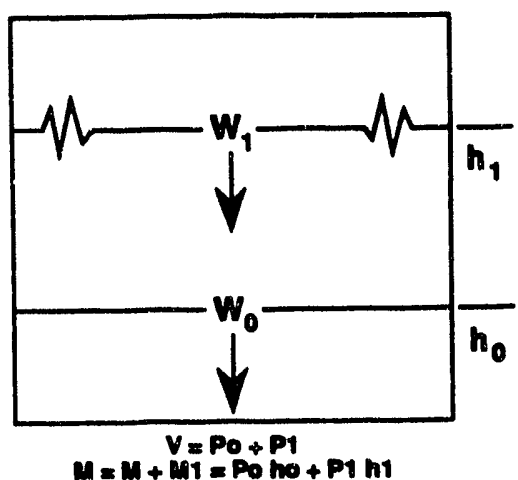

Figure 2a. Modified Housner Method

\section{Approximate Solution}

From Figure 1 we define $H=27 \mathrm{ft}, R=41.5 \mathrm{ft}$. Therefore $H / R=0.65$ and $R / H=1.54$. Since $H / R<1.5$ we use the Modified Housner Method. ${ }^{3}$ For water, $\gamma=62.5 \mathrm{lbs} / \mathrm{ft}^{3}, p=$ $1.94 \times 10^{-3}$ mass density, and $W=9,125$ kips.

The Modified Housner Method considers the hydrodynamic effects to be represented as the sum of the convective and impulsive parts. Following the procedure in reference 3, we first calculate $W_{1}$ and two values of $b_{1}$, one excluding dynamic fluid pressure and the other inclading the dynamic pressure. $W_{1}$ is a weight given in Figure $2 a$ and the h's represent the dimensions which locate the resultant forces.

Using the definitions defined by the Modified Housner Method.

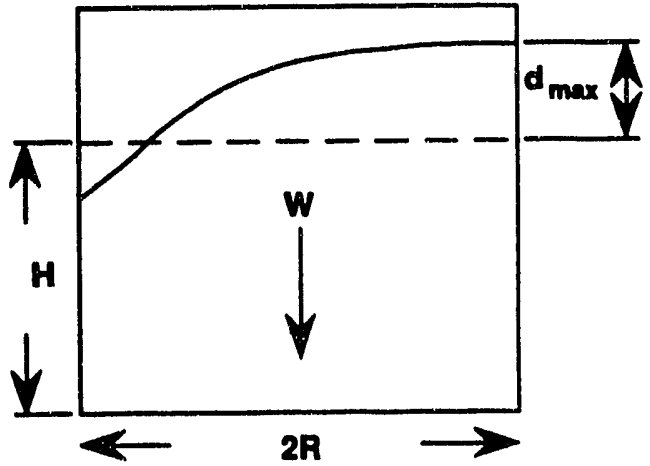

Figure 2b. Modified Howsner Method (Sloshing)

$W_{1}=W_{2} C_{5} \times R / H \times \tanh C_{4}$

where $C_{5}$ is $0.318<C_{5}<0.455$

Assuming the value of Veletsos

$C_{s}=0.455$

$W=9,125$, for water in kips

$R=41.5$

$\mathrm{H}=27$

$C_{4}=1.84 \mathrm{H} / \mathrm{R}=1.17$

then

$W_{1}=5260.3$ kips

When the flexible model was considered in DYNA3D, it was necessary to extend the fluid model $1 \mathrm{ft}$ to allow the tank wall to be $0.052 \mathrm{ft}$. This made $R=42.5$, ft rather than $41.5 \mathrm{ft}$ and the approximate results will differ slightly. 
For $\mathrm{R}=41.5 \mathrm{ft}$

$$
\begin{aligned}
& \frac{h_{1}}{H}=1-\frac{\cosh C_{4}-1}{C_{4} \sinh C_{4}}=0.550 \text { Eutudiag Botoon Troesure (EBP) } \\
& \frac{h_{1}}{H}=1-\frac{\cosh C_{4}-2.01}{C_{4} \sinh C_{4}}=1.143 \text { Inctuding Botion Proceum (IBP) } \\
& \text { then } \quad h_{1}=0.550 \times 27=14.9 \mathrm{EBP} \\
& h_{1}=1.143 \times 27=30.9 \mathrm{IBP} \\
& h_{0}=0.375 \mathrm{H}=10.125 \mathrm{EBP} \\
& h_{0}=H \times 0.125\left(\frac{4}{c_{3}}-1\right)=33 \\
& C_{3}=\frac{\tanh (1.73 \mathrm{R} / \mathrm{H})}{1.73 \times \mathrm{R} / \mathrm{H}}=0.371 \\
& W_{0}=C_{3} W=0.371\left(9.125 \times 10^{3}\right)=3.4 \times 10^{3} \\
& \omega^{2}=(1.84 \mathrm{~g} / \mathrm{R}) \tanh C_{4}=1.176 \\
& \omega=1.08 \mathrm{rad} / \mathrm{sec} \\
& f=0.173 \mathrm{~Hz} \\
& T=5.78 \mathrm{sec}
\end{aligned}
$$

Using $B=0.005$ damping

$$
S_{\text {th }}=3.2 \mathrm{fthec}
$$$$
A_{1}=S_{1} / \omega=2.96
$$$$
\theta h=1.534\left(A_{1} / R\right) \tanh C_{4}=0.090
$$

Then $P_{1}=$ convective force

$=1.2 \mathrm{~W}_{1} \times \theta \mathrm{h} \times \sin \omega \mathrm{t}=5.68 \sin 1.08 \mathrm{t}$

$$
\begin{aligned}
& d_{\max }=\frac{0.408 \operatorname{coth} C_{4}}{8 / \omega^{2} \times \theta h R-1}=3.24 f t \\
& . V=\text { base shear }=P_{0}+P_{1} \\
& M=\text { overturning momeng }=M_{0}+M_{1}
\end{aligned}
$$

Consider $\sin \omega \mathrm{t}_{\max }=1.0$

$$
\begin{array}{ll}
\text { then } & P_{0}=\ddot{x} w / 8 C_{3}=0.2 \times 32.2 \text { w/g } C_{3}=677 \\
\text { and } & V=677+568=1,245 \\
M & =P_{0} h_{0}+P_{1} h_{1}=15.3 \times 10^{3} \mathrm{EBP}=39.85 \times 10^{3} \mathrm{IBP}
\end{array}
$$

Therefore we conclude.

$$
\begin{aligned}
& d_{\max }=3.24 \mathrm{ft} \\
& V_{\max }=1,245 \mathrm{kips} \\
& M_{\max }=15.3 \times 10^{3} \mathrm{EBP} \text { and } 39.9 \times 10^{3} \mathrm{IBP}
\end{aligned}
$$

Note we assumed $\max C_{s}$ and sin $\omega t \max$.

It is significant to further note that the only material property of water that is used is mass density. Viscosity, bulk modulus, etc. are not included in the material model used in the Modified Housner Method. The model used in DYNA includes both viscosity and bulk modulus. A concern by DOE is that the material model used in the approximate solutions are not realistic as one would logically feel that viscosity does have an effect. A complete description of the material model used in DYNA is given in the following section on DYNA.
Referring now to Veletsos paper to determine the maximum pressure on the tank walls. ${ }^{4}$

The hydrodyanmic pressure $[p(2, \theta, t)]$ exerted against the wall in a rigid tank is:

$p(z, \theta, t)=\left[c_{0}(z) \ddot{x}(t)+\sum_{k=1}^{k=2} c_{k}(z) A_{k}(t)\right] e H \cos \theta t$

where the finst term is the impulsive part and the socond term the corvective part. Note: $\rho$ varies as the cosine function in the circumferential direction.

From Figure 1, $H=27 \mathrm{ft}, a=R, H / a=27 / 41.5=0.65$

$\begin{array}{llll}z / H & C_{0} & C_{1} & C_{2} \\ 0 . & 0.8 & 0.85 & 0.01 \\ 0.2 & 0.77 & 0.9 & 0.01 \\ 0.4 & 0.70 & 1.0 & 0.02 \\ 0.6 & 0.6 & 1.05 & 0.04 \\ 0.8 & 0.4 & 1.15 & 0.08 \\ 1.0 & 0 & 1.3 & 0.12\end{array}$

The option is available to either use curves in Ref. 4 or compute the values; it was decided in this case to utilize the curves.

Given $\ddot{x}(t)=0.2 \times 32.2=6.44 \mathrm{t} / \mathrm{sec}^{2}$

$$
\begin{aligned}
& A=\frac{2 \pi V}{T}=\frac{2 \pi 3.2}{5.8}=3.5 \\
& T_{1}=0.95 \sqrt{\mathrm{a}}=6.1 \\
& H / 2=0.65 \\
& T_{1}=6.1 \\
& A_{1}(t)=2.96 \approx 3.0 \\
& T_{2}=48 \sqrt{a}=3.0 \\
& S_{V}=3.2 \mathrm{H}_{2}
\end{aligned}
$$

$P(2, t)$ given that $\theta=0$ the $\cos \theta=1$

$\begin{array}{rcr}Z & \begin{array}{c}\text { P } \\ \text { Zkips/fit) }\end{array} & \\ 0 . & 0.4 & \text { Botton of Tank } \\ 5.5 & 0.4 & \\ 10.8 & 0.394 & \\ 16.2 & 0.371 & \\ 21.6 & 0.327 & \\ 27 & 0.222 & \text { Top of Fluid }\end{array}$

For $\theta=90, p=0$

$$
\begin{aligned}
& f_{2}=\frac{\pi}{2}[\lambda(2) g / a \tanh (\lambda(2) H / a)]^{H /}=0.32 \\
& T_{2}=1 /(2)=3.125
\end{aligned}
$$

Since $T_{2}$ was asumed equal to 3.0 , the approximation is valid 


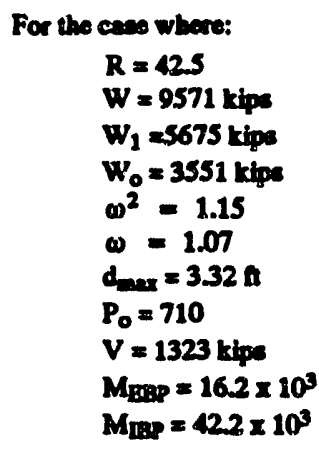

\section{DYNA3D MODEL}

The following specific items must be noted:

- the fluid selected is water

- a slip surface exists between the fluid and the structure

- separation is permitted

The tank is modeled as a rigid elastic material. Since DYNA is explicit, the time step is determined by the program based on the size of the smaliest element which would be a shell element. While it is possible to increase the time step by using pseudo properties, one would have to use an elastic plastic model of the material description for the tank.

In this case, the tank was modeled as elastic, and therefore the time step could not be altered and was approximately 0.001 sec. The time history bad 20 sec. of motion, $10 \mathrm{sec}$. of strong motion. Initially, only $4 \mathrm{ft}$ clearance was provided between the top of the tank and the water as shown in Fig. 1, which was based on approximating $d_{\max }$. Since the computer calculation after reaching the peak acceleration (.2g) for the third time exceeded the $4 \mathrm{ft}$ clearance, and as there was no slide surface between the top of the tank and the fluid, the computer calculation went unstable. When the fluid exceeded the $4 \mathrm{ft}$ clearance, it occupied the same space as the tank. Therefore, the calculation had to be terminated after 2 seconds. A slide surface between the top of the fluid and the top of the tank would resolve this problem but not other problems which are inherent sfter it reaches the $\mathbf{4} \mathrm{ft}$ clearance as discussed earlier.

We will proceed to go through each section of the 1989 Manual and note the features that were used in this calculation which are in general not described in the 1989 or earlier manuals.
The first section are the control cards which dictate the contents of the input file. In this problem, we had 4 materials, (to mone casily separate the sections of the tunk), 696 nodes, 300 solid elements (to describe the fluid) and 224 4-node shell elements (to describe the structure). Control card "4, had " 3 " load curves ( $x, z$, gravity), "57" velocity/ acceleration boundary condition cards (to give each node on the base $\ddot{x}$, to include $\ddot{y}$ it is repeated, “114", and for $\ddot{x}$, $\ddot{y}$, and $\ddot{z}$ it is " $\left.171^{\prime \prime}\right), ~ " 4^{\prime \prime}$ sliding interfaces ( 2 luid, 2 between walls and top and bottom plates), and "1" for base acceleration in the $\mathbf{z}$ direction (gravity is incorporated in this manner since listing all the nodes of the luid would be cumbernome and the method usually used is not applicable to fluids). Control card " 5 contains a 0.1 eec time step for gathering of data and a $1.0 \mathrm{sec}$ duration of the calculation. Control card "49 was utilized to avoid hourglassing granted aspect ratios of 1 to 1 would be helpful, but to avoid hourglassing in this problem, the artificial viscosity was changed from the default value to numbers recommended by the Manual.

The subsequent section contains the material properties cards. The tank was modeled as an elastic rigid material whoee modulus was that of reinforced concrete and whose Poiseons ratio was 0.2 . The mass density was 4.65E-03, E = $432 E+03$, Poissons Ratio $\mu=0.2$. Because it was identified as a 4 node shell element, the material properties are followed with a card which has shear factor (1.0), number of through shell thickness integration points (4), printout option [3, (resultants, atreseses at all points)], and quadrature rule $[(0$, Gauss $)]$. The subsequent card has the thickness at each node (2 ft). It is posaible to put the thickness in elsewhere but it is simpleat in this section.

Initially, we had a thickneas everywhere equal to $2 \mathrm{ft}$ and inade the atructure rigid. Then, we kept the top plate and foundation $2 \mathrm{ft}$ and its materisl description as clastic and of reinforced concrete and changed the thickneas of the walls to $0.052 \mathrm{ft}$ and its clastic description to one of steel where its density, modulus, and Poisson's ratio are properties of steel; $15.23 \mathrm{E}-03,4.32 \mathrm{E}+06,0.28$ respectively, in the appropriate units.

The two cards referring to the shear factor etc. and thicknesses must be included after ench 4 node shell material description. Finally, we come to the material model for water. In this case, we were advised by LLNL to wee material no. 9 with equation of state 1 . A simpler model would hove been model mo. 5, but that model does not contain the visconity term. In the model used, no. 9, the first card is the mass density, the second card the pressure cutoff $\left(-1.0 \mathrm{k} / \mathrm{t}^{2}\right)$, and the viscoaity (67.2E-05). The equation of atate bas the bulk modulus (43200.) and the initial relative volume $V_{0}=1.0$ in the appropriate untis. 
These cards are followed by the node definitions. Both the node definitions and element definitions are obtained from the preprocessor INGRID. The boundary conditions are edited to permit 6 degrees of freedom. The rotations normal to the upper and lower plates are constrained automatically or one designate the appropriate boundary condition (3.), and the nodes for the solid elements are constrained to prohibit any rotations. Two nodes at the base are grounded so that the tank would not have excessive motion. After the node definitions we have the element definitions. The element definitions, must be in the same order as that in the Manual i.e. solid elements come before the 4 node shell elements. In the description of the 4 node shell element, a blank card must follow each element definition. The blank card tells the code to obtain the thickness from the material property cards. if separate thicknesses were required for each element, then these blank cards would be utilized.

The 4 node element description is followed by the time histories or load curves. Load curve 1 is $x$ acceleration in $g$, load curve 2 is the vertical, $z$, time history in g's, and load curve 3 is gravity which consists of 4 points describing gravity. Note that since the values are in g's, they must be converted to $\mathrm{ft} / \mathrm{sec}^{2}$, the units of the program.

In the description of the load curves, the first card contains the load curve number, number of points in the load curve, and the stress initialization. The last entry, stress initialization, has options: 0 for transient analysis only, 1 for stress initialization but not analysis, and 2 applies to both stress initialization and transient analysis. The only option that is available is $\mathbf{0}$. If you use $\mathbf{2}$ for example, not only does the option not work, but the termination time is ignored and you lose control of the program. That is, if one is running the problem interactively, none of the sense switches work except sense sw 2 which only tells you the time of the calculation and the $\mathrm{dt}$ of the calculation. The program runs on until you either reach the capacity of the Cray memory or break the calculation. When you break the calculation, you will find that no results have been recorded and the plot file is empty. Therefore, one must use option 0 for initialization. This error is in all the Manuals including the last Manual that was published, the May 1991 issue. The time histories are input under the section on "Velocity/Acceleration Specification Cards for nodes and Rigid Bodies". In this section we have the base node number, the load curve number, the applicable degrees of freedom, the all important scale factor, and identification that it is node acceleration. This can be repeated so that 2 horizontal and one vertical acceleration can be input simultaneously.
The following section contains the sliding interface definitions. In this case, we use type no. 7 which ties the shell edge to the shell surface in order to tie the walls to the top and bottom plates. For the interface between the fluid and the tank we use option no. 3, sliding, with friction (.2 for both static and dynamic friction), and separation. Most of the data for this section was provided by the pre-processor INGRID but had to undergo editing because 4 node shell elements were used. Finally, we put in gravity by utilizing the section on base acceleration in the $\mathrm{z}$ direction whose load curve is gravity. Note node numbers do not appear bere as all nodes are given the $\mathbf{- 1} \mathbf{g}$ acceleration of gravity. The output file repeats and digests the input file 80 that reviewing it is helpful in determining the correctness of the input file. Where the input consists of basically data, the output spells out the definition associated with each data entry.

The engineering output from DYNA is generally obtained graphically. The output file from DYNA is a plot file which can be run with the post-processor TAURUS. While one should be able to move the graphics file from the Cray to the VAX noting that the file is a binary file and not an ASCI file, WSRC has been unable to make this work after 2 years. One of the authors regularly transmitted binary files from the Cray at Livermore to the VAX at LBL without any difficulty. Therefore, the graphics results were obtained on the Cray. The TAURUS post-processor on the Cray does not have the versatility of drivers that are on the TAURUS on the VAX. Since we are limited to emulators, we cannot get color on the Cray using TAURUS. This is important in studying contours and fringes.

\section{Comparison of Results}

Using TAURUS we can locate the position of the nodes of interest on the bottom plate, the wall, and top of the fluid. At time equal to approximately .57 sec., the peak ground horizontal acceleration is $2 \mathrm{~g}$ 's. from the time history. Actually, it is several seconds later that the maximum values are obtained as it takes several seconds for the propagation of the wave through the structure and the fluid as the response is not instantaneous. Therefore, all results are obtained for approximately $.57 \mathrm{sec}$. time although there is also a peak at .45 seconds. 
The approximate solution assumes a peak acceleration and not a time history. Using $t=57$, we obtain with TAURUS the slosh height of the water, the shears and moments of the bottom plate, and the pressure exerted aloug the tank wall. We compare these values to the approximate solutions.

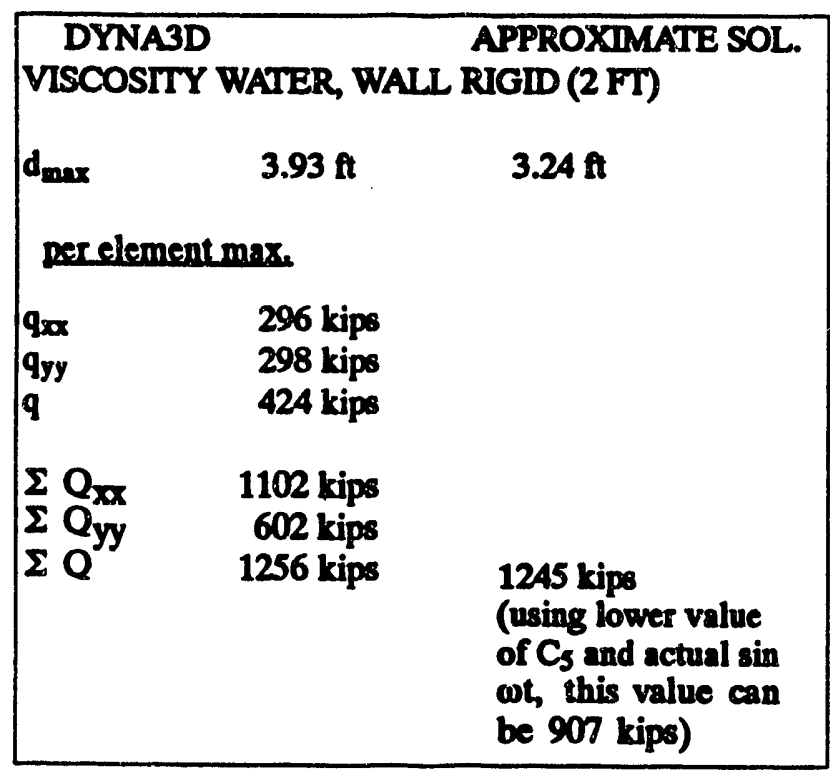

\begin{tabular}{|c|c|c|}
\hline \multicolumn{2}{|c|}{$\begin{array}{l}\text { DYNA } \\
\text { perelementmax. }\end{array}$} & APPROXIMATE SOL. \\
\hline $\begin{array}{l}M_{x x} \\
M_{y y} \\
M_{x y}\end{array}$ & $\begin{array}{l}1270 \text { kip ft } \\
1070 \text { kip ft } \\
2940 \text { kip ft }\end{array}$ & \\
\hline $\begin{array}{l}\Sigma M_{x x} \\
\Sigma M_{y y} \\
\Sigma M_{x y} \\
\Sigma M^{\prime}\end{array}$ & $\begin{array}{r}9080 \text { kip ft } \\
8520 \text { kip ft } \\
418 \text { kip ft } \\
12451 \text { kip ft }\end{array}$ & $\begin{array}{l}\text { M (EBP) } 15,300 \text { kip ft } \\
M \text { (IBP) } 39,850 \text { kip f }\end{array}$ \\
\hline \multicolumn{3}{|c|}{$p(z)\llcorner\theta=0, t=57 \sec$ (rigid tank) } \\
\hline $\begin{array}{l}z=0 \\
z=10 \\
z=15\end{array}$ & $\begin{array}{l}0.8 \text { kips/fit } \\
0.54 \\
0.254\end{array}$ & $\begin{array}{l}0.4 \mathrm{kips} / \mathrm{ft}^{2} \\
0.4 \\
0.22\end{array}$ \\
\hline
\end{tabular}

Changing the wall thickness to $0.052 \mathrm{ft}$ and the wall material to steel, we obtain the following results.

\begin{tabular}{|c|c|c|}
\hline \multicolumn{2}{|c|}{ FLEXIBLE WALLS } & \multirow[b]{2}{*}{$\begin{array}{l}3.32 \mathrm{ft} \text { (Corrected for } \\
1 \mathrm{ft} \text { increase in fluid } \\
\text { radius, all approx. } \\
\text { values }\end{array}$} \\
\hline$d_{\max }$ & $3.69 \mathrm{ft}$ & \\
\hline \multicolumn{2}{|c|}{ perclement max. } & \\
\hline $\begin{array}{l}q x x \\
q y\end{array}$ & $\begin{array}{l}277 \text { kips } \\
272 \text { kips } \\
389 \text { kips }\end{array}$ & \\
\hline 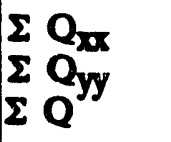 & $\begin{array}{l}766 \text { kips } \\
384 \text { kips } \\
857 \text { kips }\end{array}$ & 1323 kips \\
\hline DYNA & & APPROX. SOL. \\
\hline $\begin{array}{ll}\Sigma & \mathbf{M}_{\mathbf{x x}} \\
\Sigma & \mathbf{M}_{\mathbf{y y}} \\
\Sigma & \mathbf{M}_{\mathbf{x y}}\end{array}$ & $\begin{array}{l}10468 \text { kip ft } \\
14640 \text { kip ft } \\
0 \\
17900 \text { kip ft }\end{array}$ & $\begin{array}{l}16260 \text { kip ft (EBP), } \\
42240 \text { (IBP) }\end{array}$ \\
\hline \multicolumn{3}{|c|}{$\begin{array}{l}W=9571, W_{1}=5675, W_{0}=3551, \\
\omega=1.07, H / R=0.64, \\
R / H=1.57\end{array}$} \\
\hline
\end{tabular}

For a full tank, the approximate results would have higher values than the approximate results for a partially full tank.

Comparing the effect of viscosity, we have

\begin{tabular}{|c|c|c|}
\hline $\begin{array}{c}\text { DrNA } \\
\text { (HOH, Dax) }\end{array}$ & $\begin{array}{c}\text { DKA } \\
\text { (3500 vin. HOH, Aax.) }\end{array}$ & APRROX \\
\hline $\begin{array}{l}\Sigma \text { Q } 857 \text { bips } \\
\Sigma \text { M } 17900 \text { kip A } \\
d \operatorname{dim} 3.69 \text { n }\end{array}$ & $\begin{array}{l}\Sigma Q 1025 \text { kips } \\
\Sigma Q 21213 \text { kip th } \\
\text { dax } 3.20 \text { h }\end{array}$ & $\begin{array}{l}\text { Q } 1323 \text { kips } \\
\text { M } 16260 \text { kip A } \\
d_{\operatorname{mem} 3.32 ~} \text { h }\end{array}$ \\
\hline
\end{tabular}


Several additional DYNA calculations were performed and the results are as follows:

1. When the calculation went past 3 seconds, the fluid (water) exceeded the clearance of $4 \mathrm{ft}$ and the calculation went unstable.

2. When the top was removed, the fluid wanted to flow over the tank, and then the calculation went unstable.

3. When the top was removed and the tank walls were raised an additional ten feet, the calculation ran for 6 seconds and the fluid climbed up the tank wall.

\section{Conclusion and Discussion of Results}

This analysis was directed to validation of the fluid structure interaction problem and to investigate the effect of viscosity. The results have shown that the DYNA solutions for both the flexible and rigid tanks are compareble to the approximate solutions. The limitation of DYNA to several cycles of ground motion is consistent with the approximate solution in that in the approximate solution only one frequency is used and the peak astiaration value. If the limitation to DYNA is the material formulation and or the element size, then the problem of unning for longer times can be overcome. If however, the distortions are excessive and Lagrangian limit is reached, then the problem may not be solvable. As long as the time history is of sufficient duration to include the fundunental frequency of the system, then the DYNA calculations will give you solutions comparable to the approximate method. A slide surface could be inserted between the top of the fluid and the top plate, however, while the fluid could not penetrate the top plate, the solution obtained would be invalid if there would be severe distortion and the Lagrangian limit reached.

Clearly, the application to tornado analysis where an impulsive force is applied, is not relevant to the problem encountered in fluid structure interaction. The limitations encountered in the fluid structure interaction problem is not applicable to soil structure interaction, for as the structure oscillates it moves the soil and a gap is created between the soil and the structure; the soil does not oscillate with the structure as in the case of the fluid sloshing. Slide surfaces permit separation which is what is expected to happen with soil structure interaction.
The effect of the higher viscosity in DYNA is to reduce the max. slosh height and increase the base shear and moment. This is what one would anticipate with a higher viscosity, bowever this effect of viscosity is relatively small. The approximate solution which does not addreas viecosity, produces a higher base shear than the DYNA solution with the higher viscosity, but a lower moment than both comparable DYNA calculation i.e. viscosity of water and that of 3500 times the viscosity of water. The maximum slosh beight is closer to the viscous fluid than the viscosity of water. Viscosity appears to have an effect of the order of $16 \%$ when one compares the two DYNA calculations. The advantage of using DYNA over the approximate solution is that it not only addresses viscosity, but has the advantage of providing a lot of additional detailed results. The shear, moment, and stresses as well as the strains and displacements are available whereas this level of detail is not svailable in the approximate calculation. The variation in shear value depending on whether one uses the Veletsos coefficient or Newmark coefficient is greater than differences obtainable in the DYNA calculation. In fact, using a lower coefficient, one obtains results in the flexible case much closer to the DYNA calculation for base shear. O the other hand, the higher value appears to be more consistent with the rigid tank based on the base shear. Hence, the coefficient appears to depend on rigidity of the tank wall which is not addressed in the ASCE reference.

\section{References}

1. Chen, J. C., et al., Eight World Conf. on Earthquake Engr., San Francisco, CA, July 21-28, 1984, UCRL 90029.

2. SIMQKE, A Program for Artificial Motion Generation, NISEE/Computer Application, Nov. 1976, Dept. C.E.MIT.

3. Fluid/Structure Interaction During Seismic Exitation, ASCE, 1984, R. P. Kennedy, Chairman.

4. Veletsos, A. S. and J. Y. Yang, Advances in Civil Engineering, ASCE, Engr. Mech. Div. Specialty Conf., 2nd Proc. Adv. in Civil Engr. through Mech. Engr., Raleigh, NC, May 23-25, 1977. 


\section{INGRID Code - Input File}

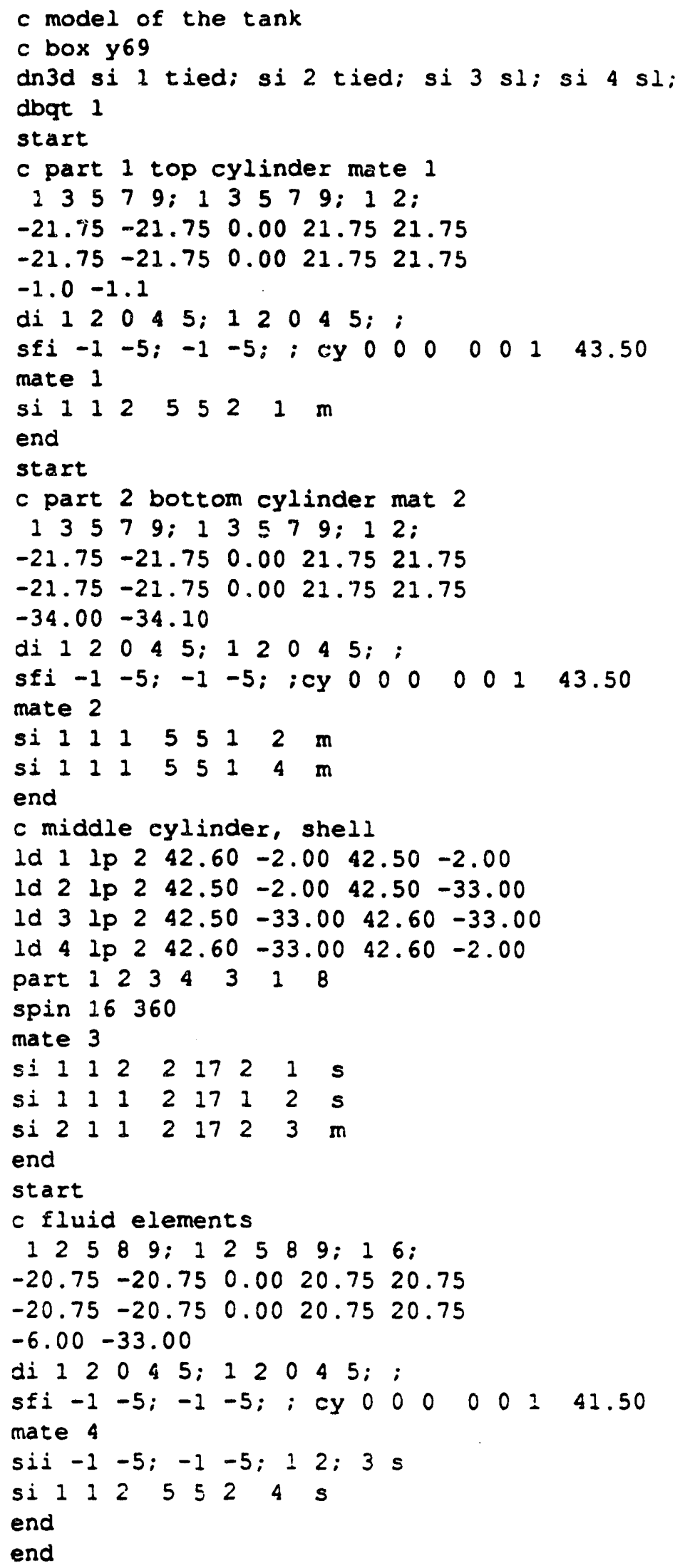




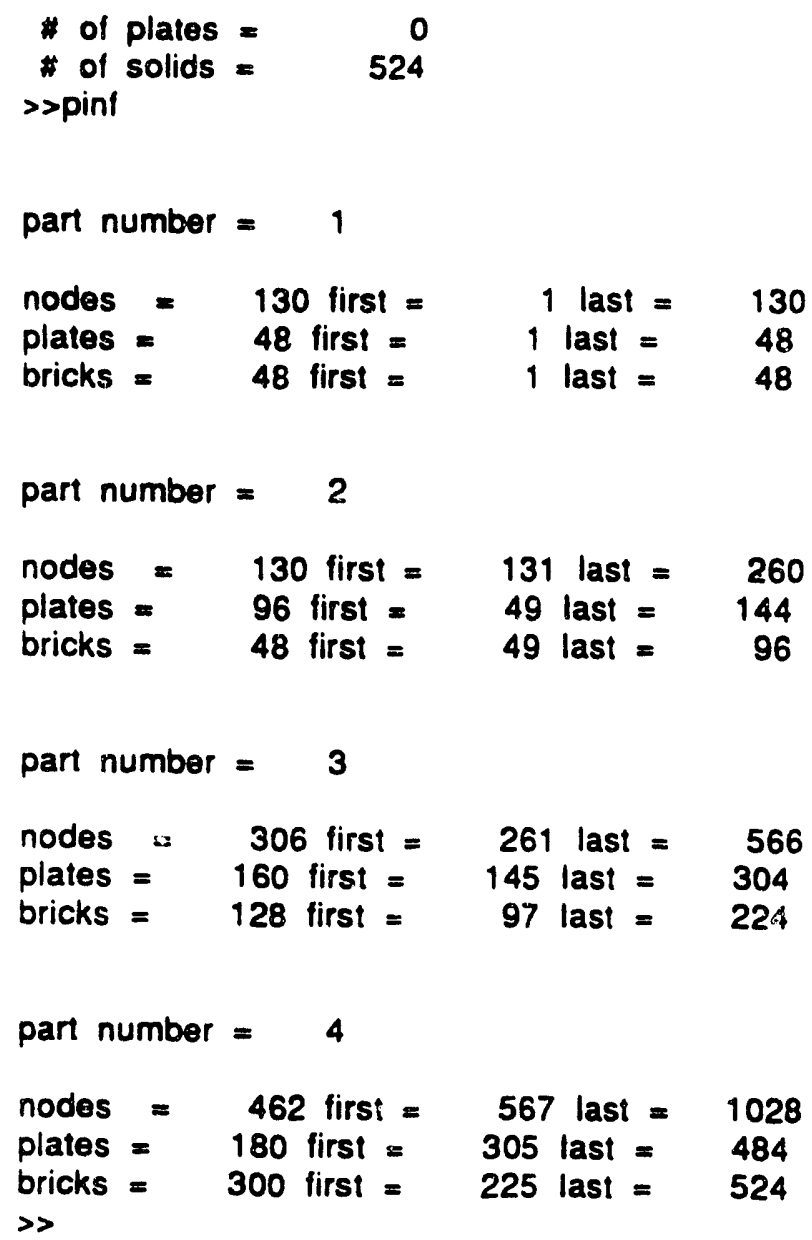


INGRID Node Display - Model of Tank

di Id

$>>d i 2 d$

$>>d i$ nodes

$>P$ P 4

$>$ di nodes

$>>d i$ id

$>P 1$

>

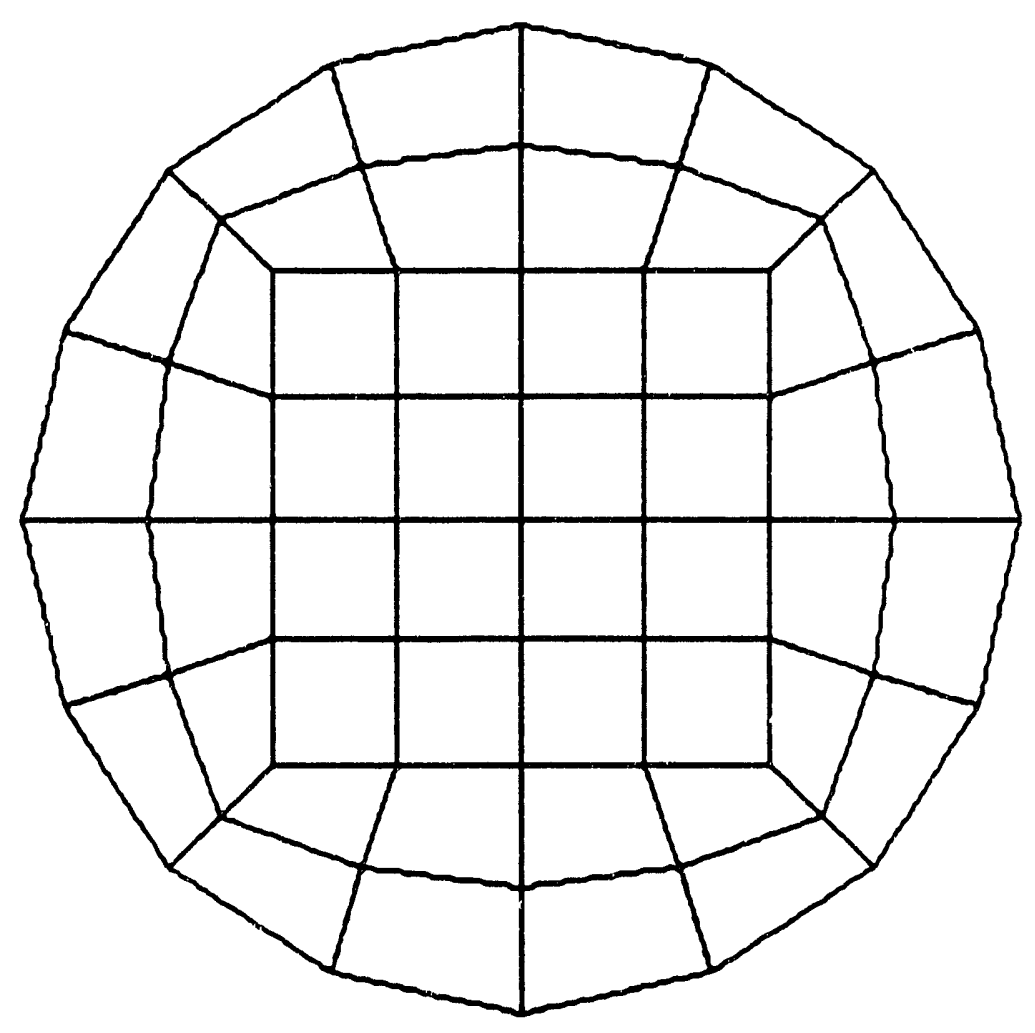


INGRID Node Display - Model of Tank

$>>P$

c model of the tank

$>d i$ nodes display

>)
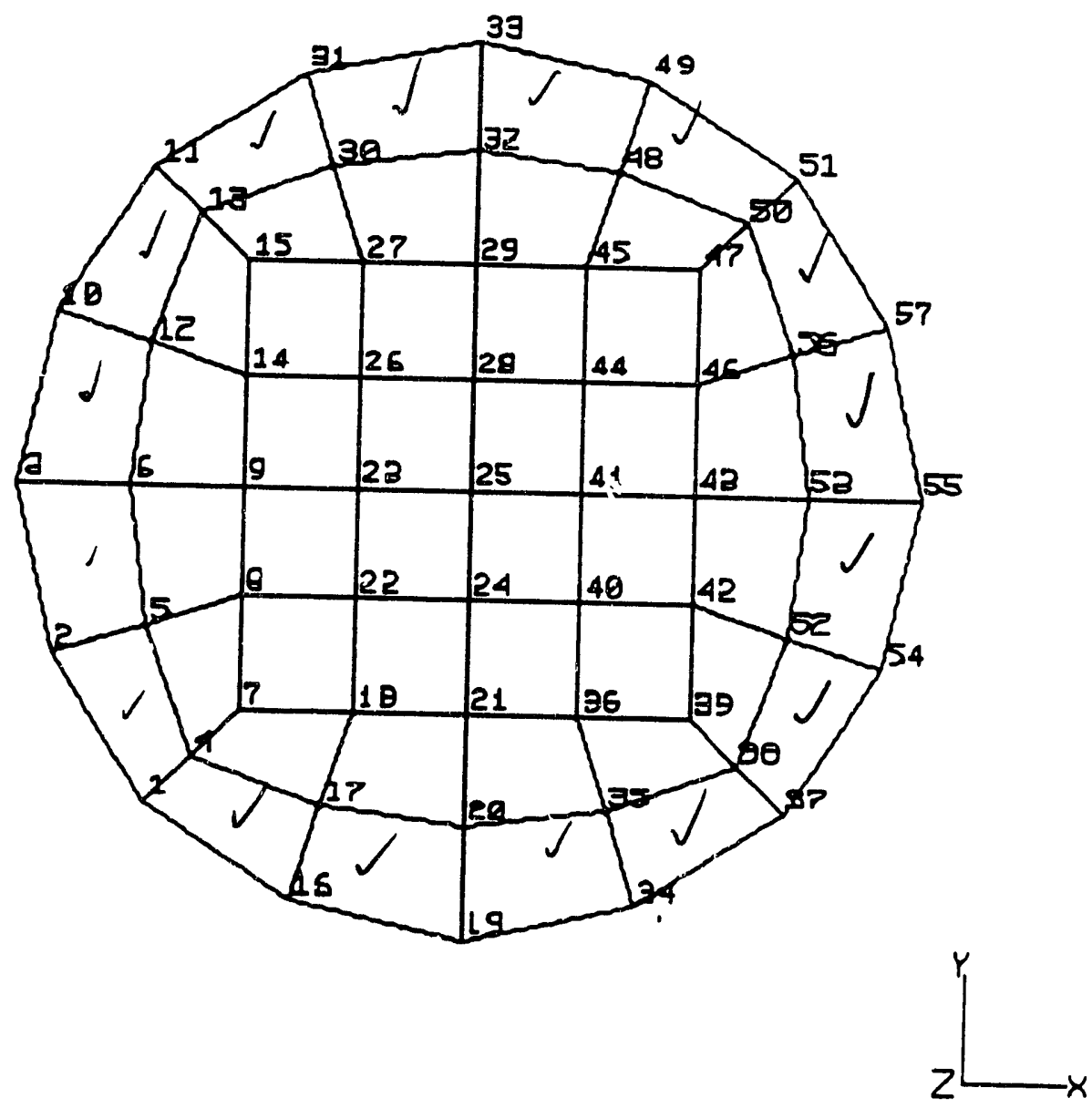

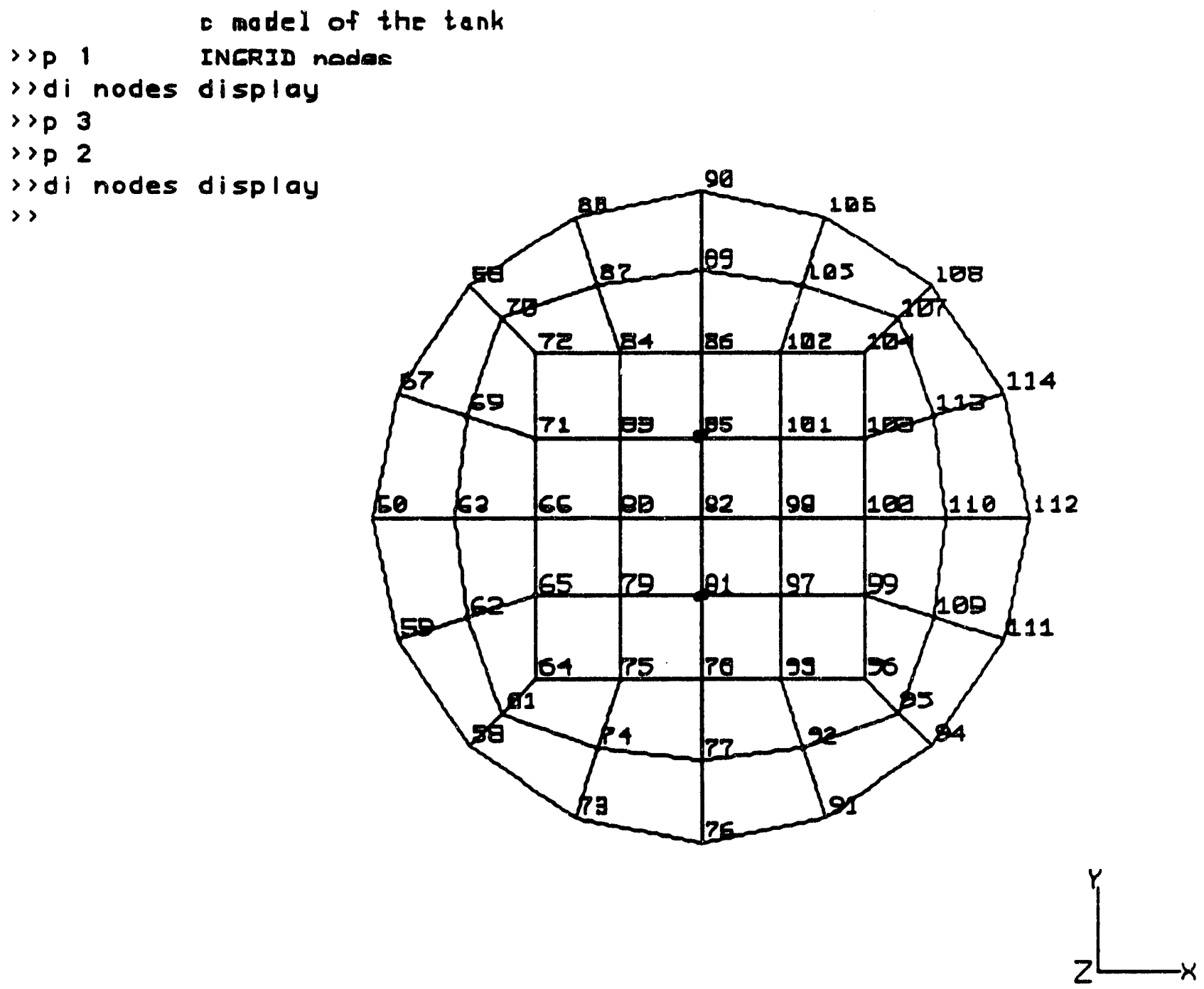


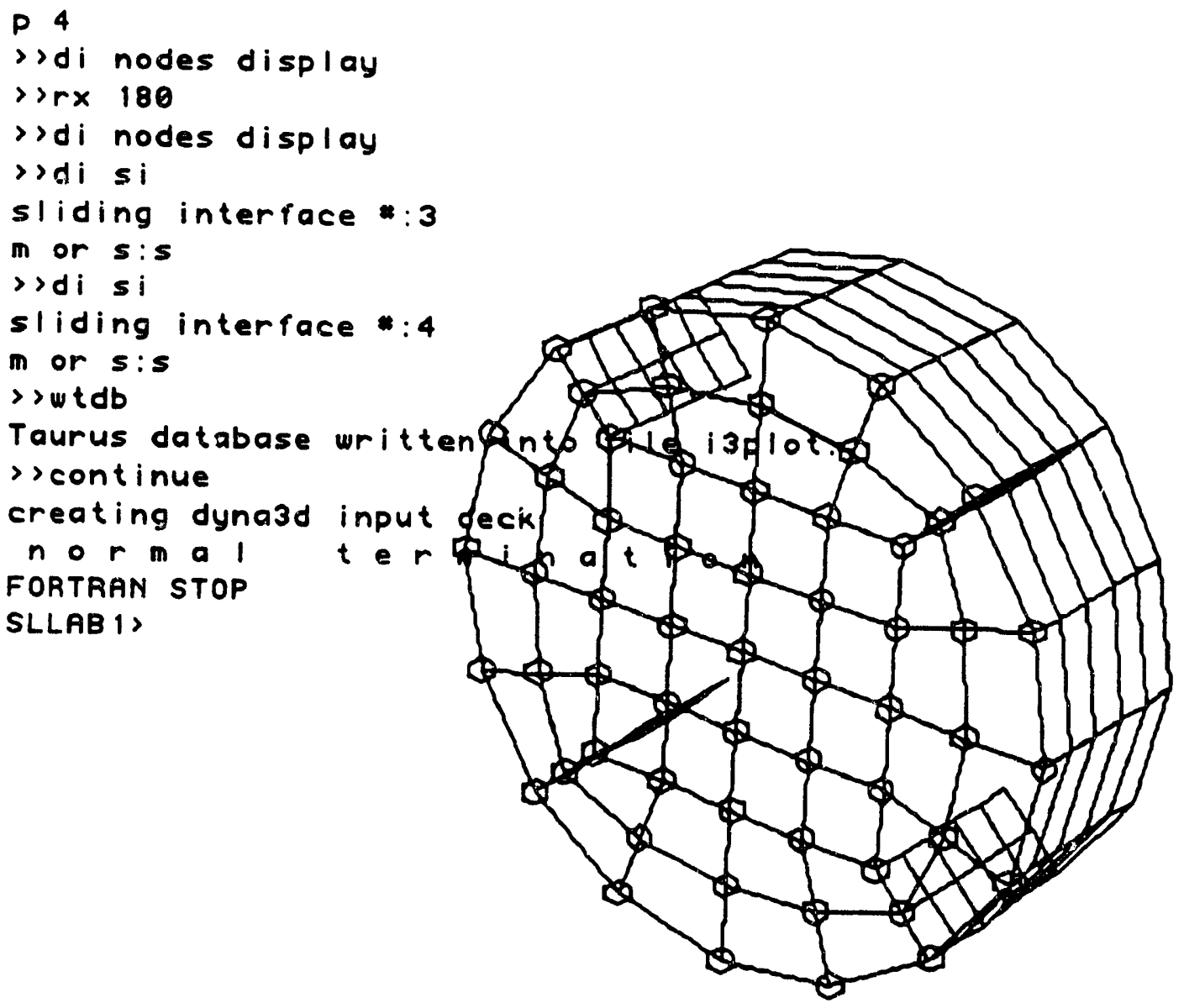


INGRID Code - Display of Slip Planes - Sliding Interface \#1
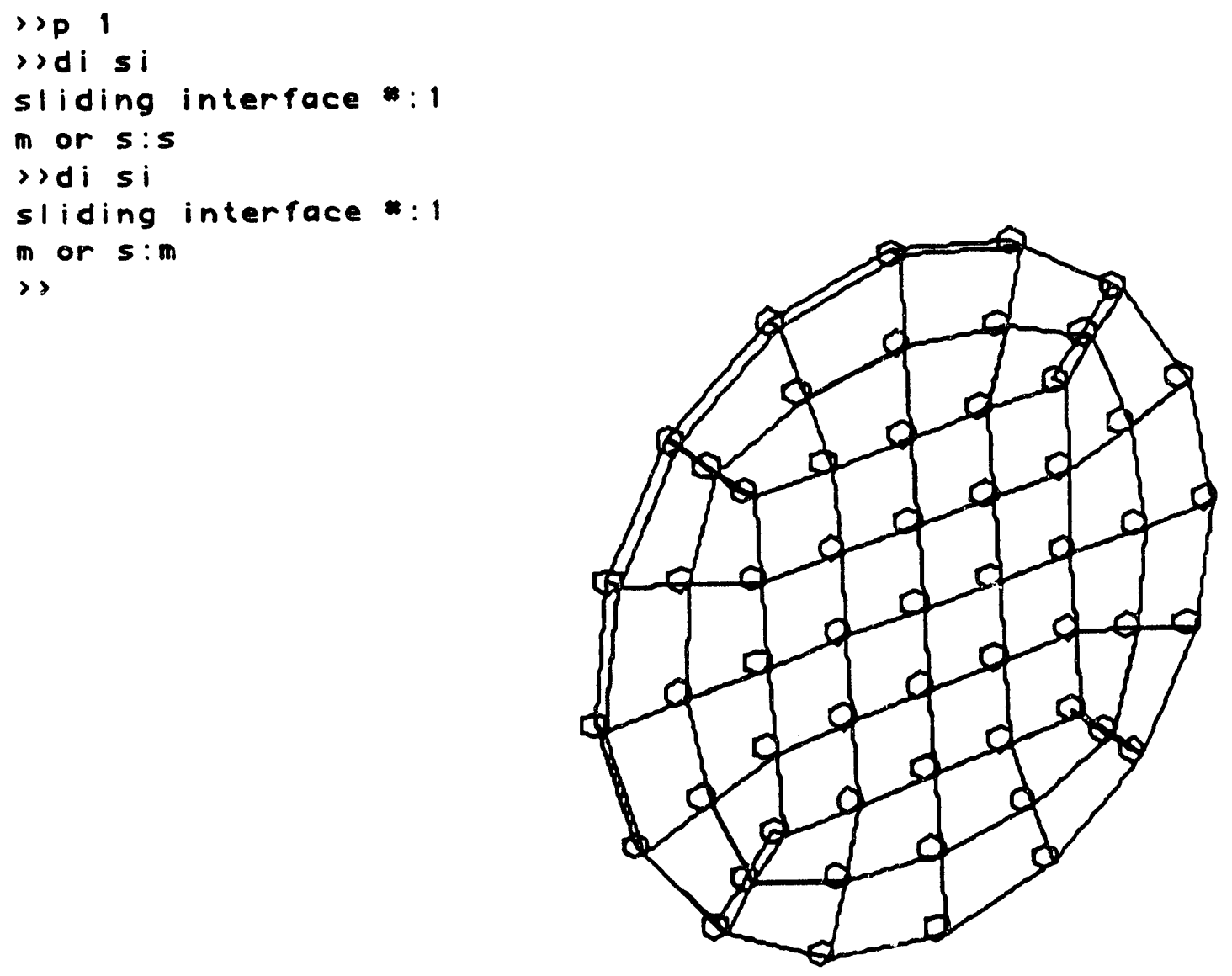
INGRID Code - Display of Slip Planes - Sliding Interface \#1, \#2

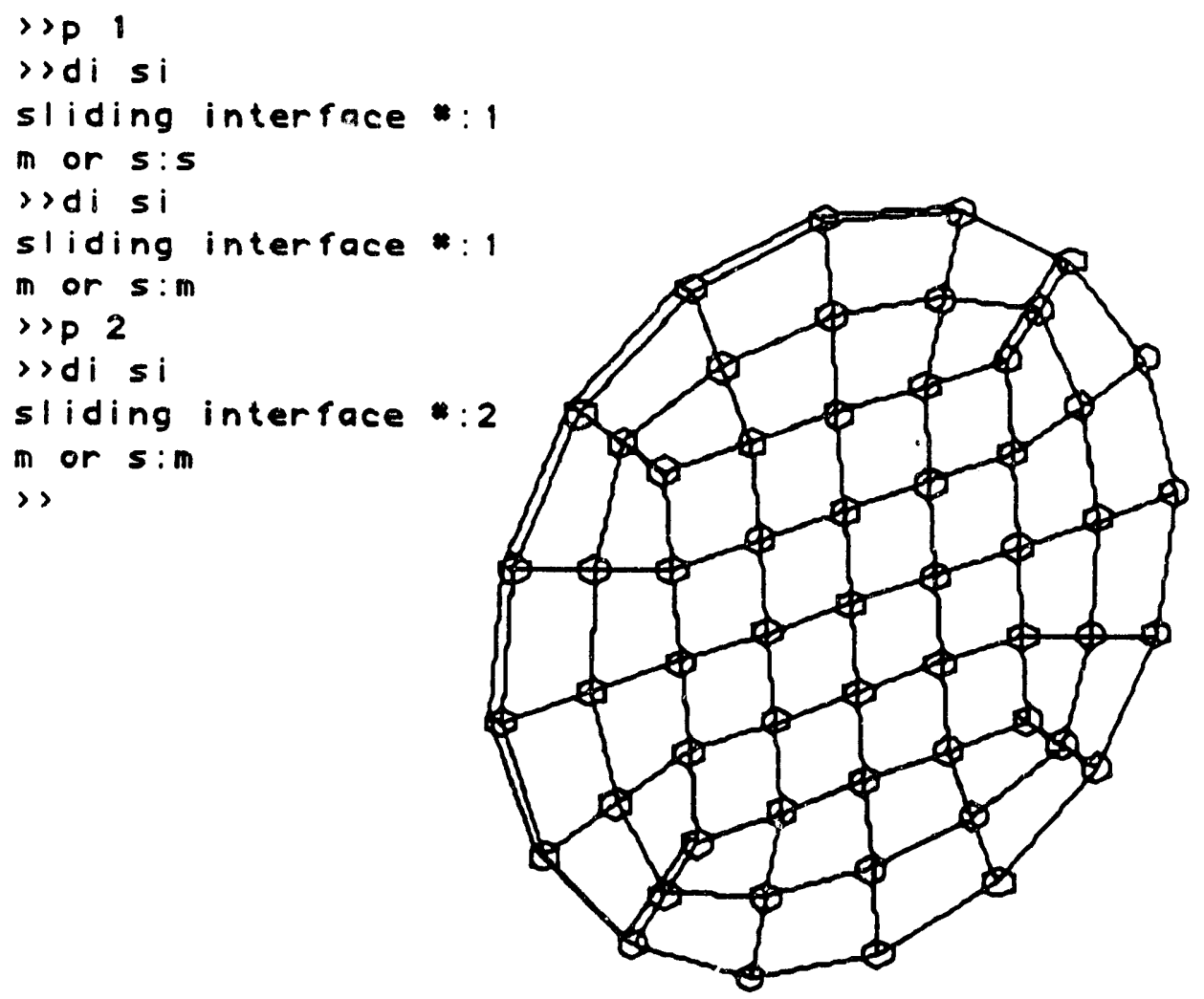


INGRID Code - Display of Slip Planes - Sliding Interfaces \#1, \#2, \#3

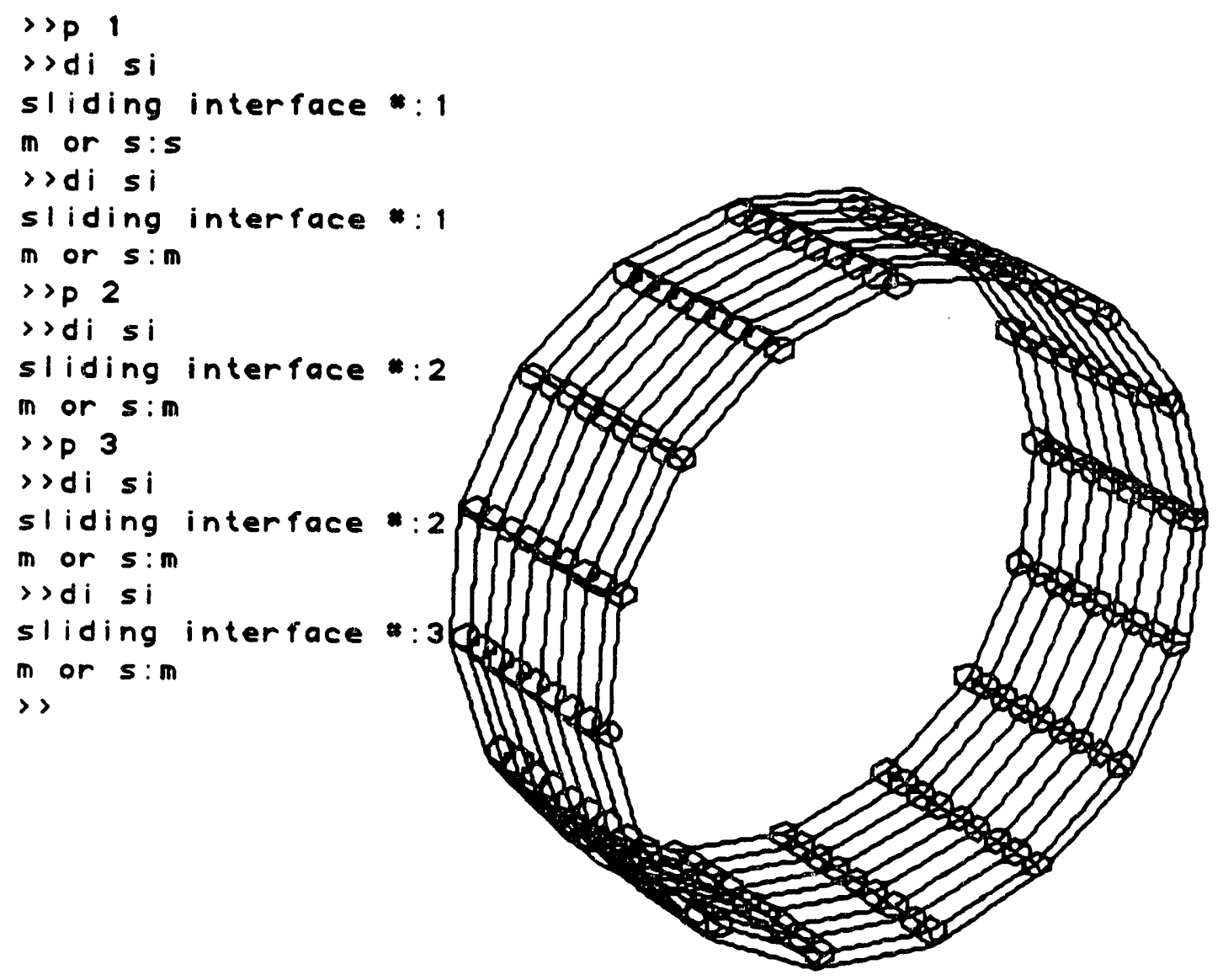


INGRID Code - Display of Slip Planes - Sliding Interfaces \#1, \#2, \#3, \#4

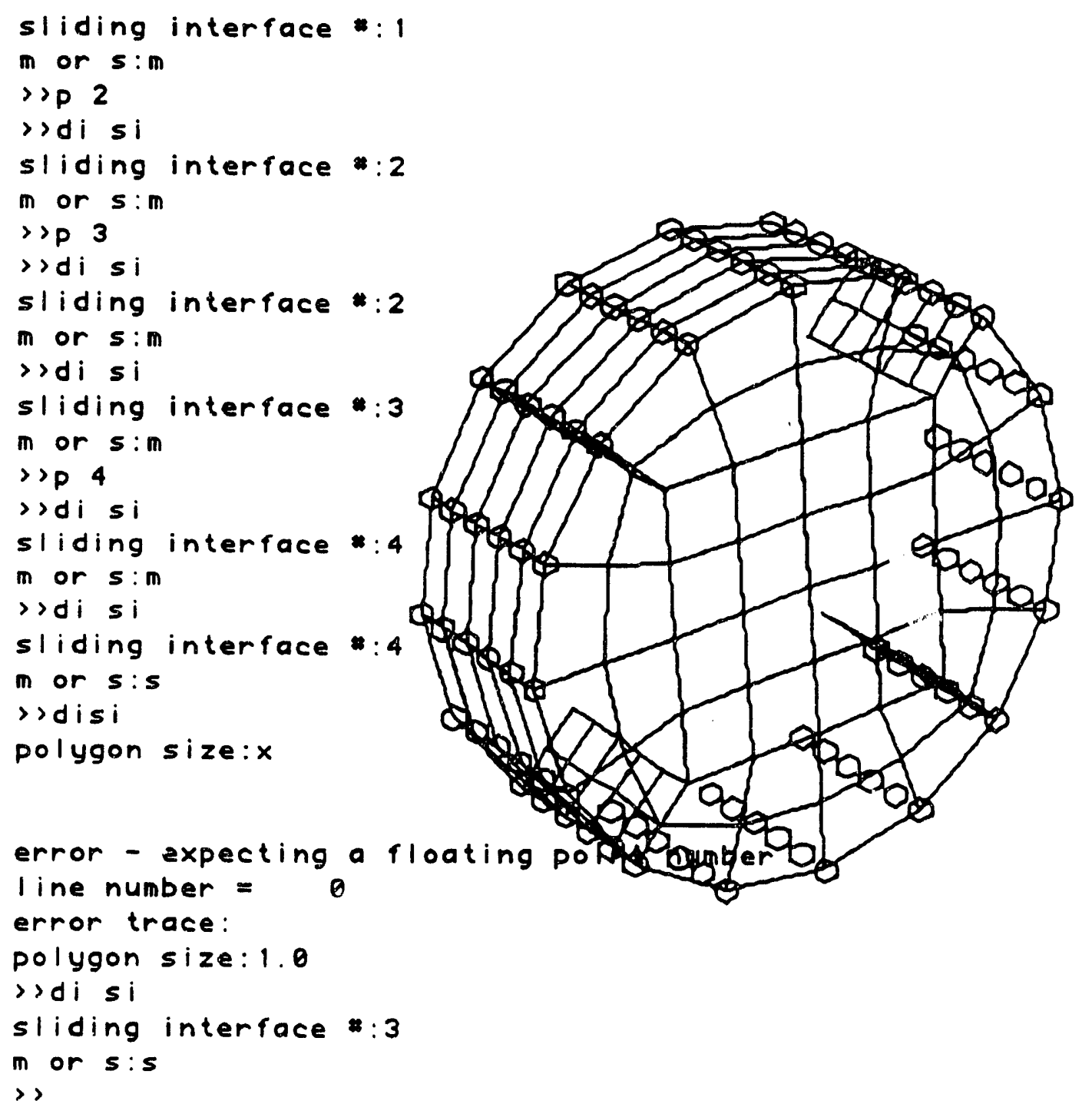


INGRID Code - Rigid Tank - Verification of Fluid Structure

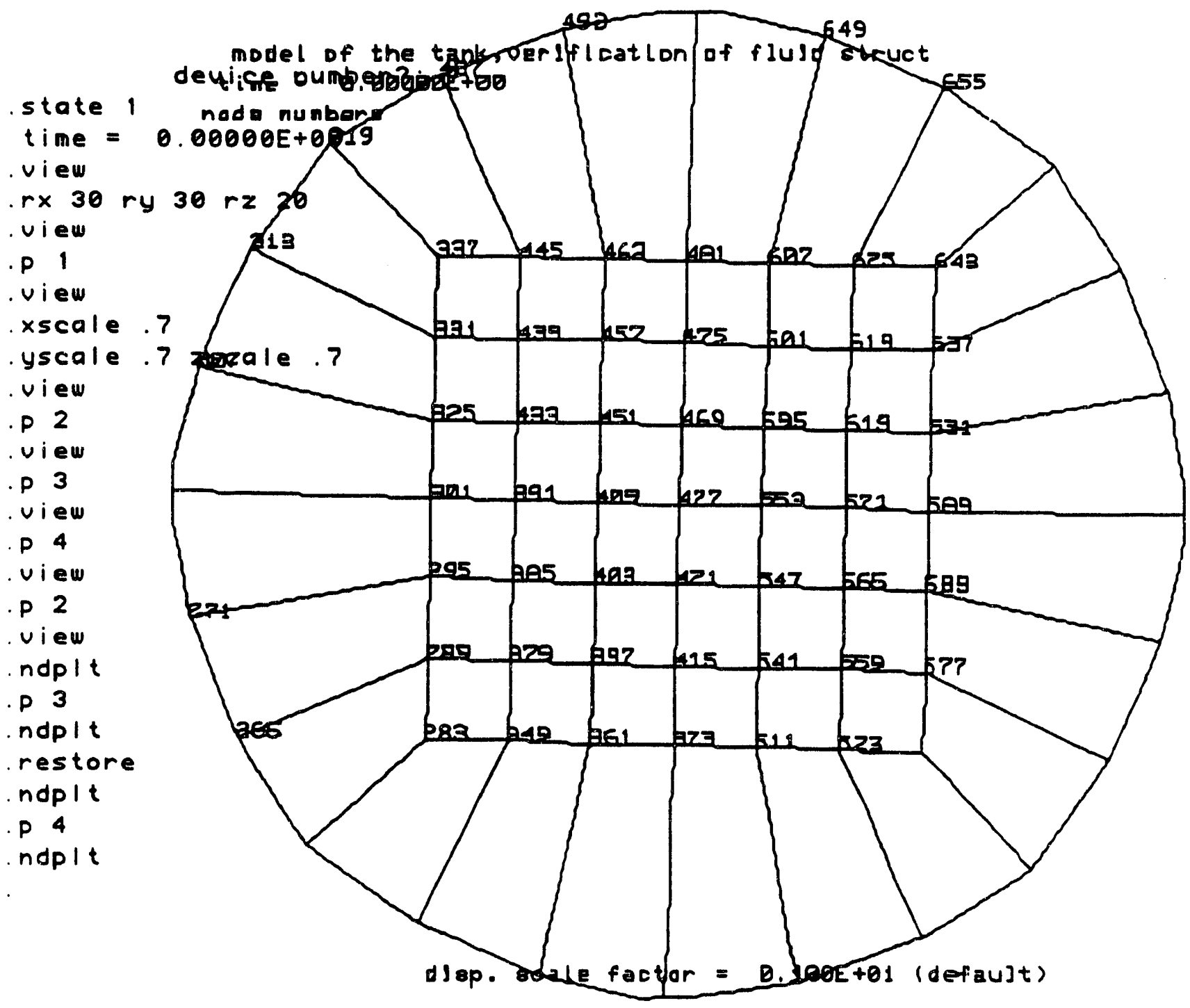




\section{INGRID Code - Rigid Tank - Verification of Fluid Structure \\ Contours of Z-displacement}

Time $=0.57$ seconds

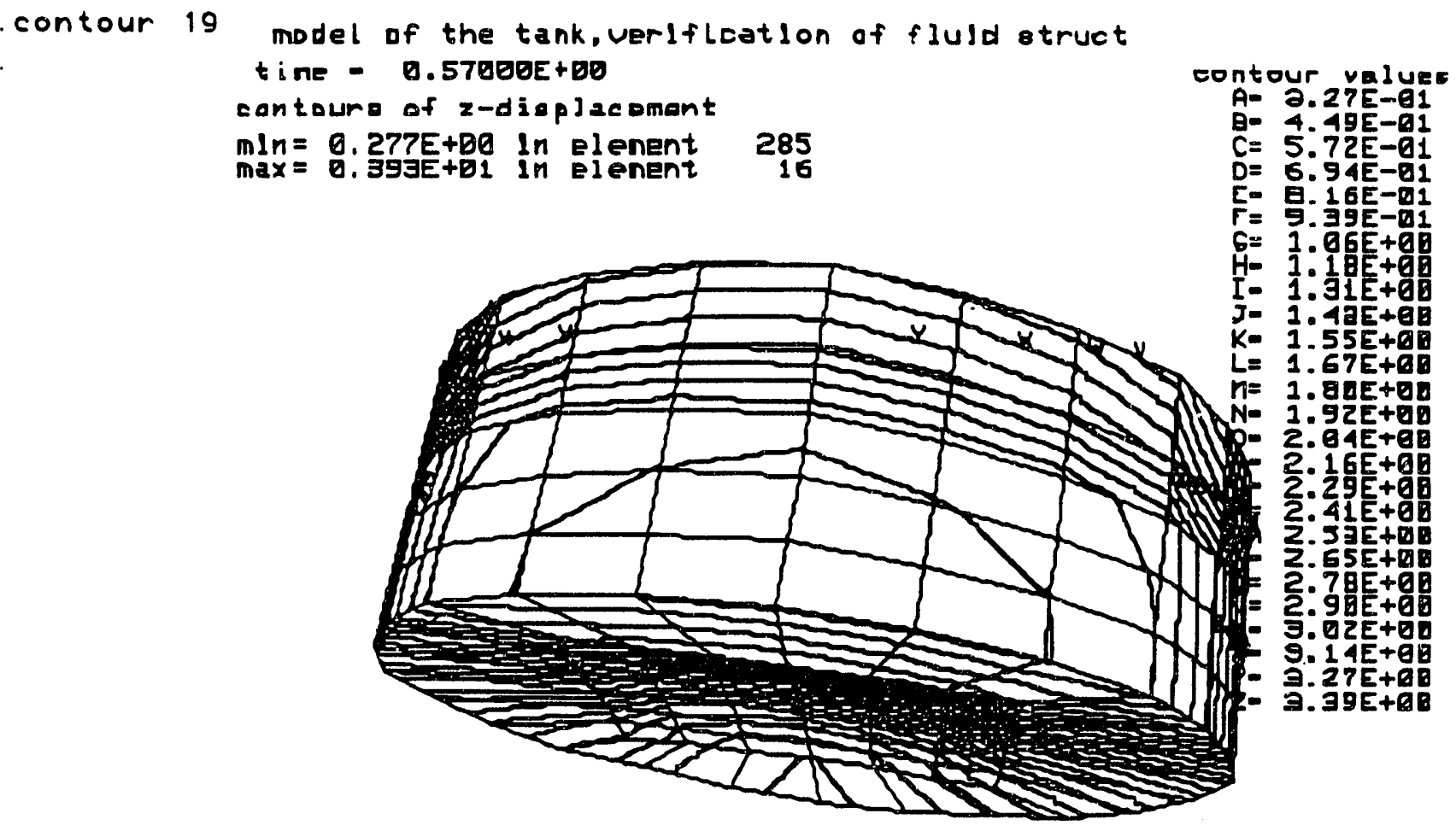

dlsp. Bcale factor $=0.100 E+01$ (default) 


$$
\begin{gathered}
\text { INGRID Code - Rigid Tank - Verification of Fluid Structure } \\
\text { Contours of Z-displacement } \\
\text { Time }=0.57 \text { seconds }
\end{gathered}
$$

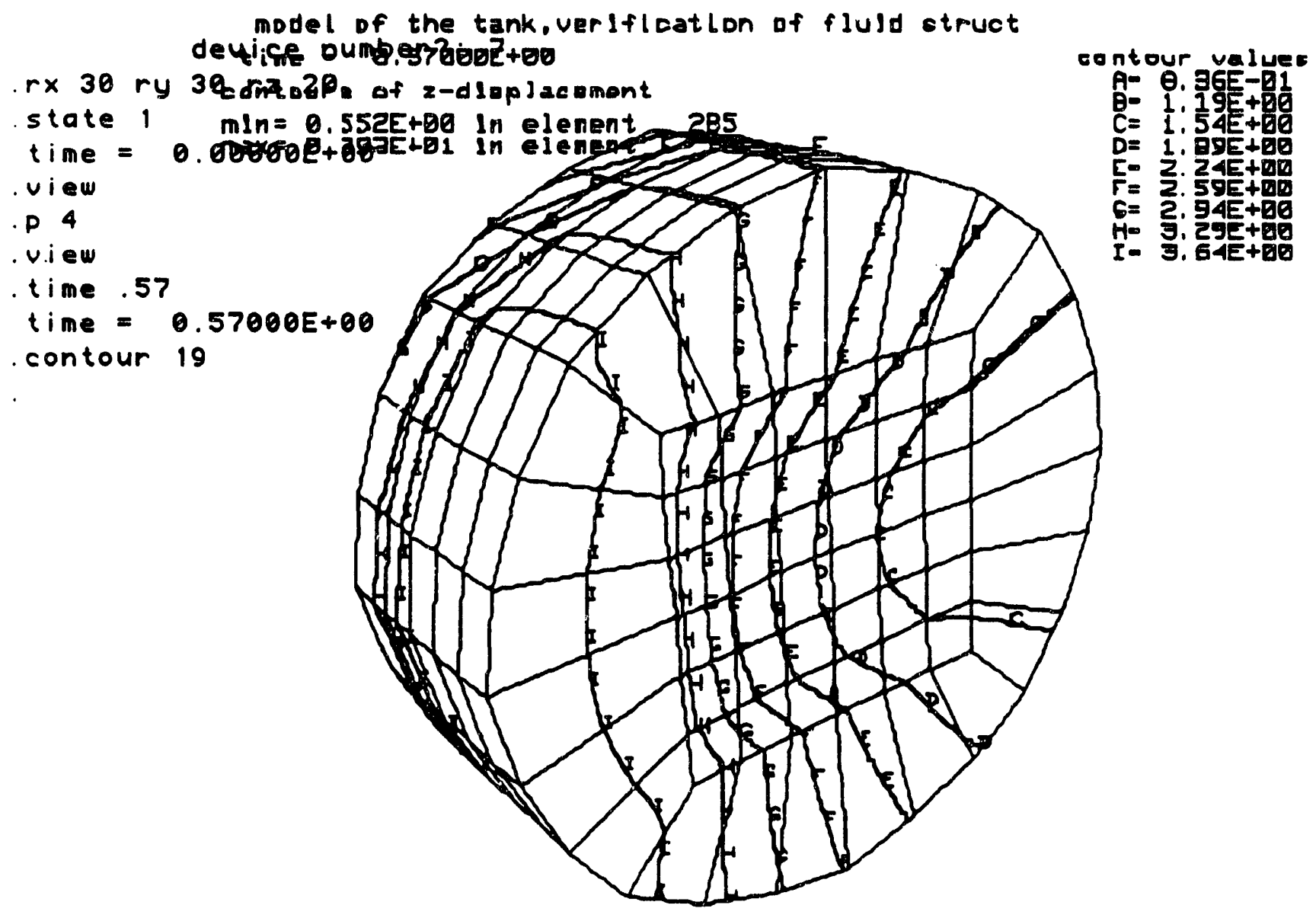

dJop. ocale factor $=0.100 E+01$ (defaujt) 


\section{INCRID Code - Rigid Tank - Verification of Fluid Structure Contours of Z-displacement}

Time $=0.57$ seconds

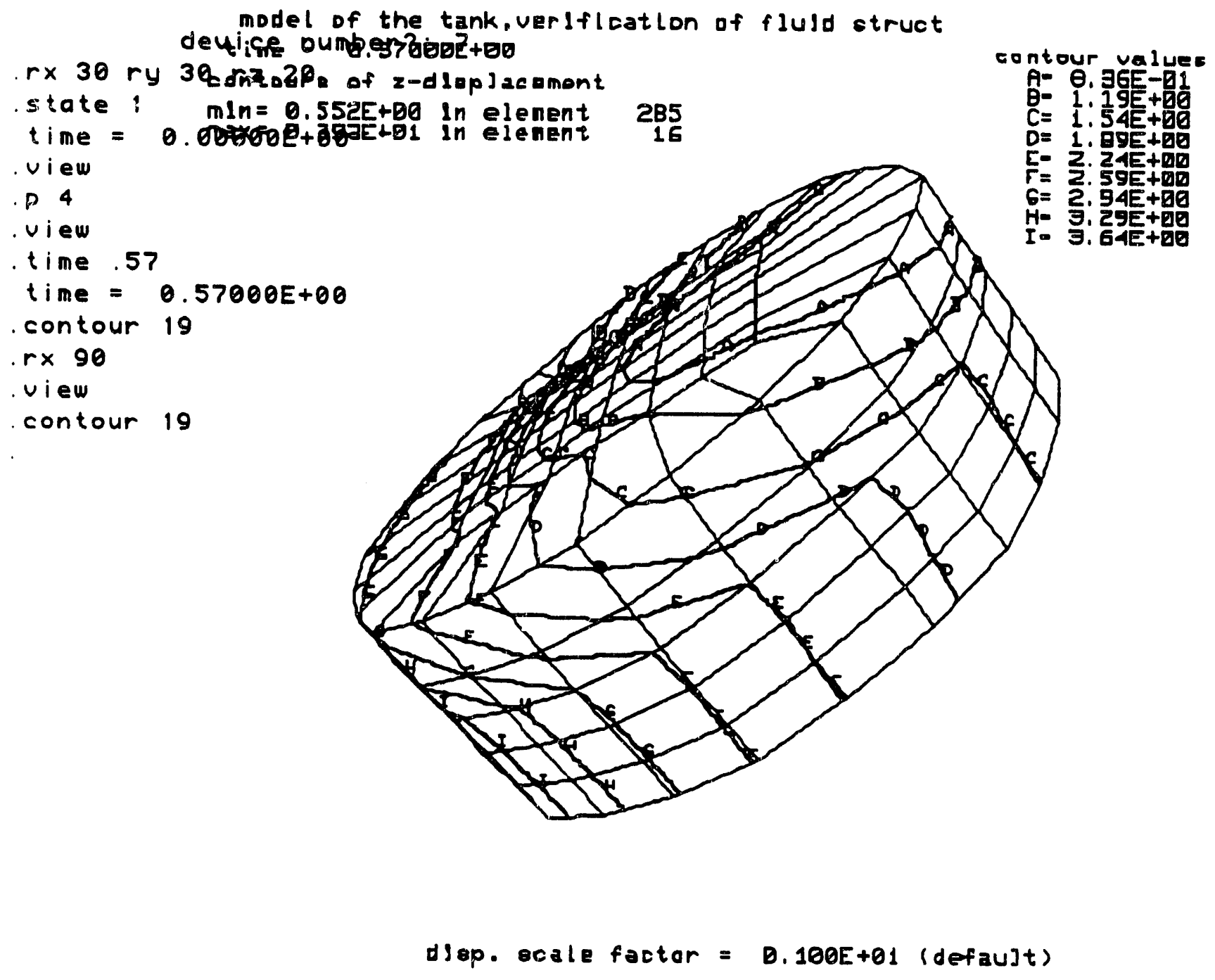



INGRID Code - Rigid Tank - Verification of Fluid Structure
Coritours of Z-displacement

Time $=0.57$ seconds

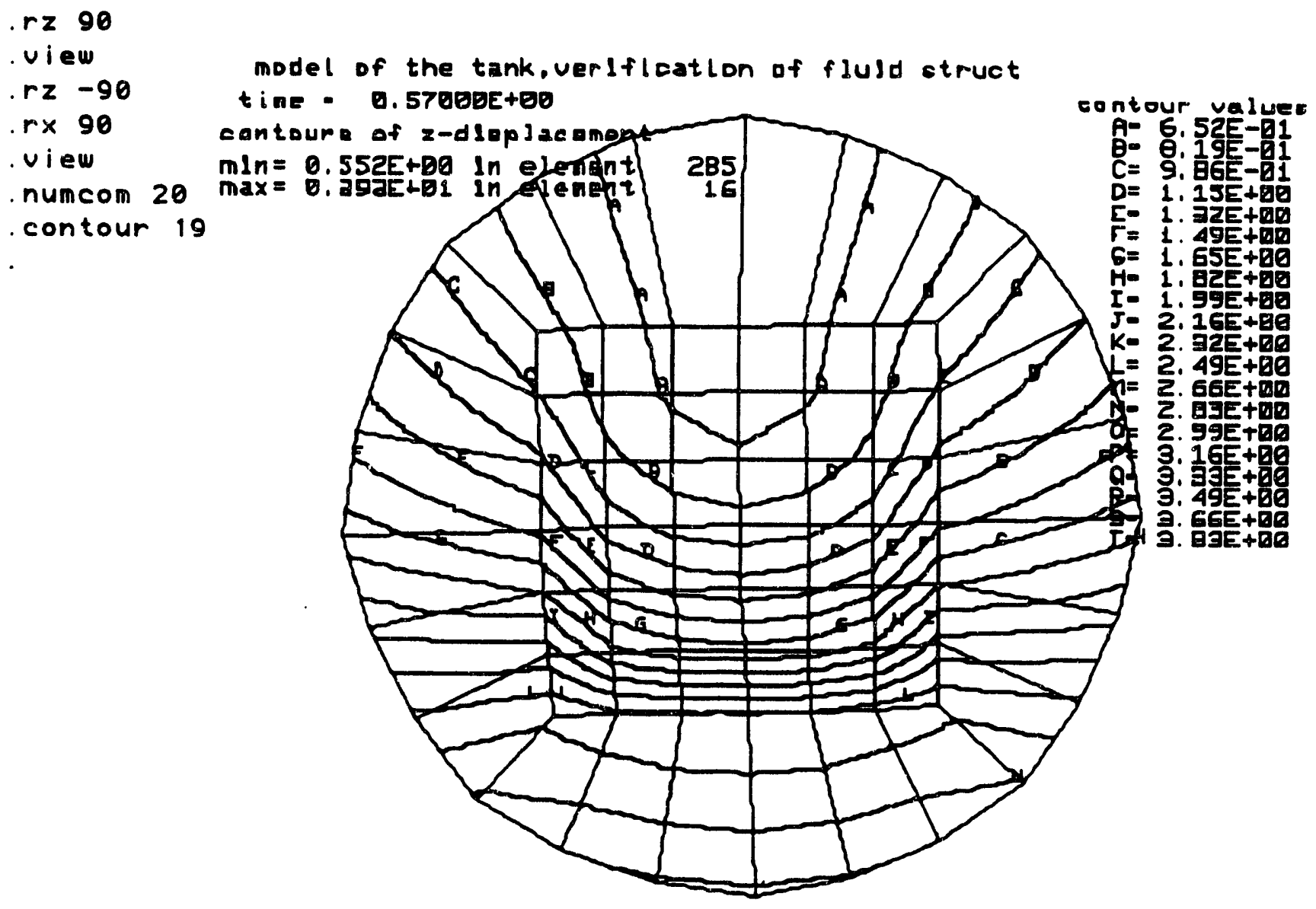

djop. ocale factor $=0.400 E+01$ 
INGRID Code - Rigid Tank - Verification of Fluid Structure

Contours of Shear Resultant (qxx)

Time $=0.57$ seconds

$r z 90$

view

$r z-90$

$r \times 90$

view

numcom 20

contour 19

.p 2

view

dsi 1.0

contour 29

model of the tank, verlflcation of fluld struct

tine - 0.57000E+BE

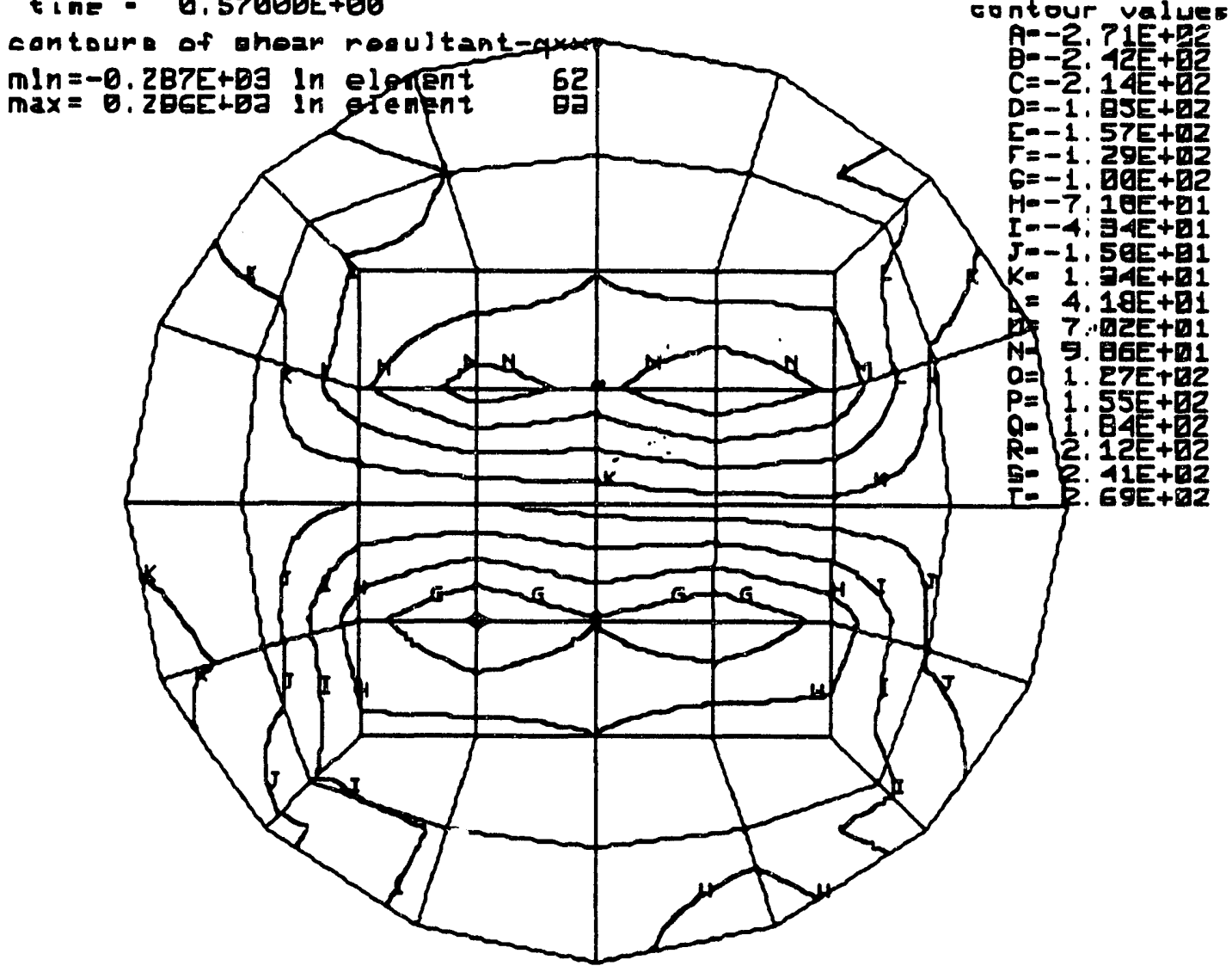

d) sp. scale factor = D.100E+01 (defaujt) 
" GRID Code -- Rigid Tank - Verification of Fluid Structure Contours of Shear Resultant (gy)

Time $=0.57$ seconds

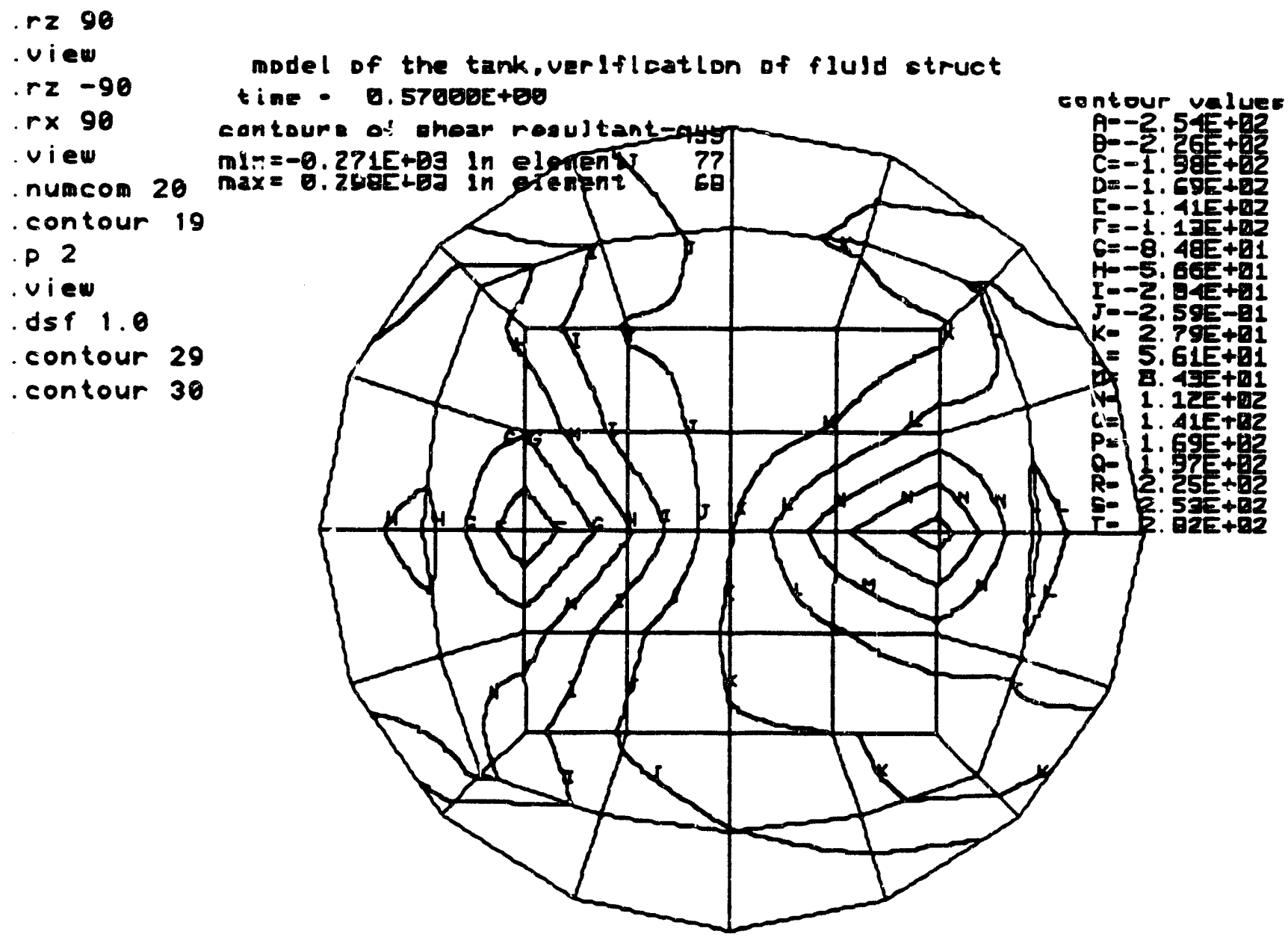

dsop. ale factor $=0.100 E+01$ (defauJt) 


\section{INGRID Code - Rigid Tank - Verification of Fluid Structure Node Numbers}

Time $=0.57$ seconds

ndplt model of the tank, verlflcation of fluld otruct

tine - 0.570EEE+ED

nod $\rightarrow$ nunbora

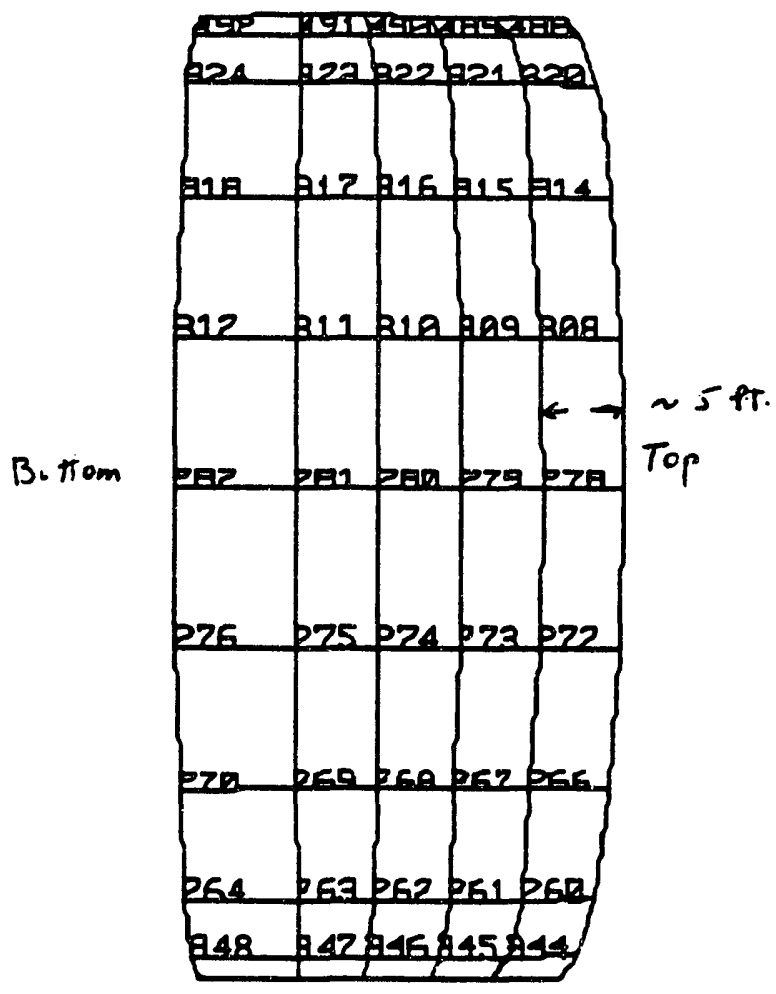

Ulop. ocale factor $=0.100 E+01$ (default) 


\section{INCRID Code - Rigid Tank - Verification of Fluid Structure Contours of $\mathrm{X}$-stress}

Time $=0.57$ seconds

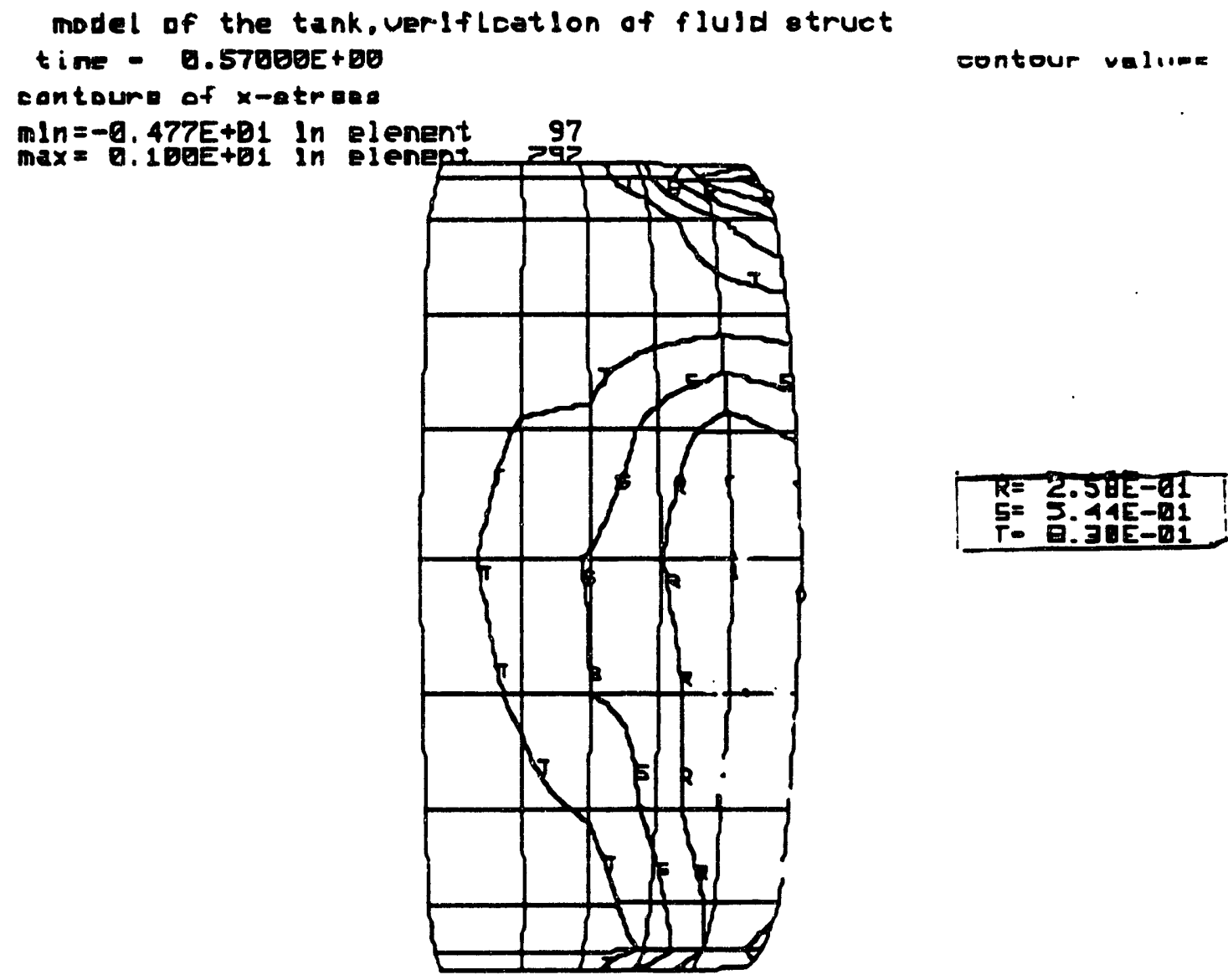

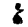

dlep. Bale factor $=0.100 E+Q 1$ (default) 
INGRID Code - Rigid Tank - Verification of Fluid Structure

Contours of Moment Resultant (mxx)

Time $=0.57$ seconds
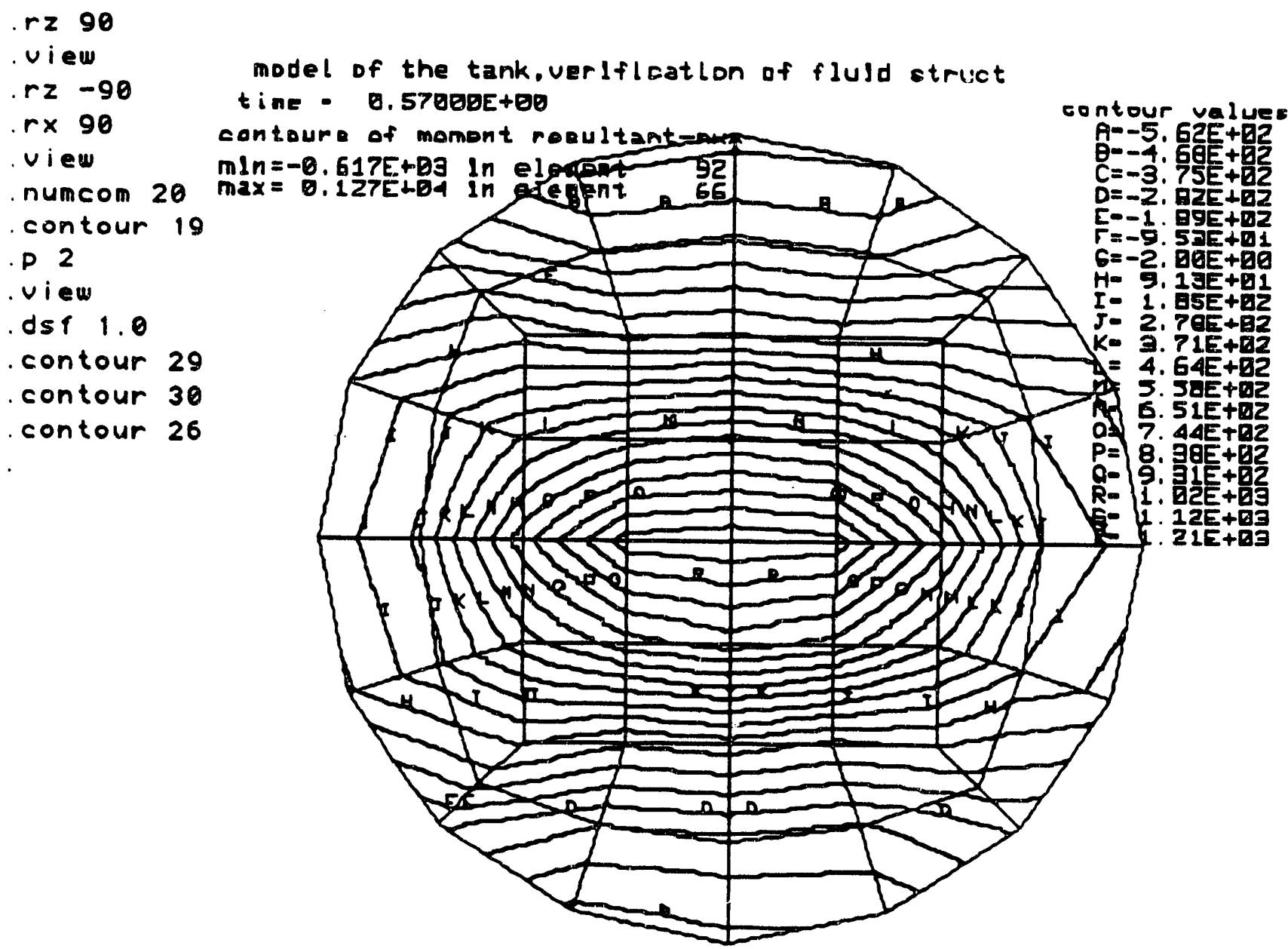

d)op. scale factor $=0.100 E+01$ (defauJt) 

INGRID Code - Rigid Tank - Verification of Fluid Structure
Contours of Moment Resultant (myy)

Time $=0.57$ seconds

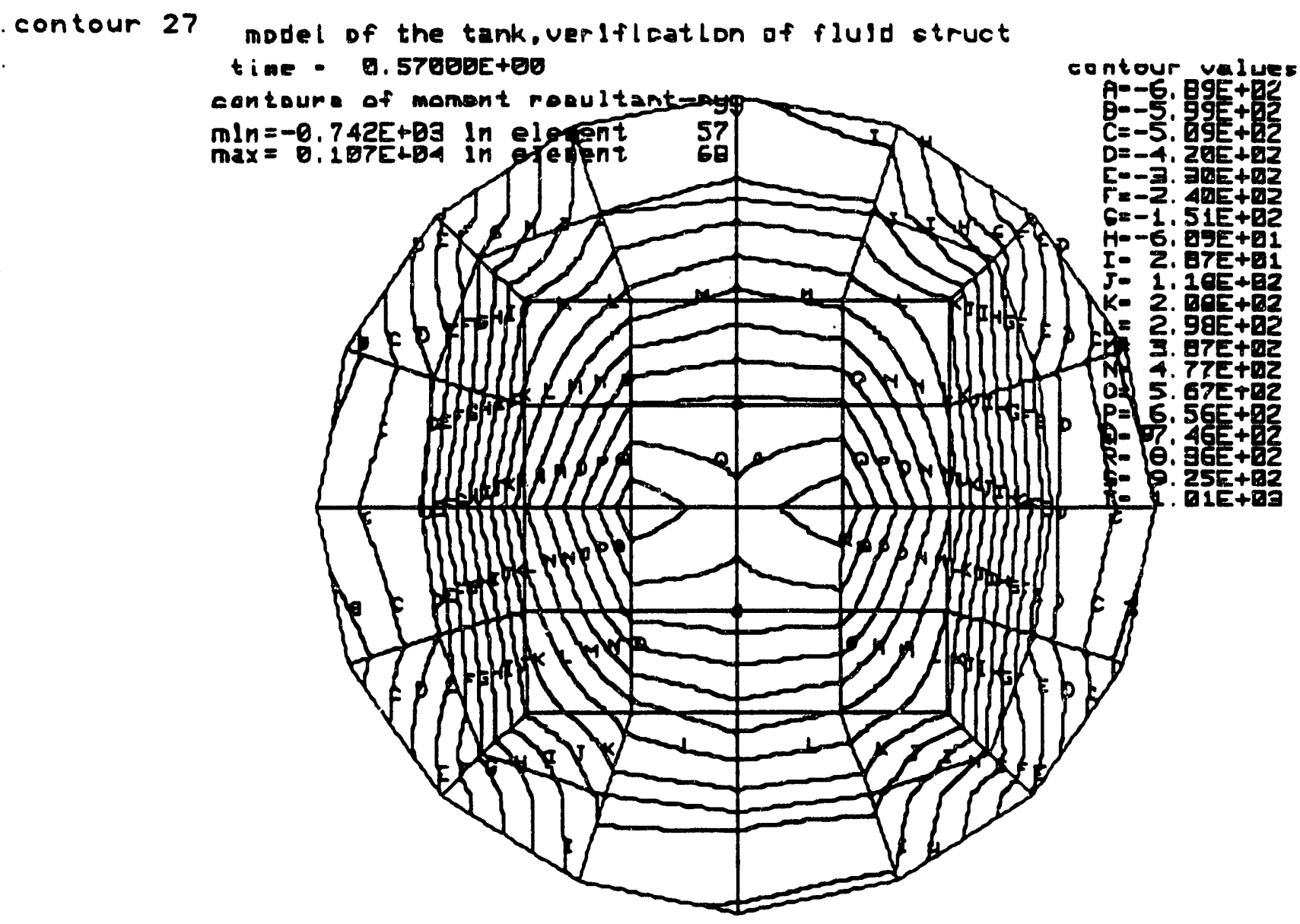

d)ap. ocale factor $=0.100 E+01$ (defaujt) 
INCRID Code - Rigid Tank - Verification of Fluid Structure Contours of Moment Resultant (mxy)

Time $=0.57$ seconds

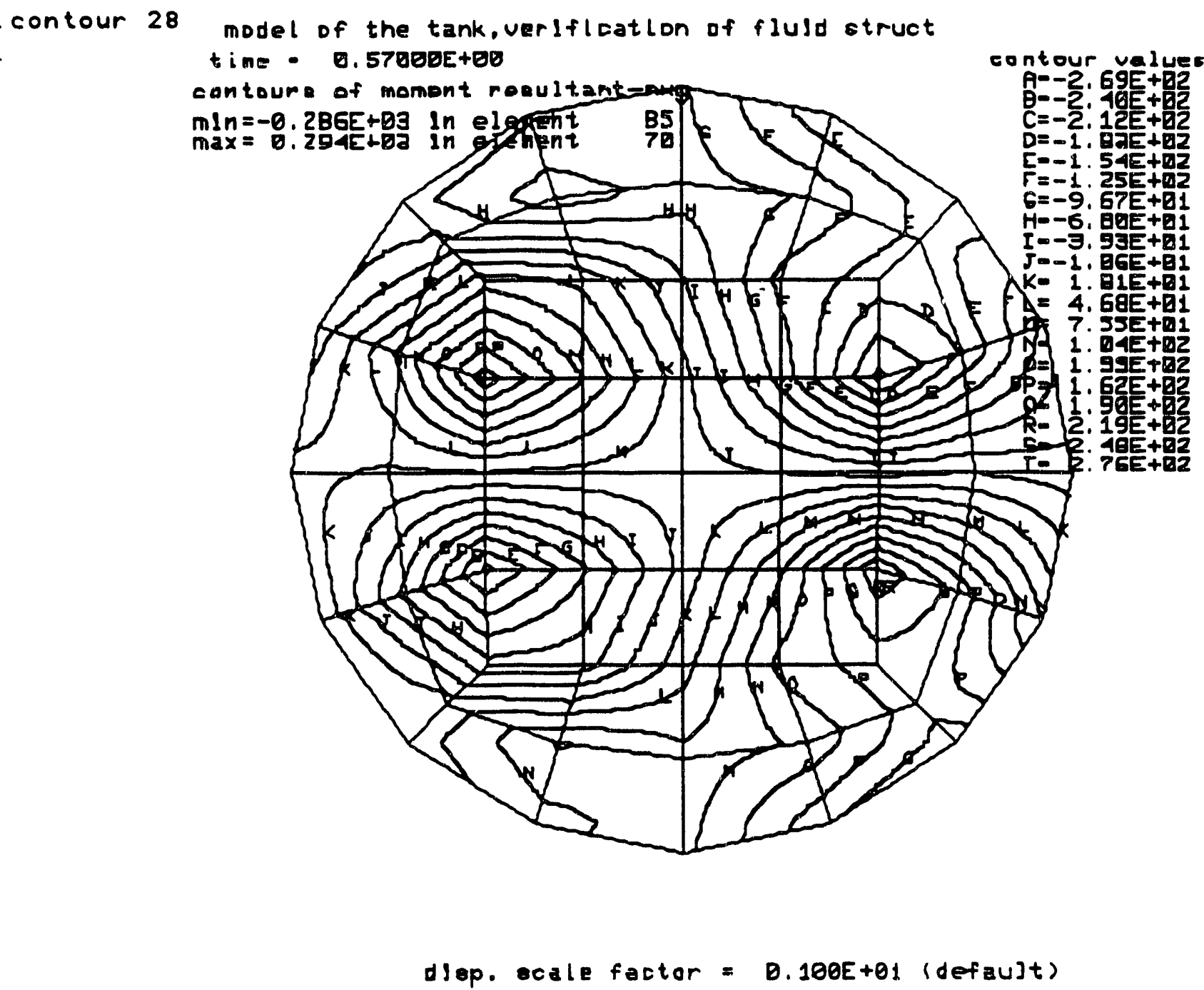




\section{INGRID Code - Rigid Tank - Verification of Fluid Structure Suríace Stress}

Time $=0.57$ seconds

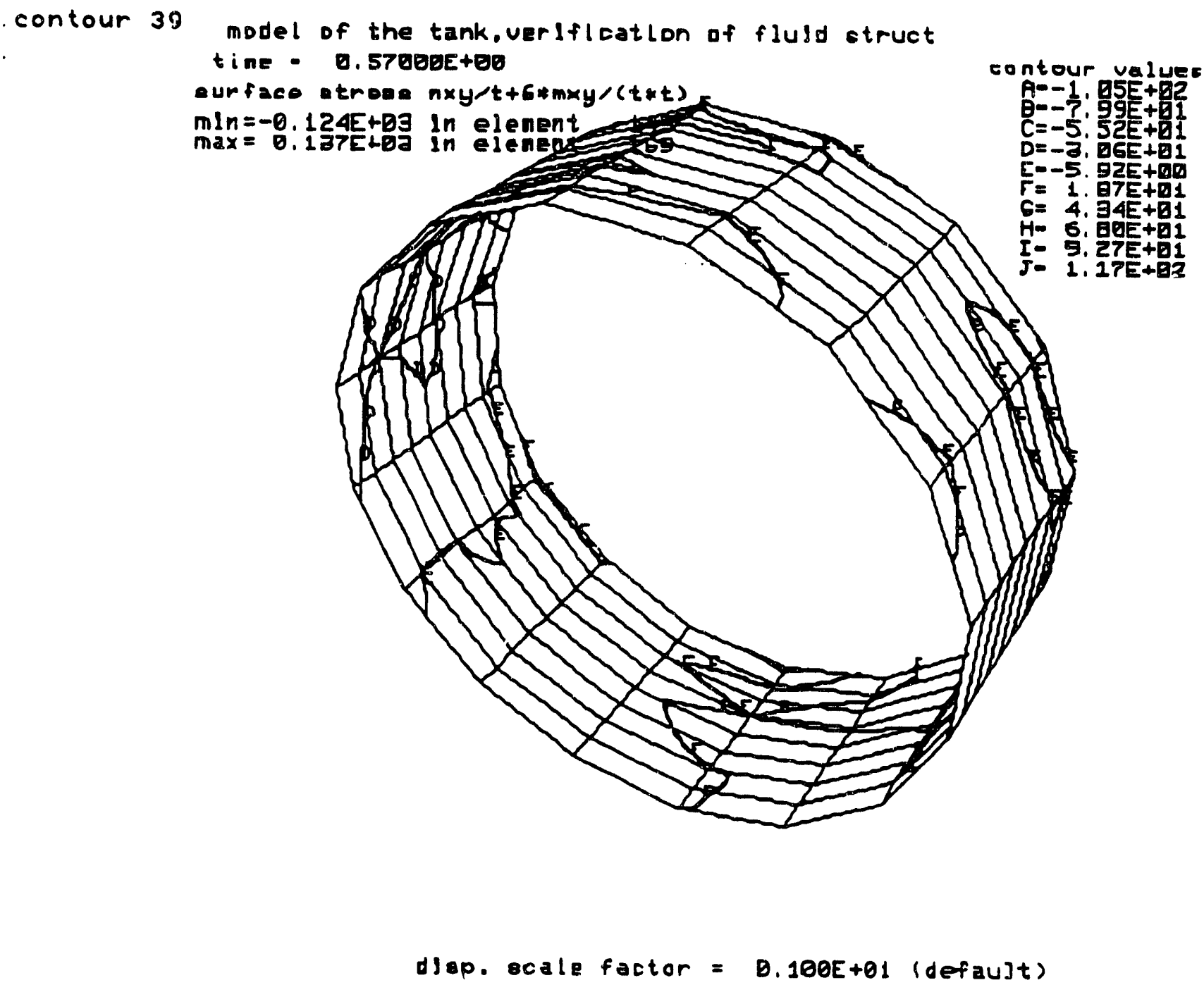




\section{INGRID Code - Rigid Tank - Verification of Fluid Structure Surface Stress}

Time $=0.57$ seconds

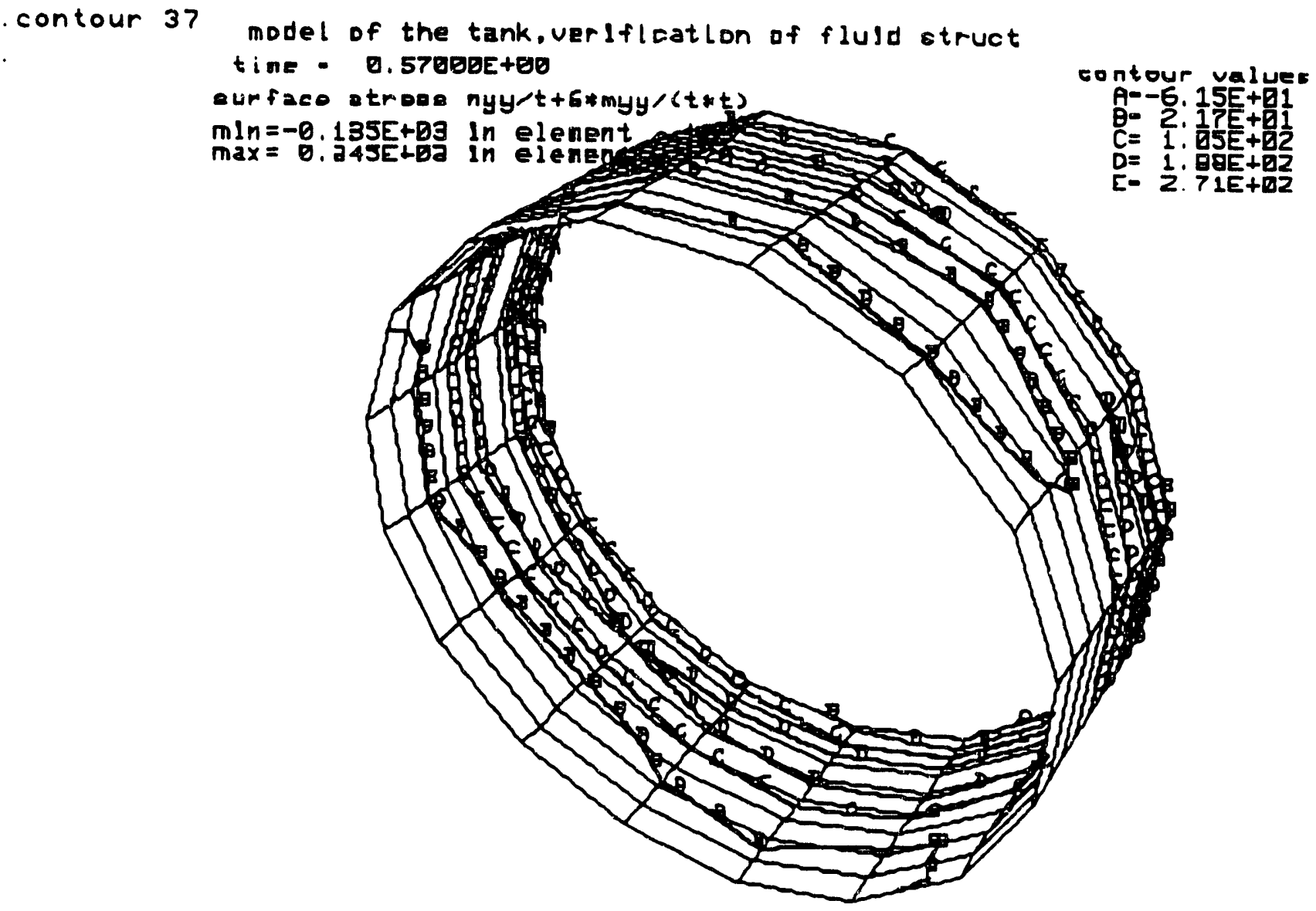

dlop. scale factor $=0.100 E+01$ (defauJt) 
INCRID Code - Rigid Tank - Verification of Fluid Structure Surface Stress

Time $=0.57$ seconds

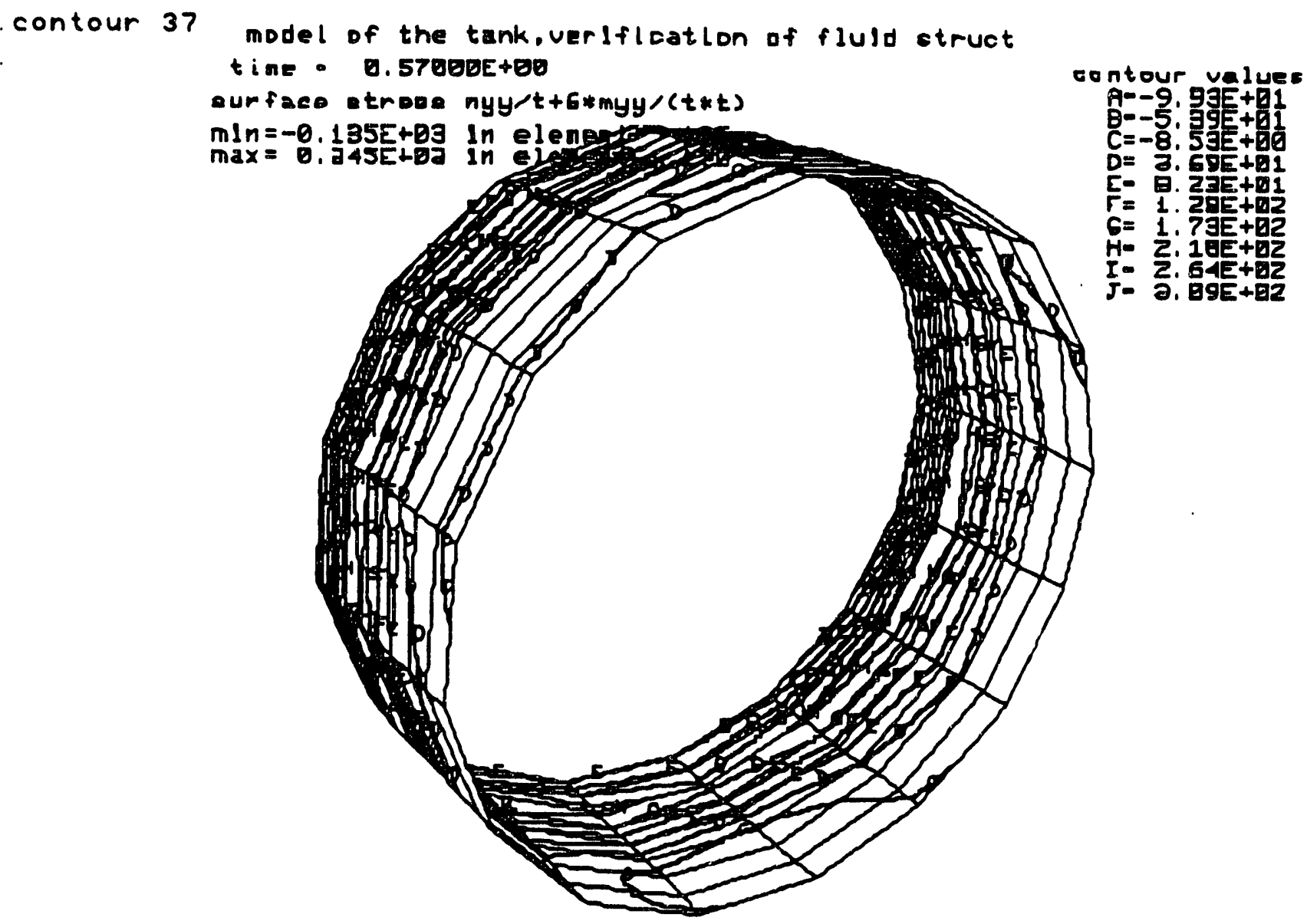

d)op. ocale factor $=$ D.180E+01 (defaujt) 
INGRID Code - Flexible Tank - Verification of Fluid Structure Node Numbers

Time $=0.57$ seconds

ndp 1 t . $P 2$

.ridplt

model flex. tank,verlfleatlon of fluld struet

time - 0.57080E+E0

nado nunbara

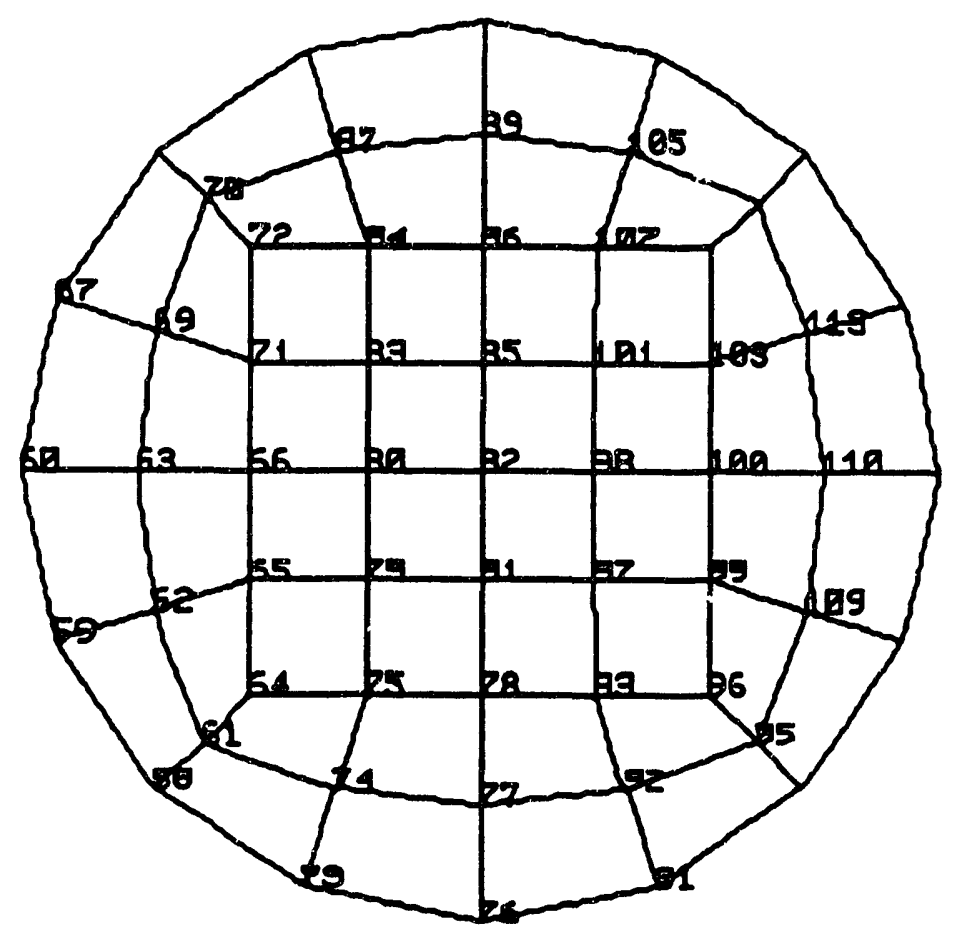

dJop. ecale factor $=$ B.100E+01 (defauJt) 

INGRID Code - Flexible Tank - Verification of Fluid Structure Contours of $\mathrm{X}$-displacement

Time $=0.57$ seconds

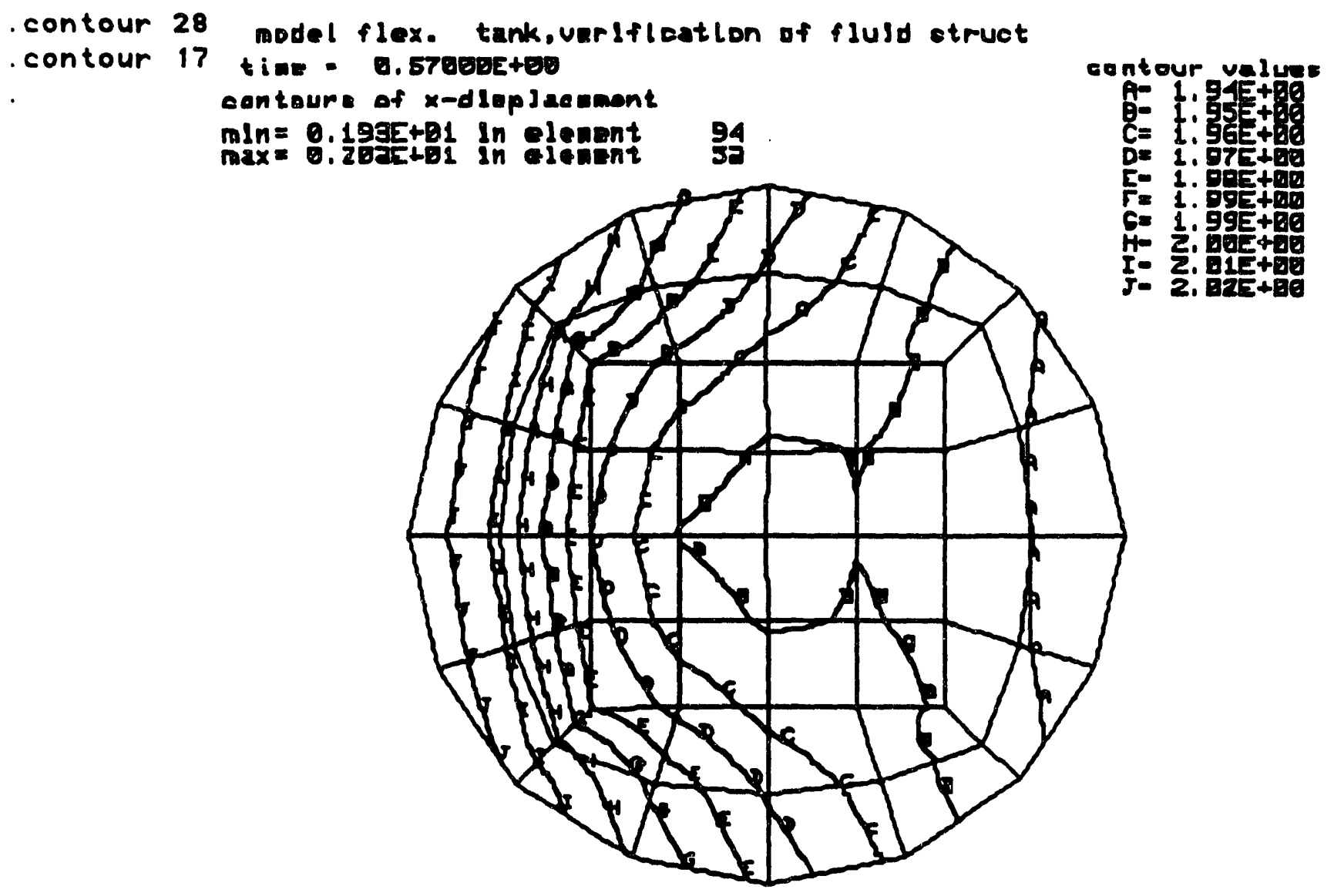

dlop. scale foctor $=0.100 E+01$ (defaudt) 
INGRID Code - Flexible Tank - Verification of Fluid Structure Contours of $X$-displacement

Time $=0.57$ seconds

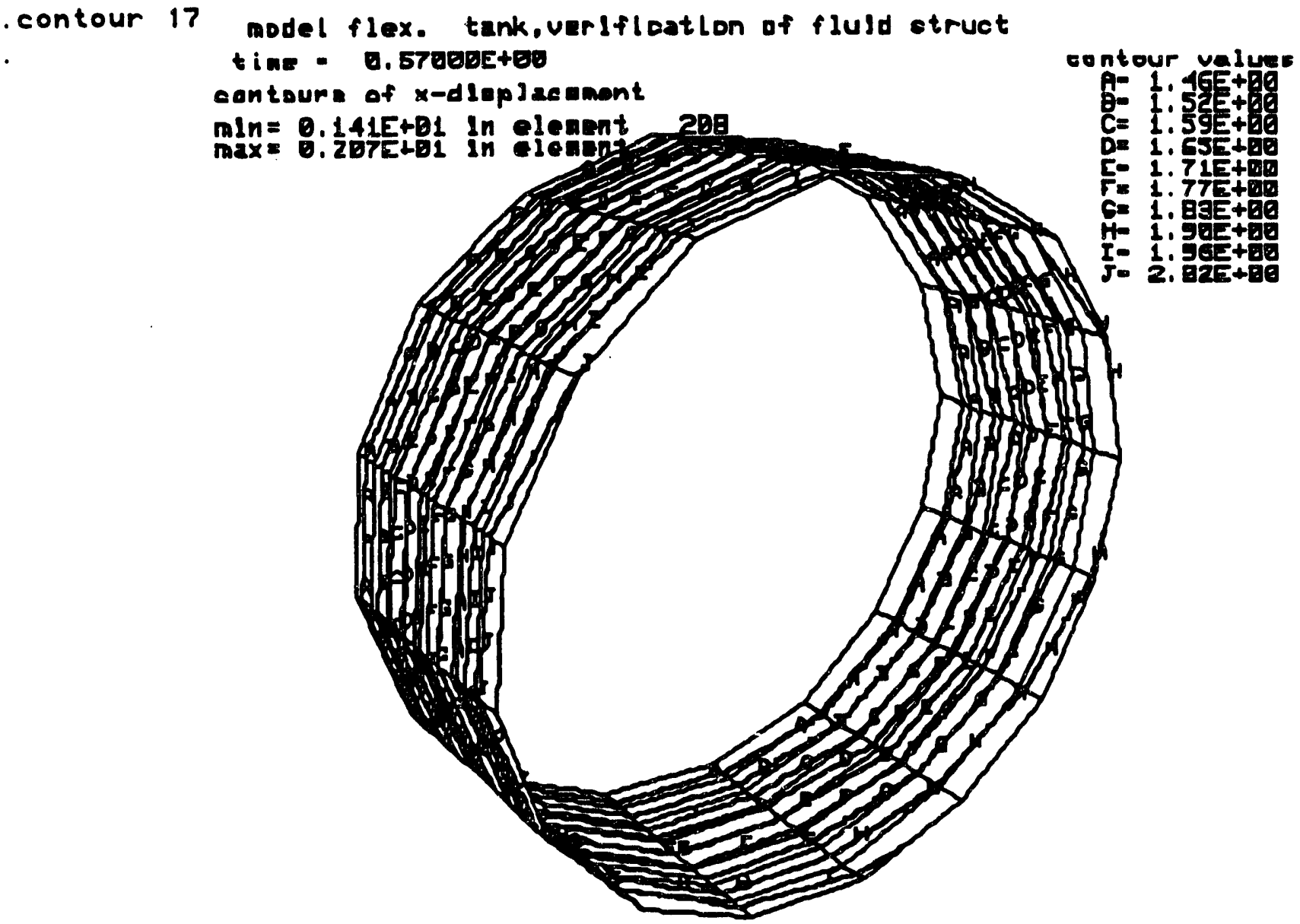

dJep. cole factor = D.100E+01 (defaut) 
INGRID Code - Flexible Tank - Verification of Fluid Structure
Contours of $X$-displacement

Time $=0.57$ seconds

contour 17

model flex. tank, verlfloation of fluld etruct

tine - 0.578bez+Eo contoure of $x$-dlopjacumont

$\operatorname{mln}=0.1$ BEEtQ1 In elenent $3 B 1$

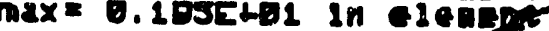

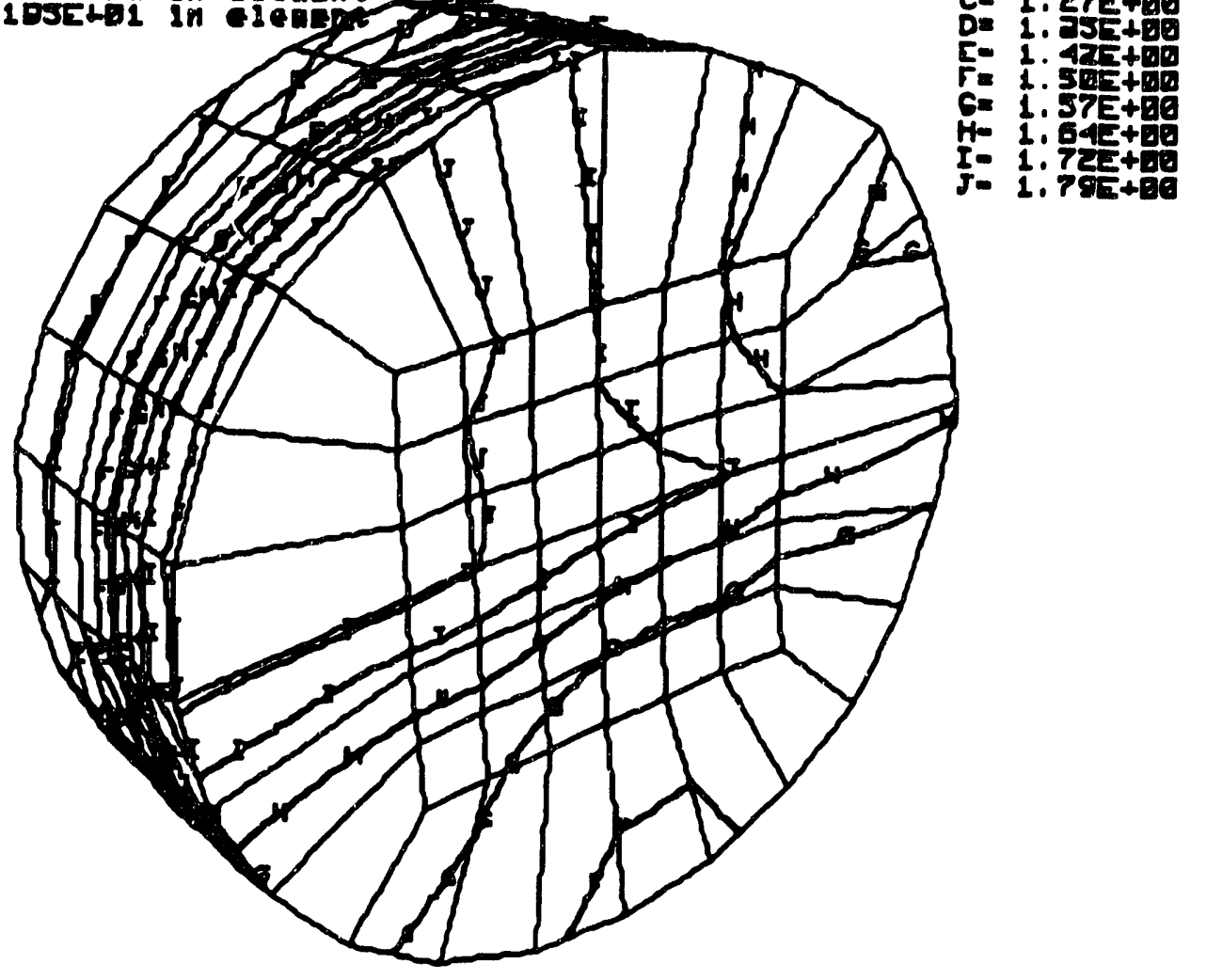

dop. ceala fector $=0.100 E+01$ (defaujt) 


\section{INCRID Code - Flexible Tank - Verification of Fluid Structure Contours of Z-displacement}

Time $=0.57$ seconds

contour 19

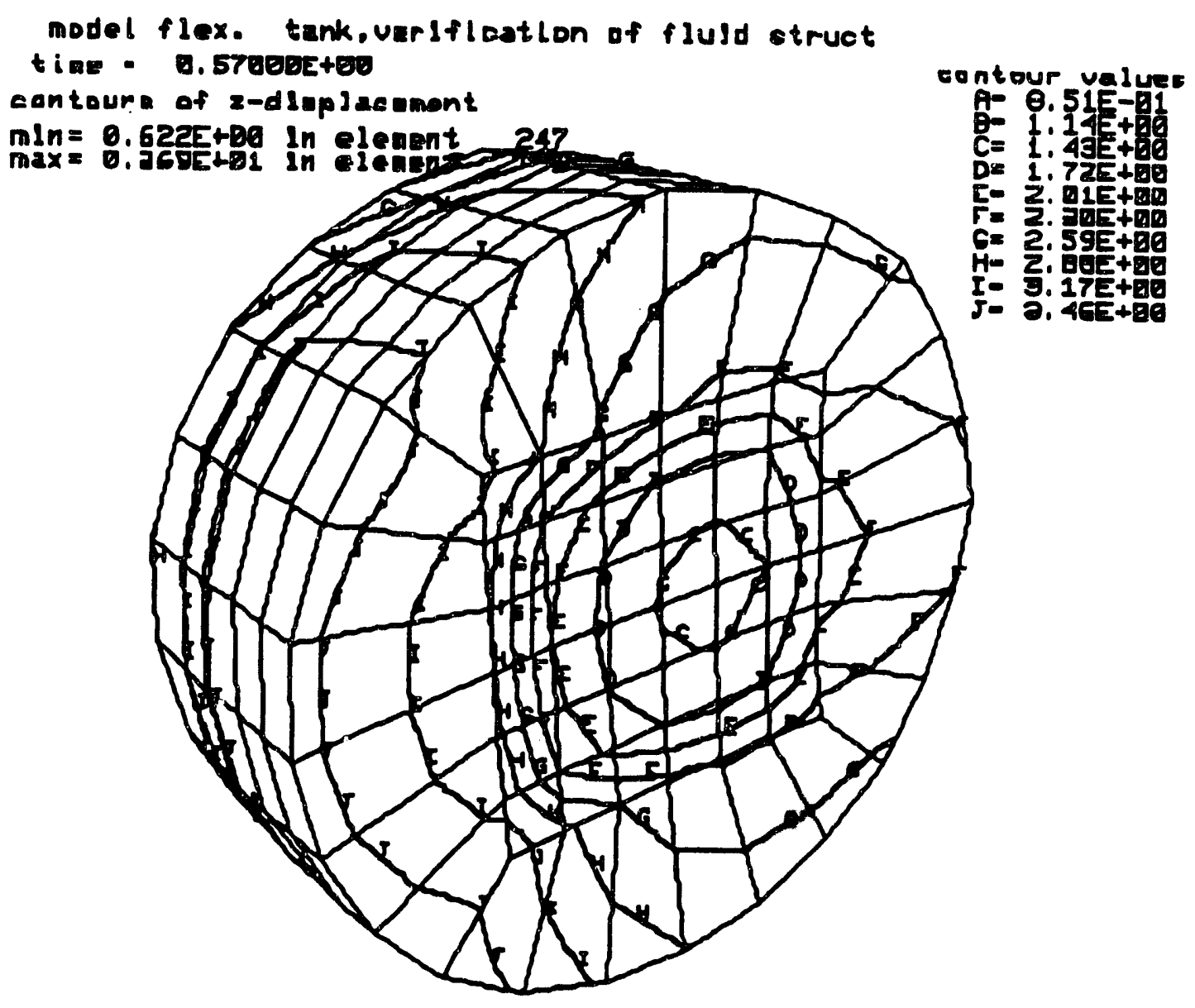

dlop. scale factor $=0.100 E+01$ (defauJt) 
INGRID Code - Flexible Tank - Verification of Fluid Structure Contours of Z-displacement

Time $=0.57$ seconds

. contour 19 model flex. tank, verifleation of fluld struct tine - 0.5706eeteo

cantours of z-dlop lacument

$\min =0.6205+80$ in elenent

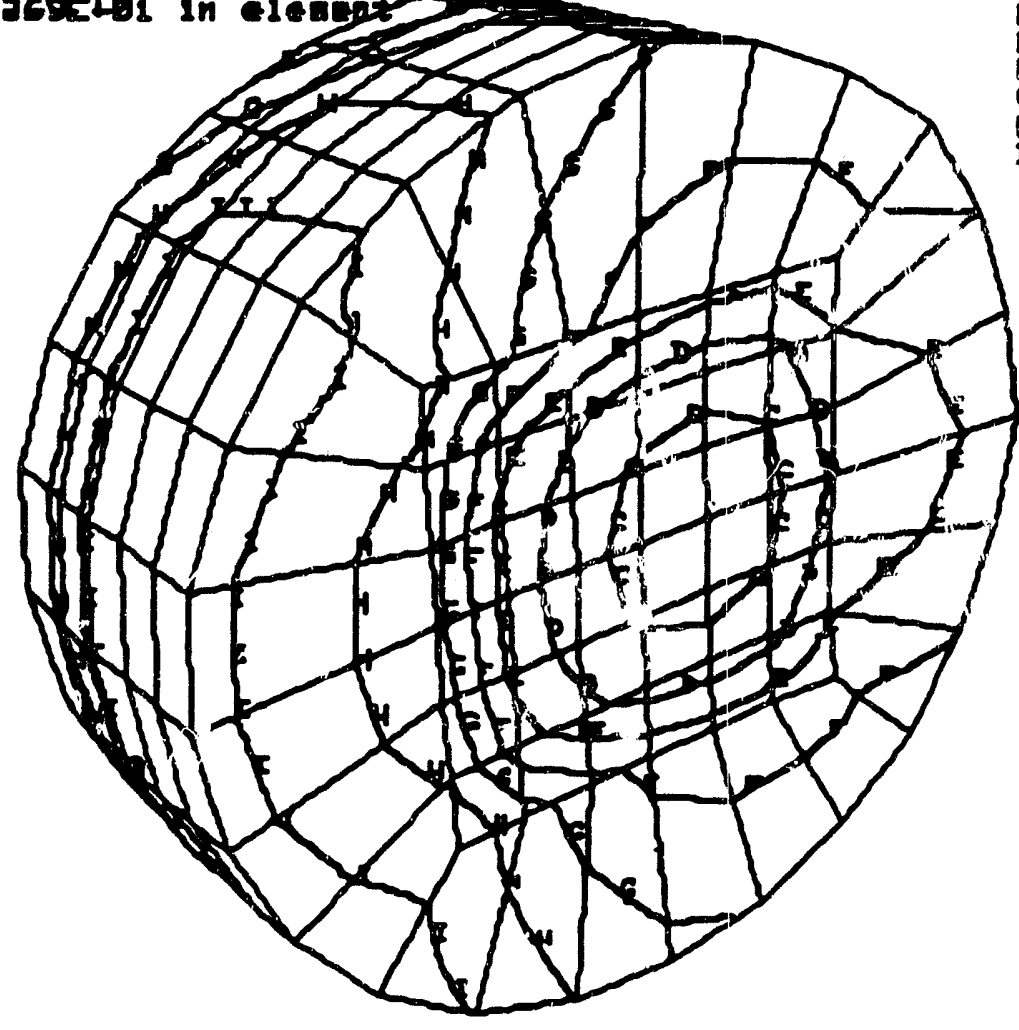

eonteur values

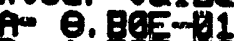

$=1.2 x+10+4$

$C=1,5 c c t=0$

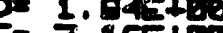

$=2.25+2 . \%$

$r=2.4=2+10$

3. I d

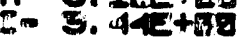

dJop. ecale foctor = D.180E+01 (defauJt) 
INCRID Code - Flexible Tank - Verification of Fluid Structure Contours of Shear Resultant ( $q x x)$

Time $=0.57$ seconds

ndp It

.p 2

.ndp It

. contour

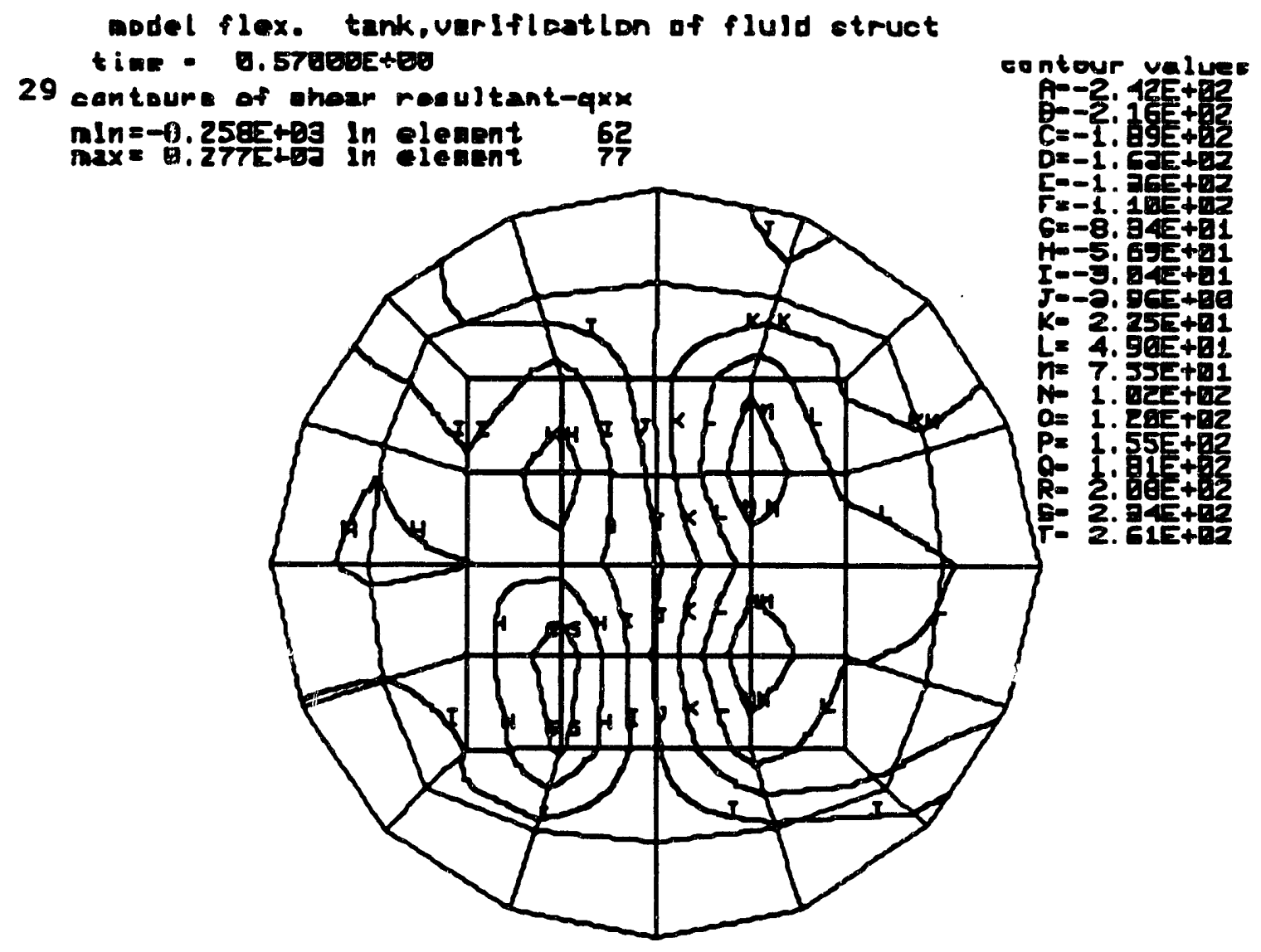

d)op. scale foctor $=0.100 E+01$ (defaudt) 
INGRID Code - Flexible Tank - Verification of Fluid Structure Contours of Shear Resultant (qyy)

$$
\text { Time }=0.57 \text { seconds }
$$

. contour 30 model flex. tank, verlfleation of fluld struct tine - 0.57080E+E0 cantours of whoar rouultant-qyy $m l n=-0.310 E+B g$ in eleaent 77 max $=0.2721+00$ in element of

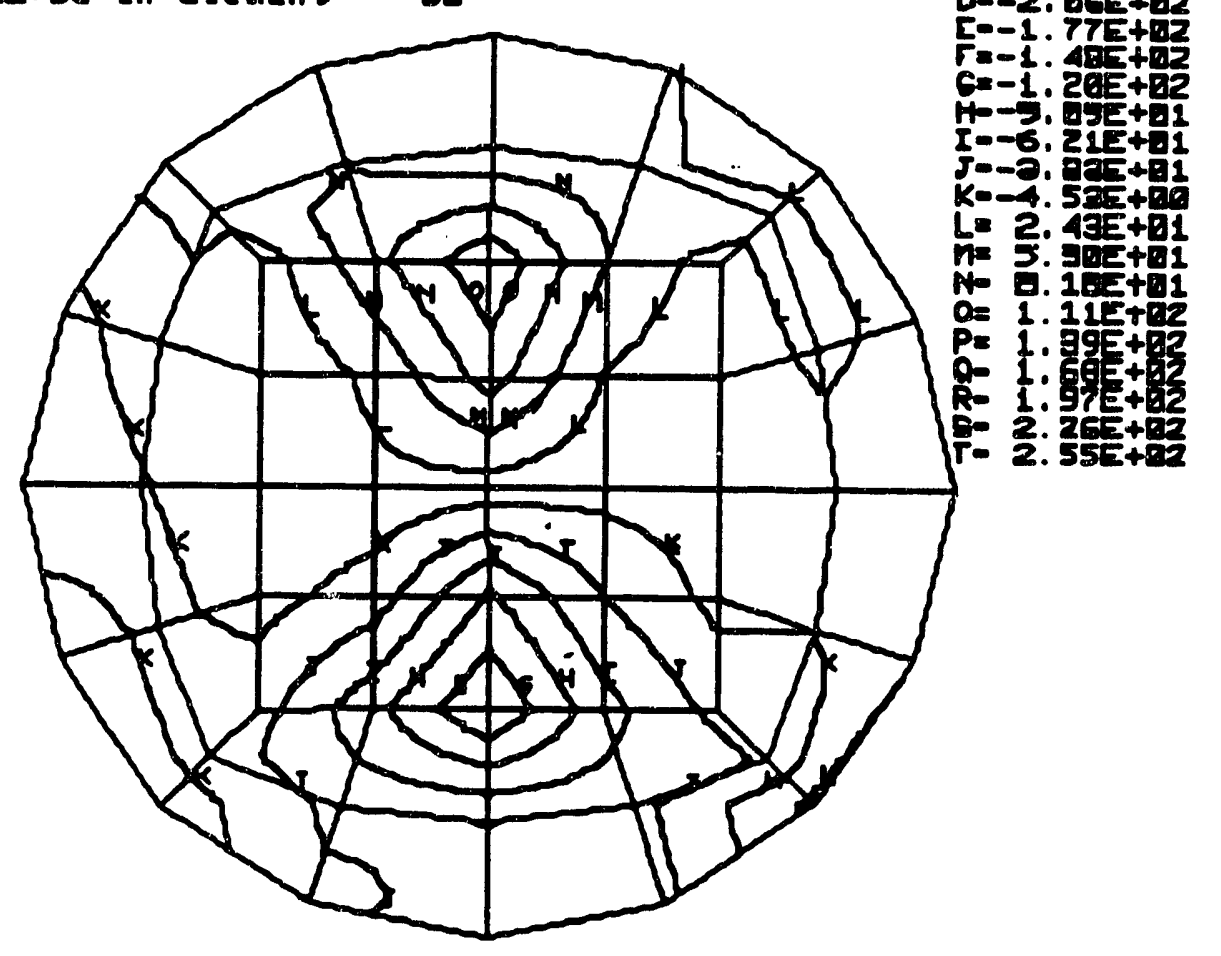

dSop. ecale foctor = D.100E+01 (defaujt) 
INGRID Code - Flexible Tank - Verification of Fluid Structure

Contours of Normal Resultant (mxx)

Time $=0.57$ seconds

contour 31

model flex. tank, verlfleatlon of fluld struct

time - 0.5708BE+E0

cantours of normal mosultant-nxx

min $=-0.112 E+84$ In elenent 57

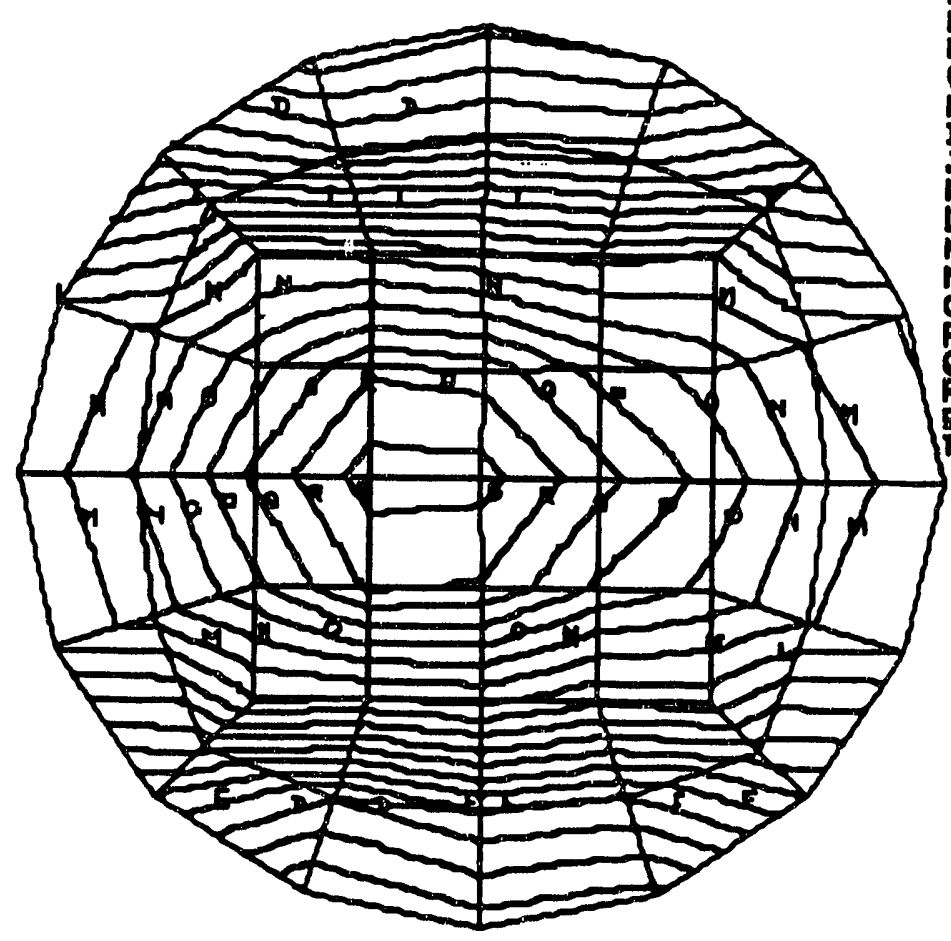

contour valuge

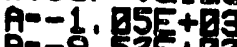

$0=-9.52=+82$

$0=-7$, 4 distez

$=-5 \cdot 45+1.2$

$5=-5.435+02$

$G=-4,41 E+E 2$

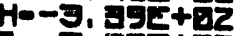

I- -2.37

5- -1. 04E+E2

K=-O.21E+D1

$L=7$. G LE+BI

ne 1.72E+42

- Z. $25 E+0.2$

$0=9.77 E+02$

$P=4.79 E+02$

- 5. 11 L+12

R- 6. 白提+易

- ?.06+口

r- a. 00 +02

djop. ocale factor $=0.100 E+01$ (defaudt) 
INCRID Code - Flexible Tank - Verification of Fluid Structure Contours of Normal Resultant (myy)

Time $=0.57$ seconds

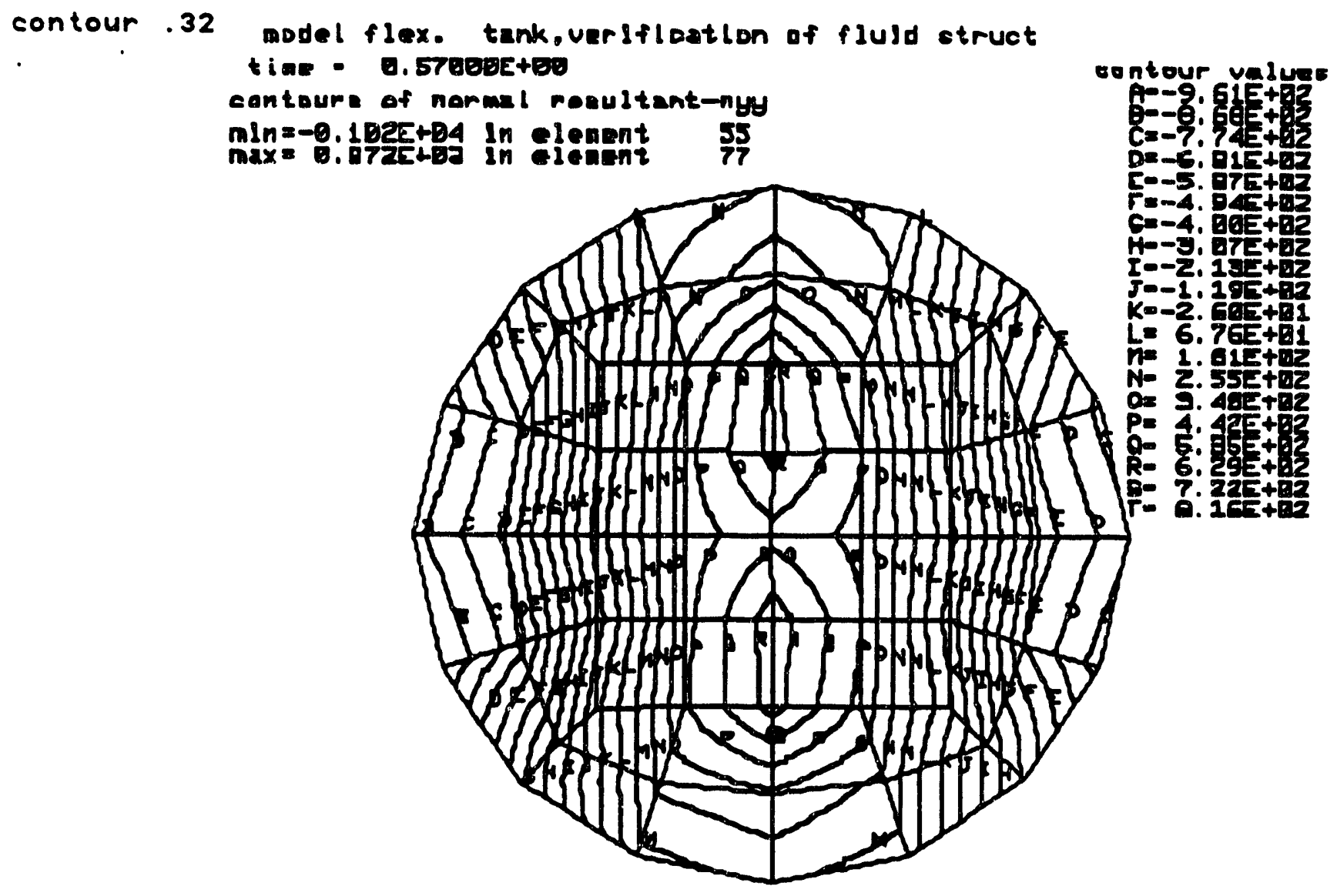

dop. ecale factor $=0.100 E+01$ (defaujt) 
INGRID Code - Flexible Tank - Verification of Fluid Structure Contours of Normal Resultant (mxy)

Time $=0.57$ seconds

.contour 33 model flex. tank, verlflestlon of fluld struct

tine. 0.57860E+E0

contoura of normal roaudtant $-n \times y$
$\operatorname{mln}=-0.546 E+B g$ in eleaent 69

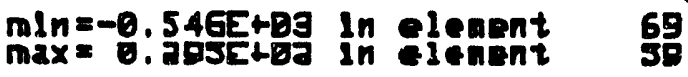

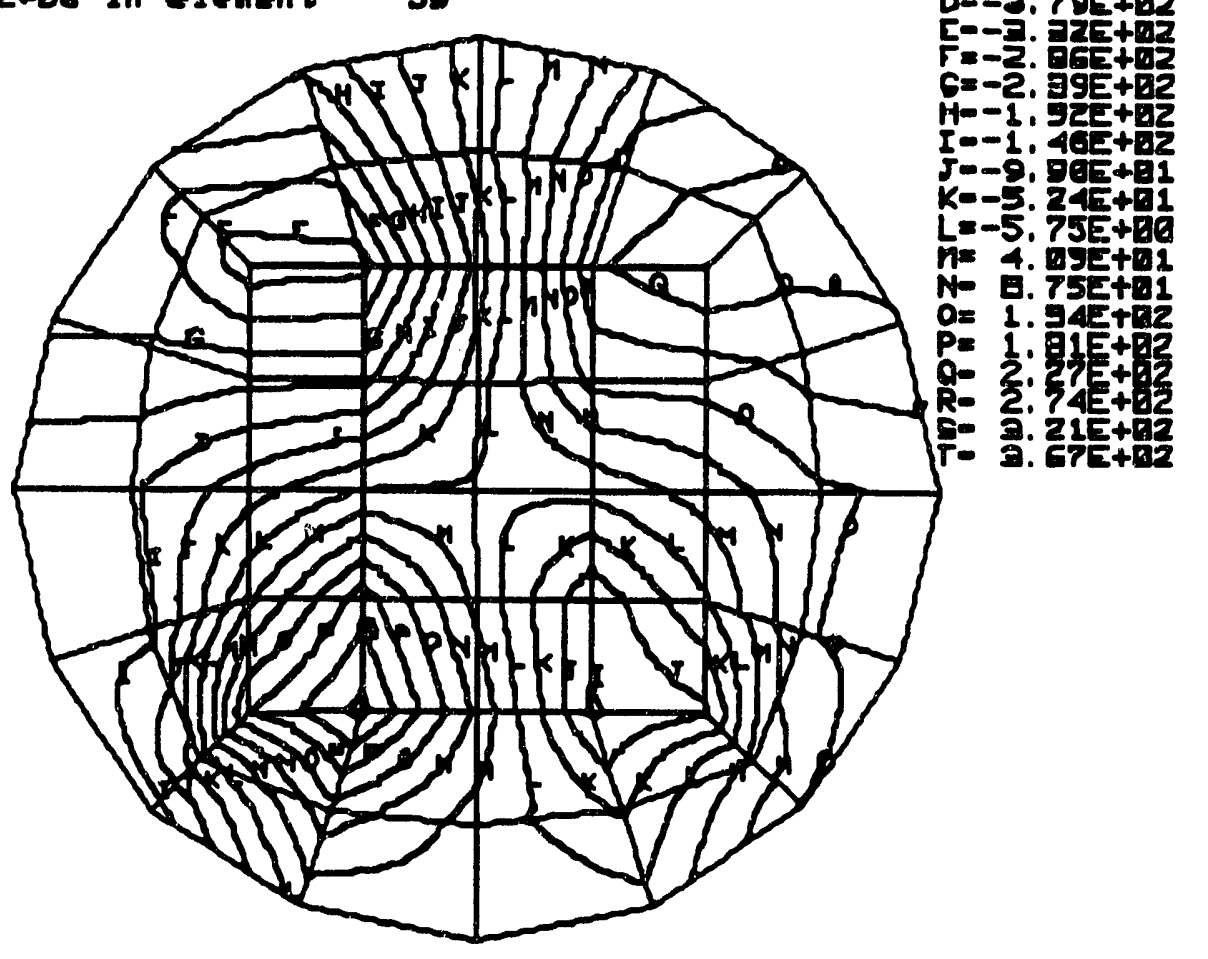

dJap. ocale factor $=0.109 E+01$ (defauJt) 
INCRID Code - Flexible Tank - Verification of Fluid Structure

Contours of Moment Resultant (mxx)

Time $=0.57$ seconds

.contour 26 model flex. tank,verlfleation of flujd atruct

tine - 0.5700EE+E0

cantours of monont roeultant-nxx

$\min _{\max =-0.202 E+02 \text { in elenent } \quad 51}$

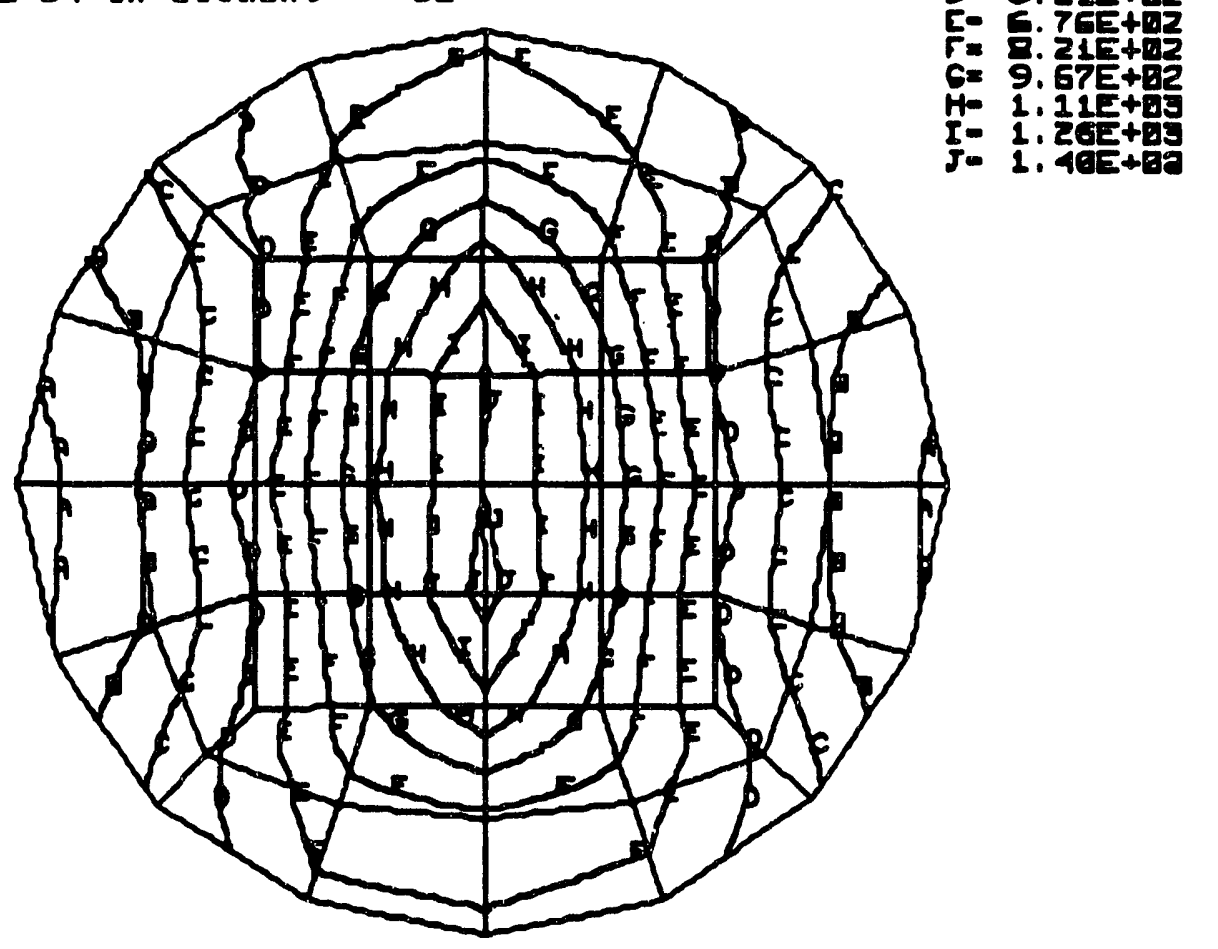

dJop. ocale factor = B.100E+81 (defaujt) 
INGRID Code - Flexible Tank - Verification of Fluid Structure

Contours of Moment Resultant (myy)

Time $=0.57$ seconds

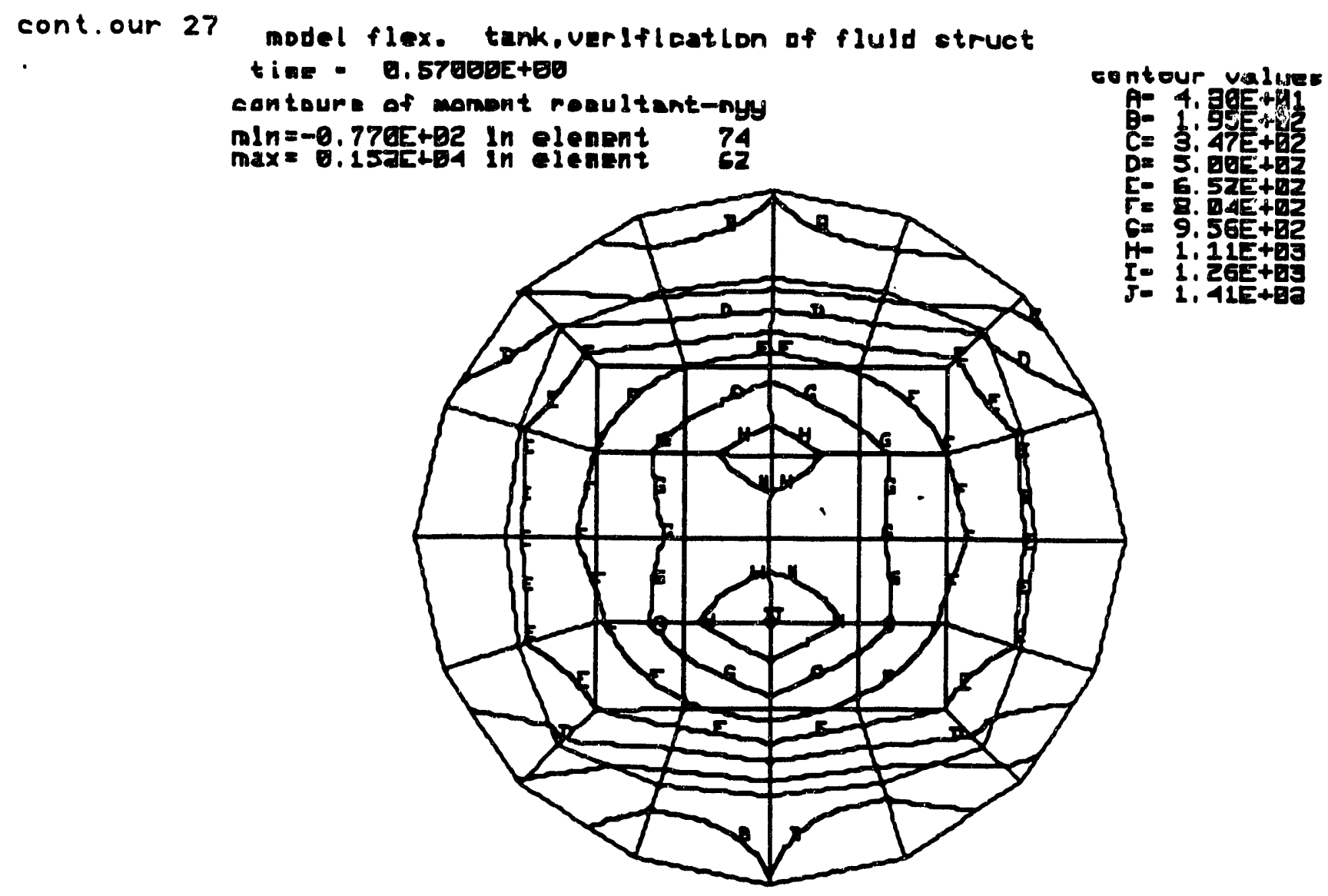

djep. ocale factor $=$ B.100E+01 (defauJt) 
INGRID Code - Flexible Tank - Verification of Fluid Structure Contours of Moment Resultant (nxy)

Time $=0.57$ seconds

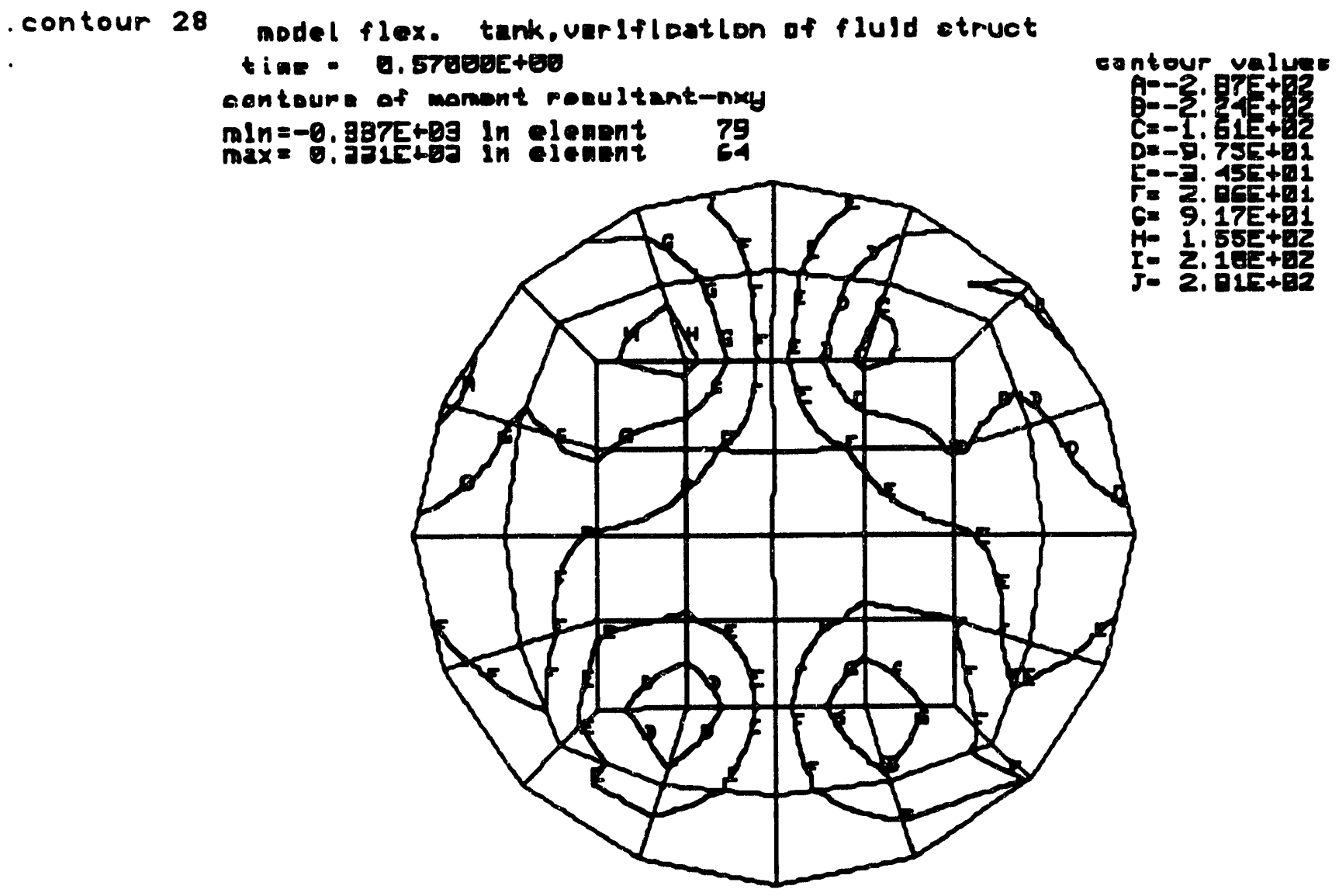

dJop. ecale factor = D.100E+01 (defaujt) 


\section{INGRID Code - Flexible Tank - 3500 Times Viscosity of Water Contours of $X$-displacement}

Time $=0.57$ seconds

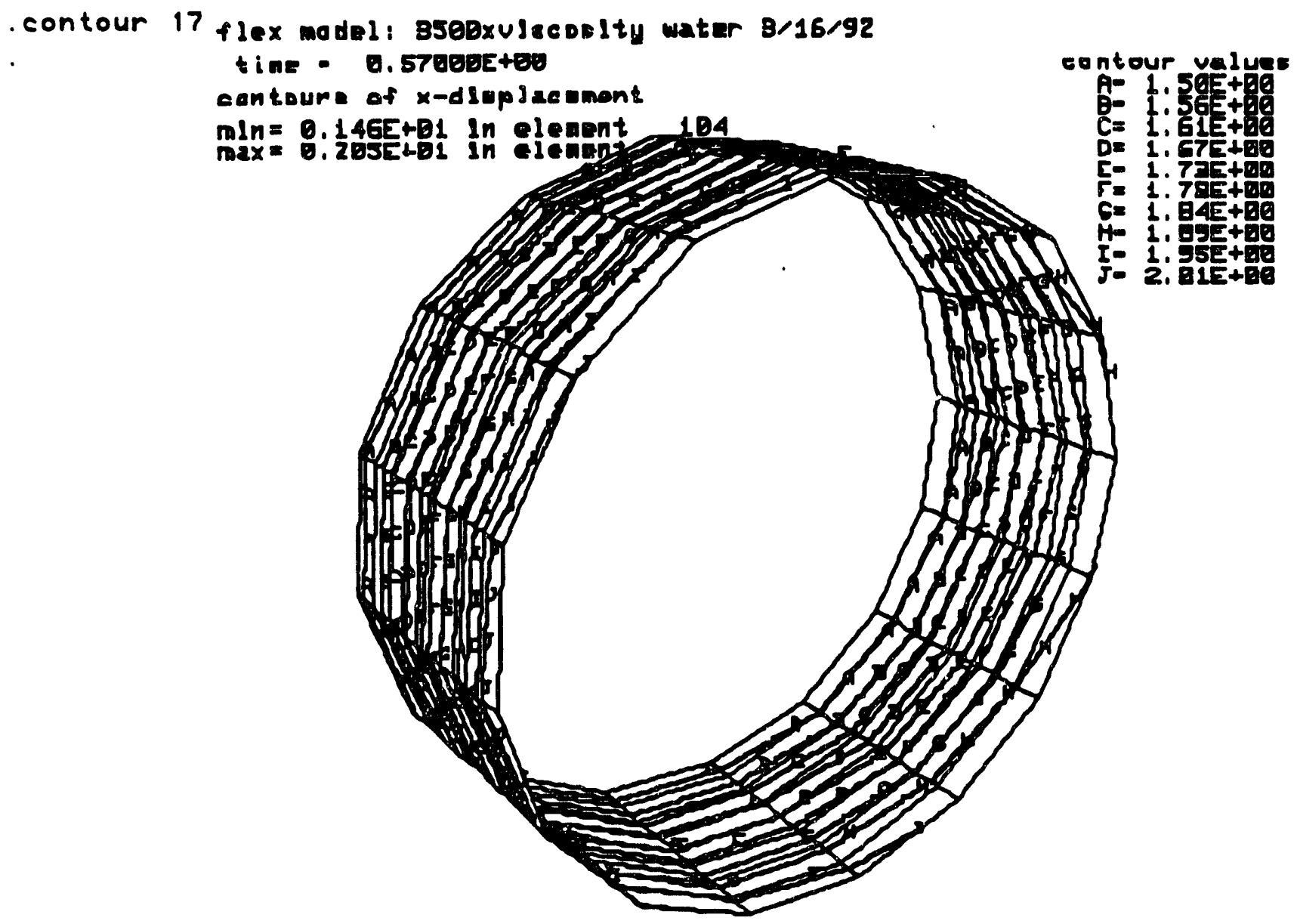

dJep. ecale foctor $=0.100 E+01$ (defauJt) 
INGRID Code - Flexible Tank - 3500 Times Viscosity of Water Contours of $\mathrm{X}$-displacement

Time $=0.57$ seconds

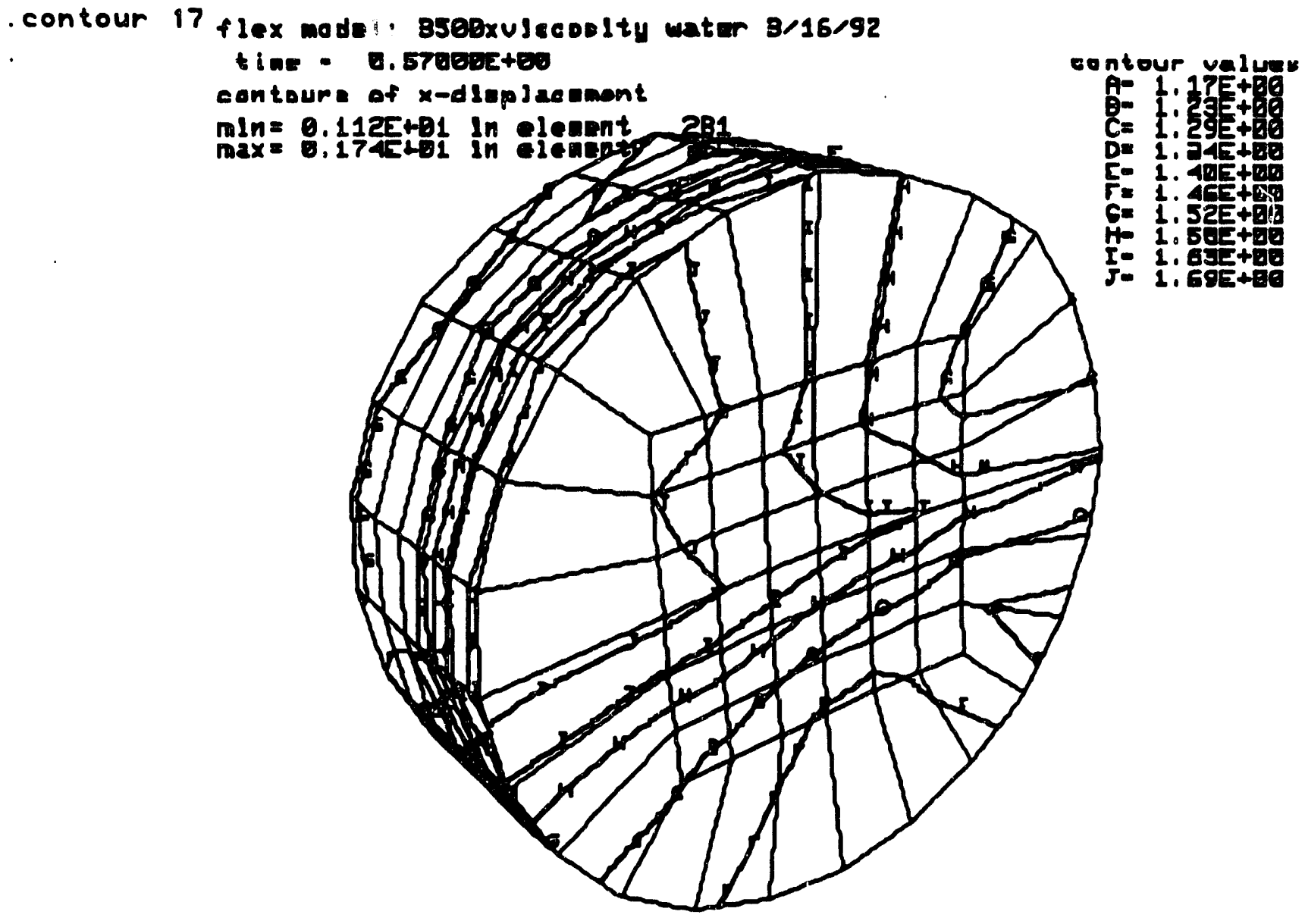

dJop. cale foctor $=0.100 E+01$ (defaujt) 

INGRID Code - Flexible Tank - 3500 Times Viscosity of Water
Contours of $\mathrm{X}$-displacement

Time $=0.57$ seconds

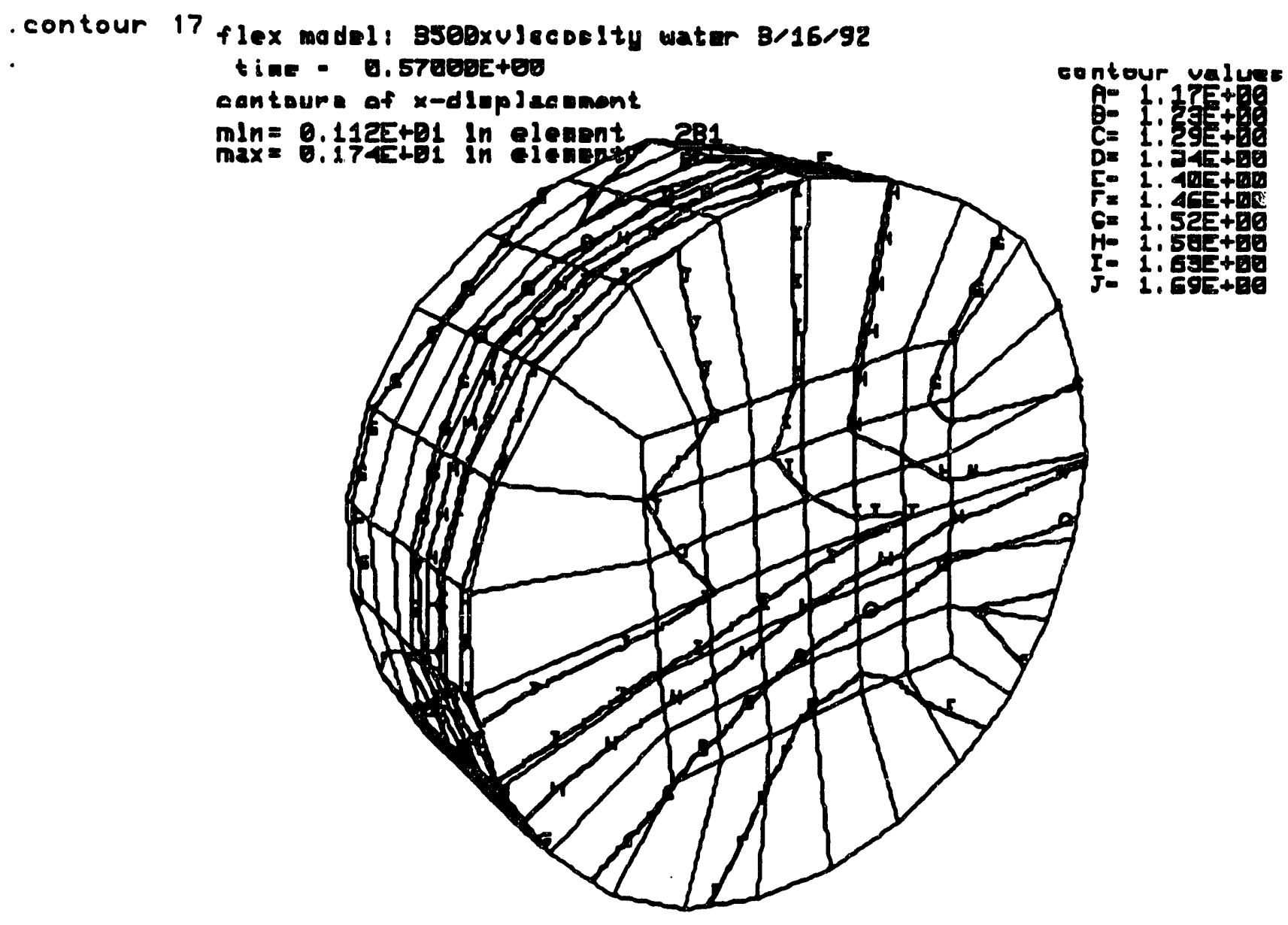

dsop. ecale foctor $=0.100 E+01$ (defaujt) 
INGRID Code - Flexible Tank - 3500 Times Viscosity of Water Contours of Z-displacement

Time $=0.57$ seconds

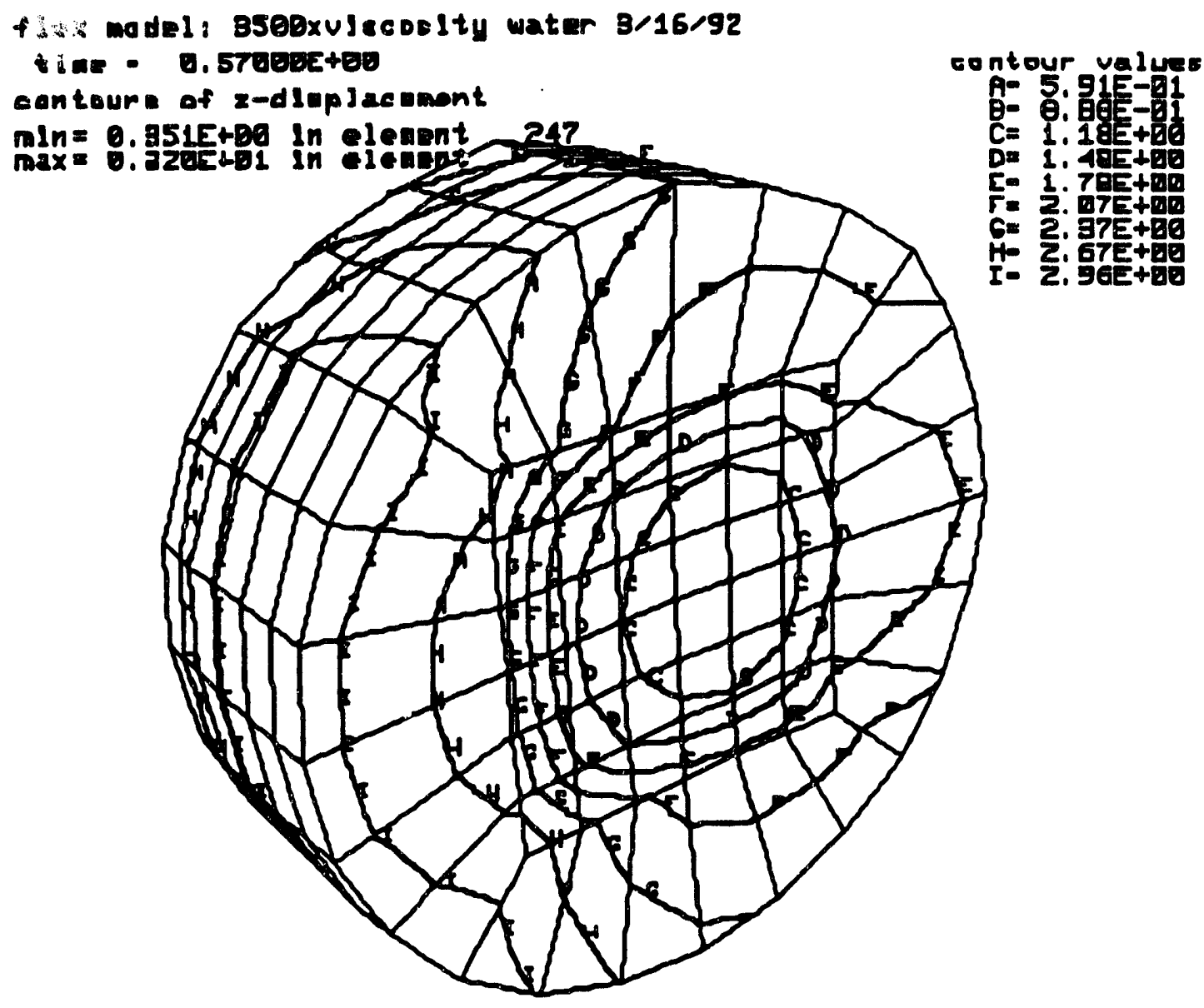

dlop. scale foctor $=$ D.100E+01 (default) 
INGRID Code - Flexible Tank - 3500 Times Viscosity of Water

Contours of Shear Resultant (qxx)

Time $=0.57$ seconds

\section{our 29 flex modeli 350 axulscoolty watar $3 / 16 / 92$ tine - 0.5700BE+E0 cantoure of ohoar moeujtant-qxx

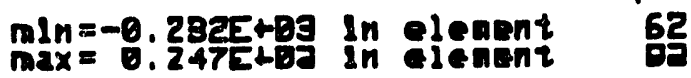

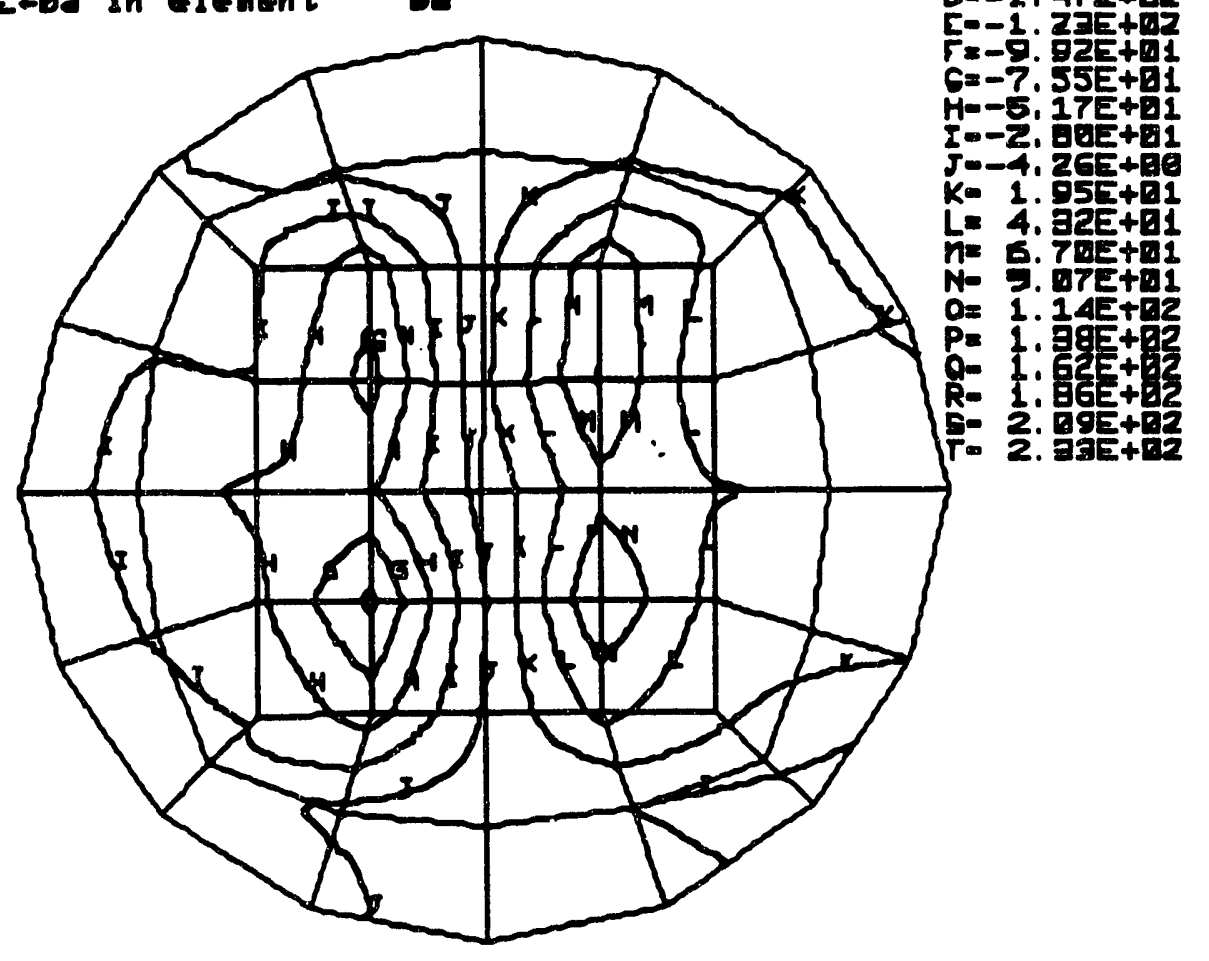

djop. cale factor $=$ D.100E+01 (default) 
INCRID Code - Flexible Tank - 3500 Times Viscosity of Water

Contours of Shear Resultant (qyy)

$$
\text { Time }=0.57 \text { seconds }
$$

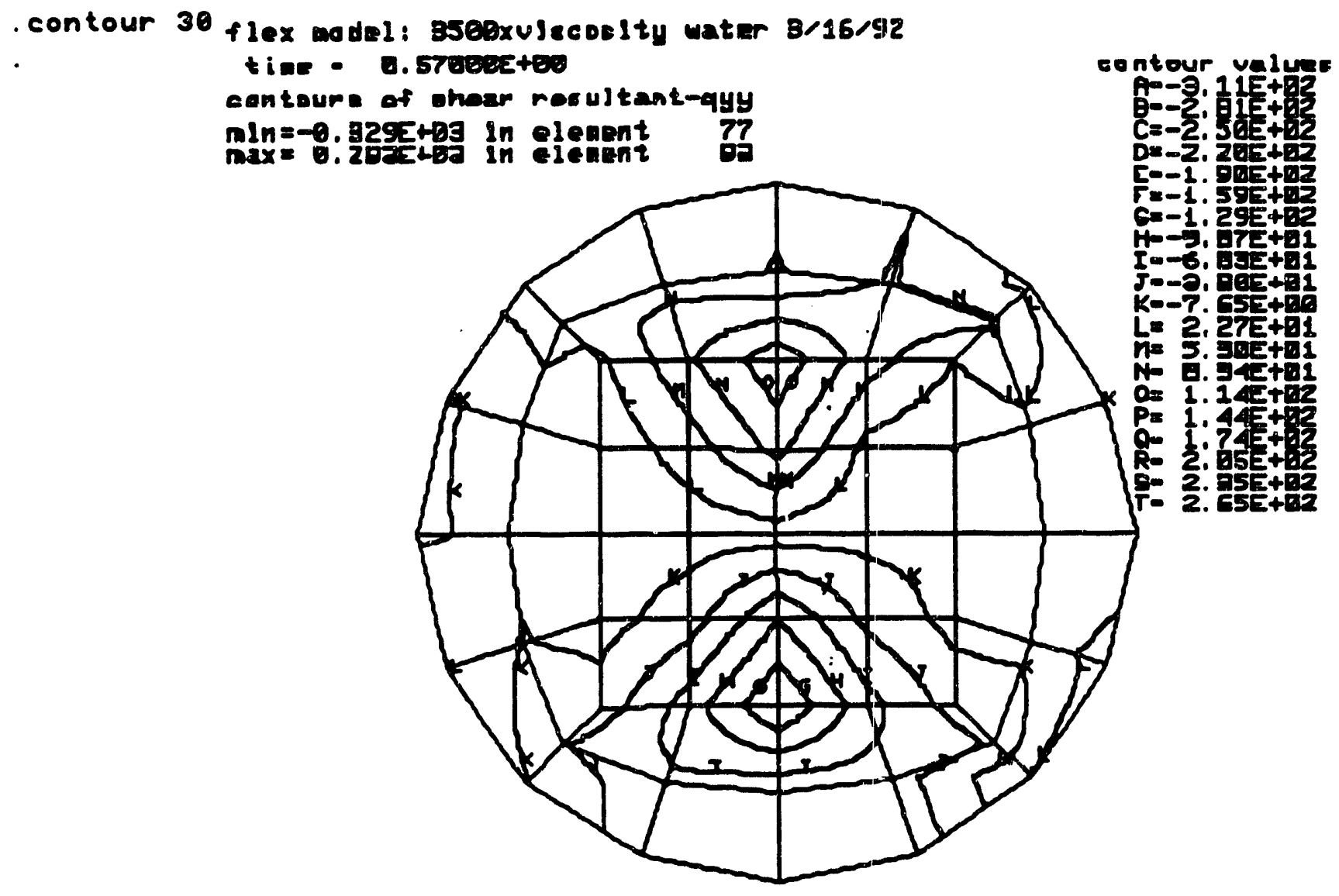

diap. ocale factor $=0.100 E+01$ (default) 
INGRID Code - Flexible Tank - 3500 Times Viscosity of Water

Contours of Normal Resultant (mxx)

Time $=0.57$ seconds

contour 31 flex model: 3508xulscoelty water 3/16/92

tine - O.5708EE+E0

contours of normal rosultant-nxx

$\operatorname{mln}=-0.112 E+B 4$ in element 57

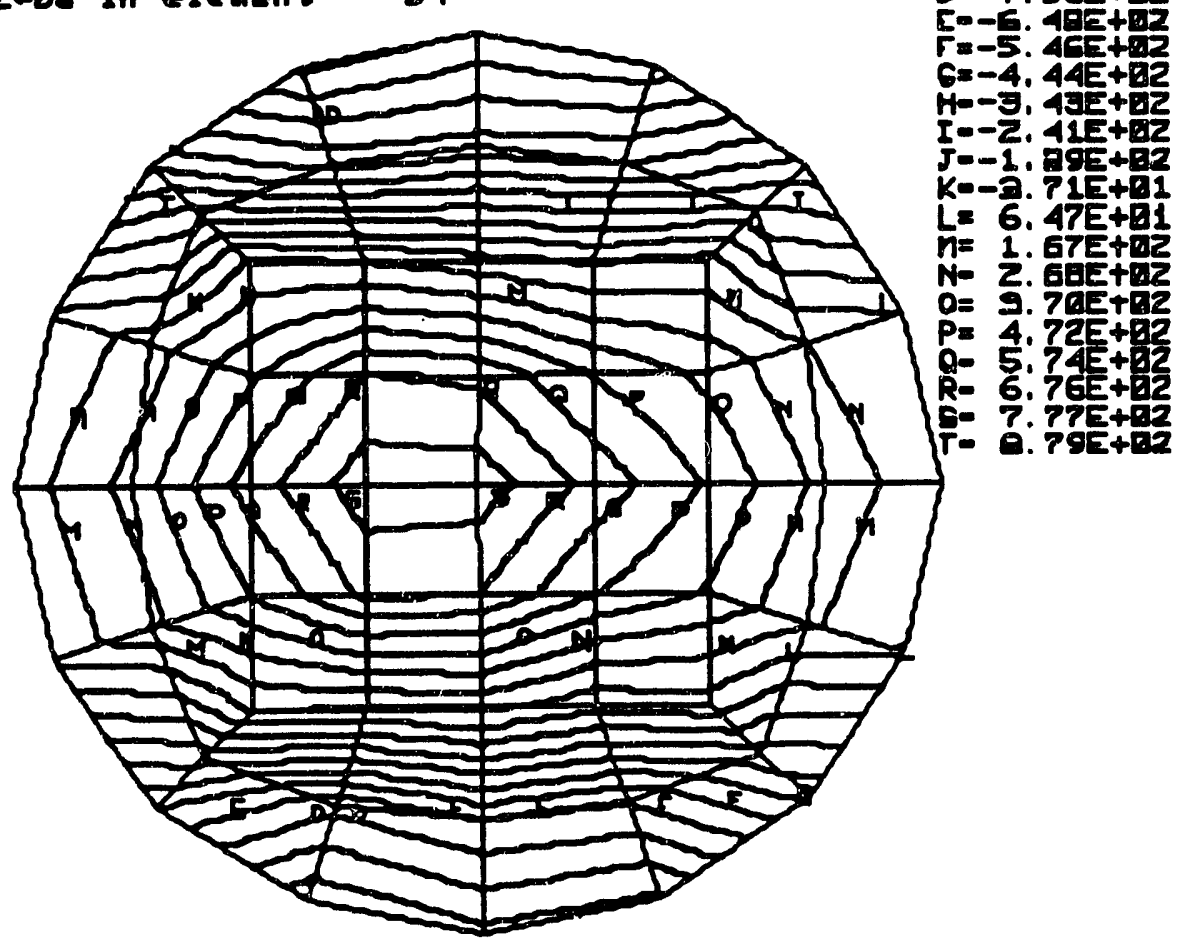

contour values

A- - - . D5E+Bg

$\theta--9,5 j E+12$

$\mathrm{C}=-8.52 E+42$

D=-7. 30 E.

C- $-6.495+202$

$r=-5 \cdot 4 c=+27$

$G=-4,44 E+E 2$

.

. $41=+62$

$n=1,67=+n$

N- 2. $6 a=+42$

$7=+2$

5.7.

$7.795+12$

d)op. ecale fector $=0.100 E+01$ (default) 
INGRID Code - Flexible Tank - 3500 Times Viscosity of Water

Contours of Normal Resultant (myy)

Time $=0.57$ seconds
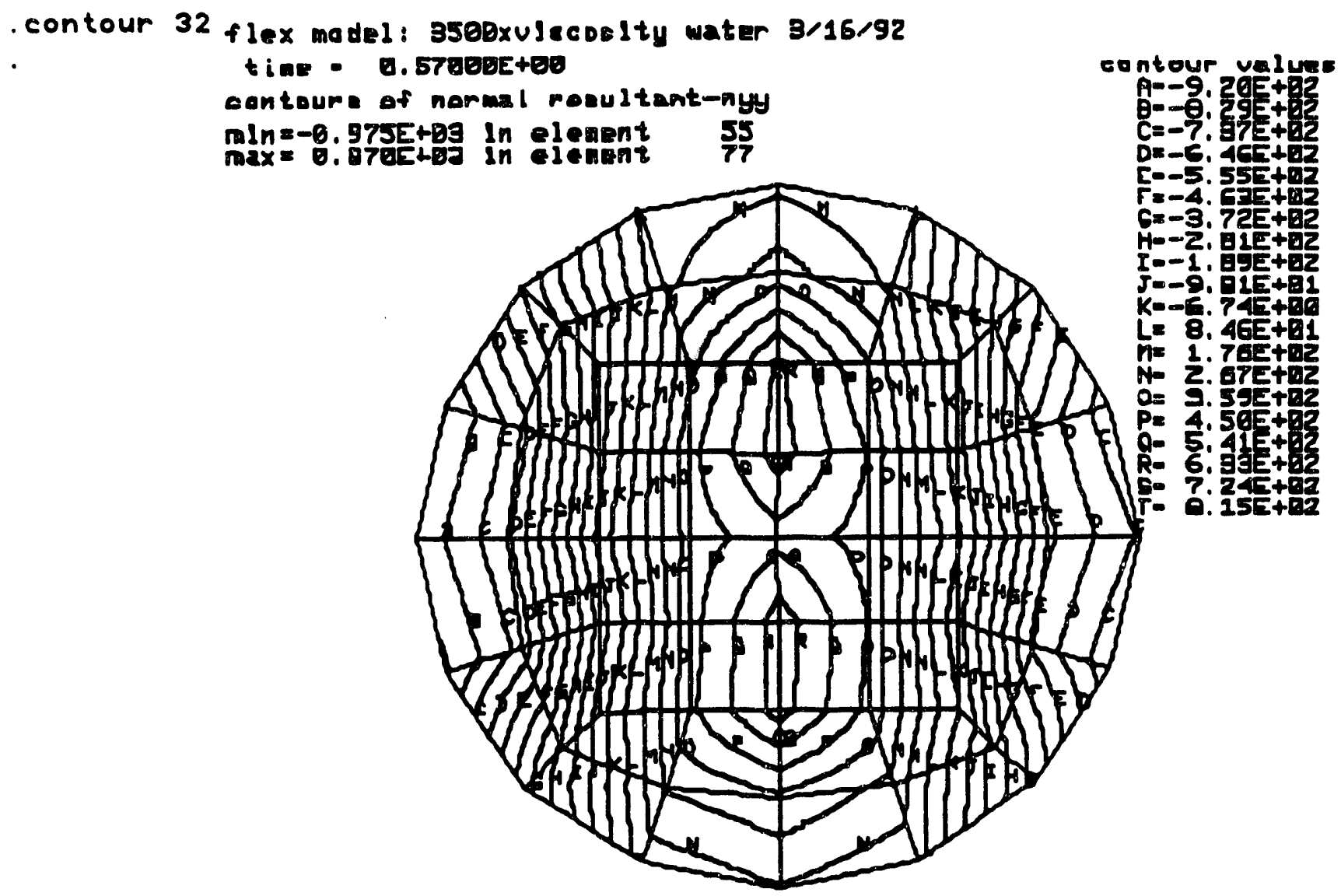

contour values:

A - -9.20E+

$\mathrm{C}=-\mathrm{\theta} \cdot \mathrm{g} g \mathrm{~g}+\mathrm{E}$

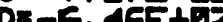

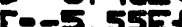

$F=-4$.

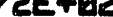

$15+91$

36E+ 1

1.

7. $245+102$

dlop. ocale foctor = B.100E+01 (defauJt) 
INGRID Code - Flexible Tank - 3500 Times Viscosity of Water Contours of Normal Resultant (mxy)

$$
\text { Time }=0.57 \text { seconds }
$$

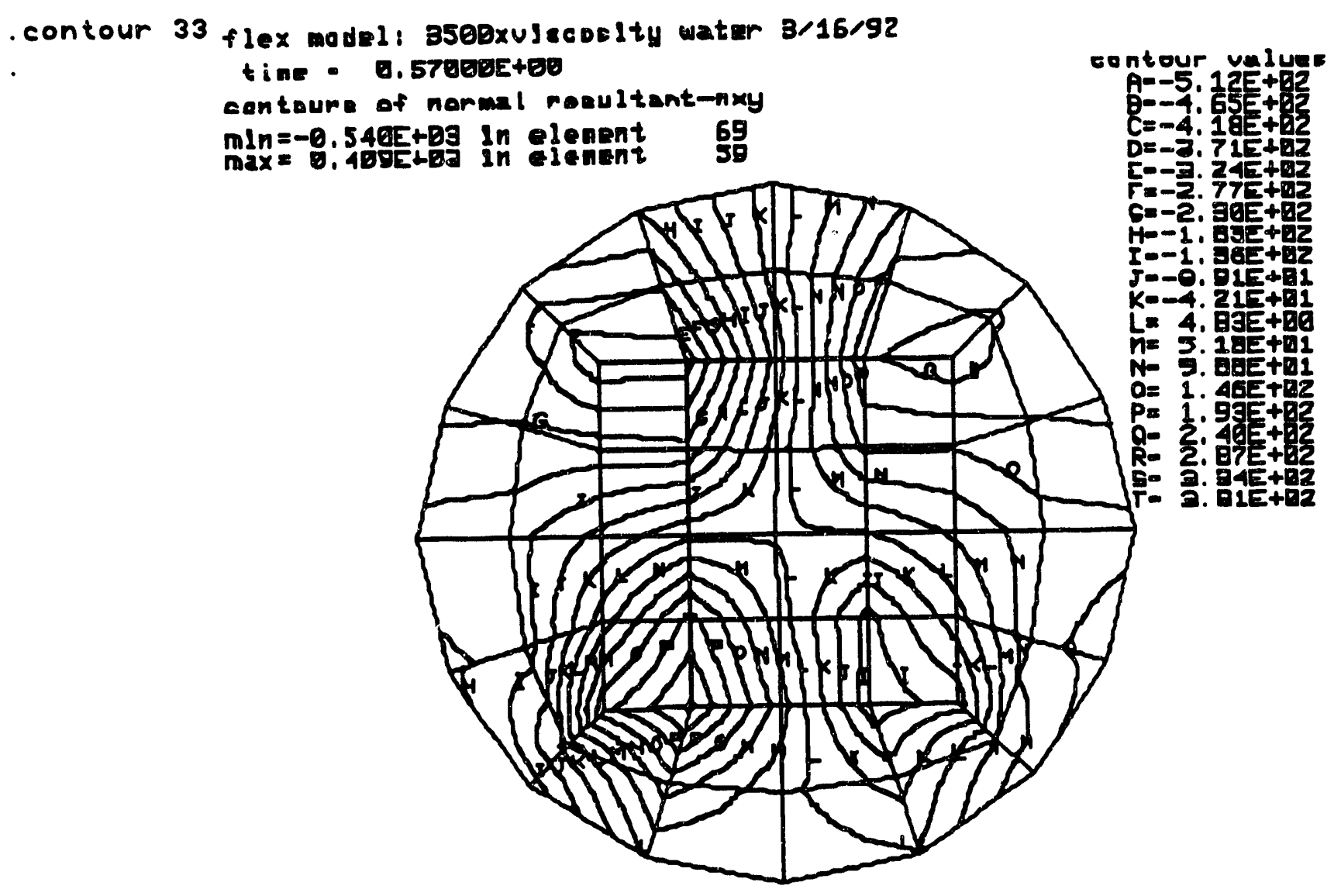

d)p. ecale foctor $=0.100 E+01$ (defaujt) 
INGRID Code - Flexibia Tank - 3500 Times Viscosity of Water

Contours of Moment Resultant (mxx)

Time $=0.57$ seroinds
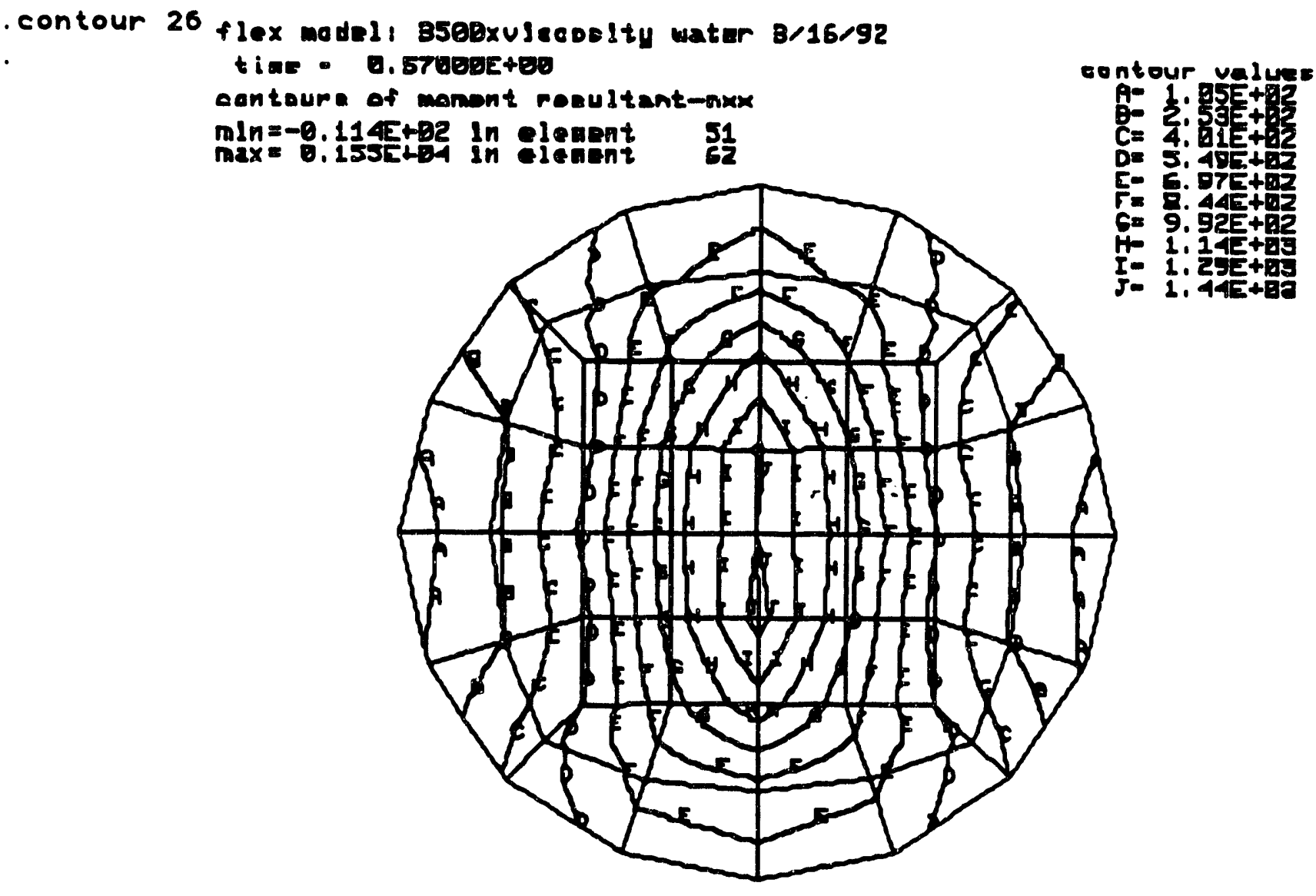

dJop. ecale foctor = B.100E+01 (defaudt) 
INGRID Code - Flexible Tank - 3500 Times Viscosity of Water

Contours of Moment Resultant (myy)

Time $=0.57$ seconds

. contour 27 flex model, B50Dxulecoelty water 3/16/92

tine - 0.57008E+E0

cantoure of monont rooultant-nyy

$\operatorname{mln}=-0.152 E+B 2$
$\max =0.155 E+b 4$

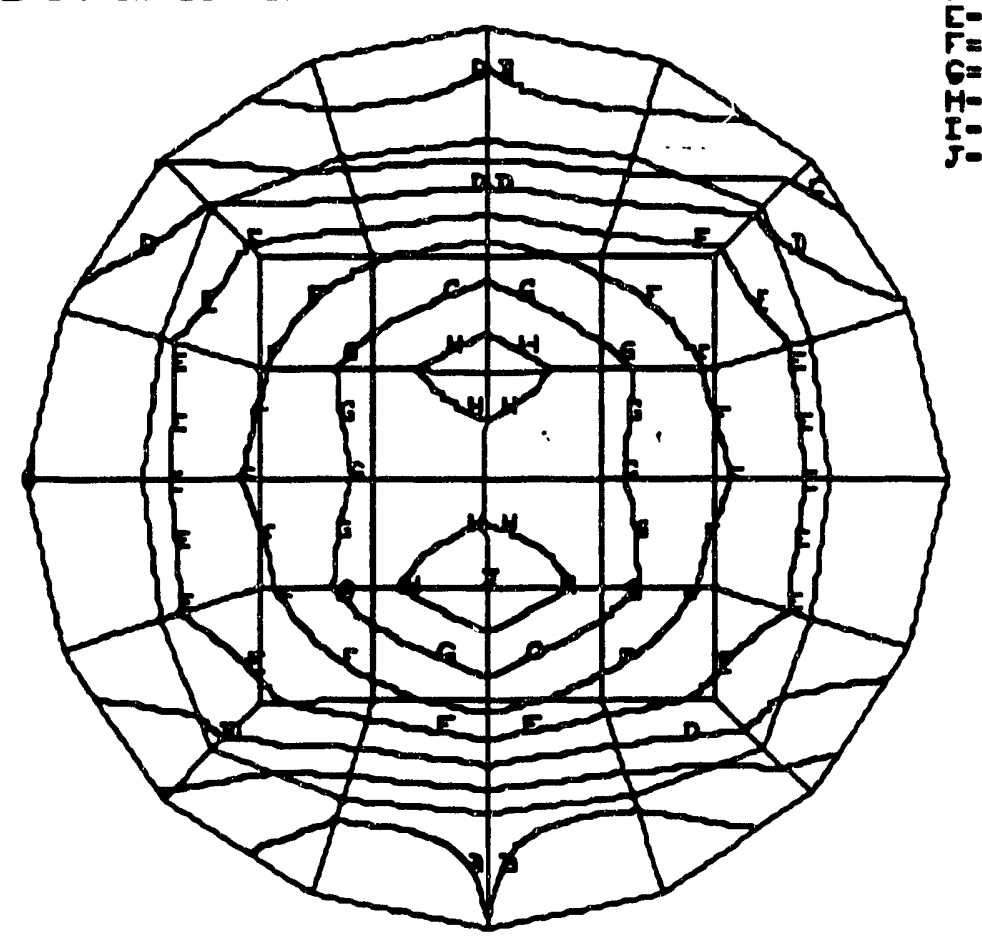

contour yadues

A- 3. 6eE+ 1

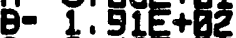

$\mathrm{C}=3.46 E+2$

D. 5. $01 E+E 2$

E- G.56E+D2

$F=\mathrm{g} \cdot 10 \mathrm{E}+\mathrm{D} 2$

$G=9.65 E+\square 2$

H- $1,12 E+\theta 9$

I- 1 . 27E+Q3

Jo 1. 4อE+Ba

dJop. ecale foctor $=0.100 E+01$ (defauJt) 
INGRID Code - Flexible Tank - 3500 Times Viscosity of Water Contours of Moment Resultant (mxy)

Time $=0.57$ seconds

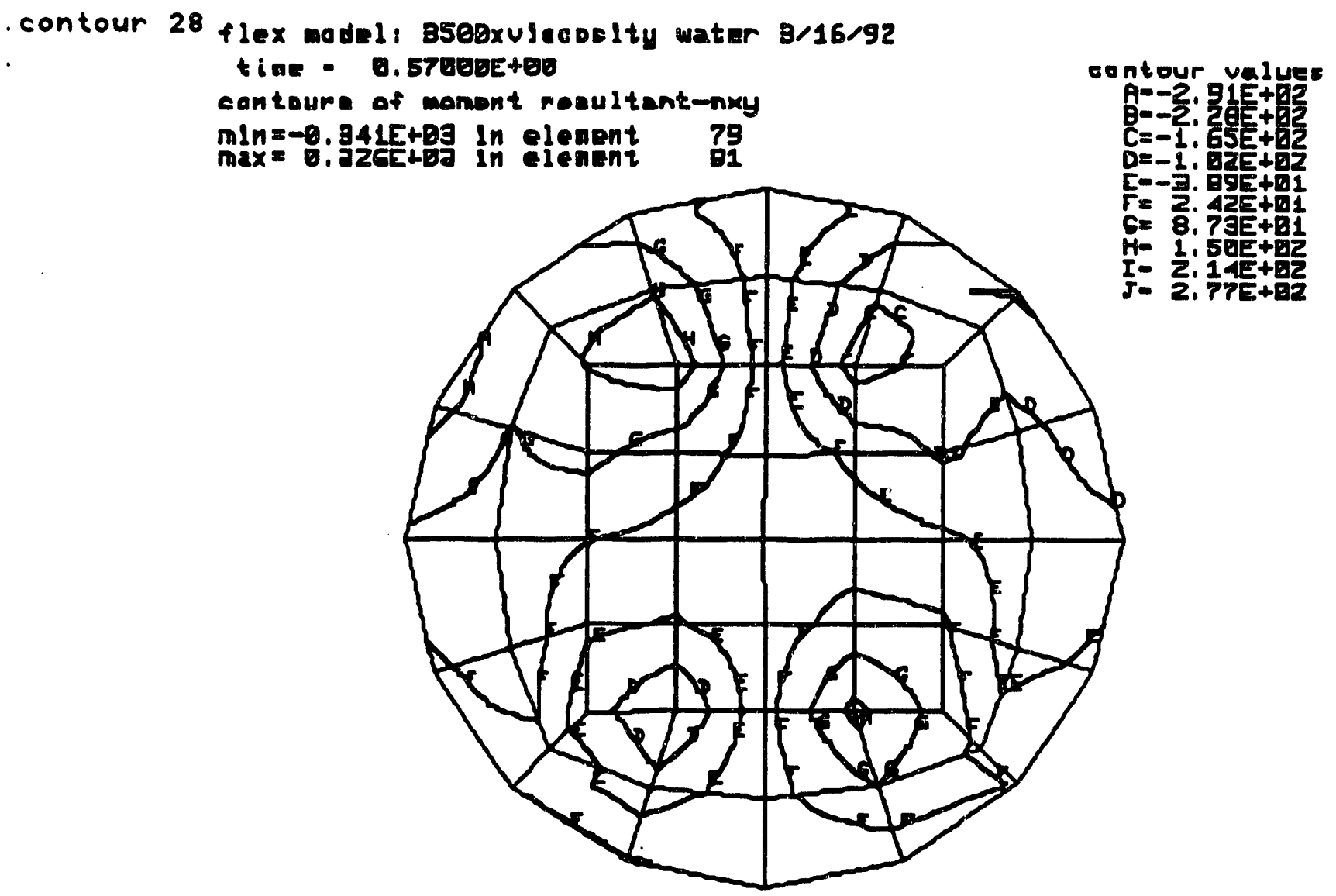

djop. ocale foctor = D.100E+01 (defauJt) 
INGRID Code - Flexible Tank - Verification of Fluid Structure

.ntime 33312 godelfflex. tank, verlflcatlon of fluld etruet

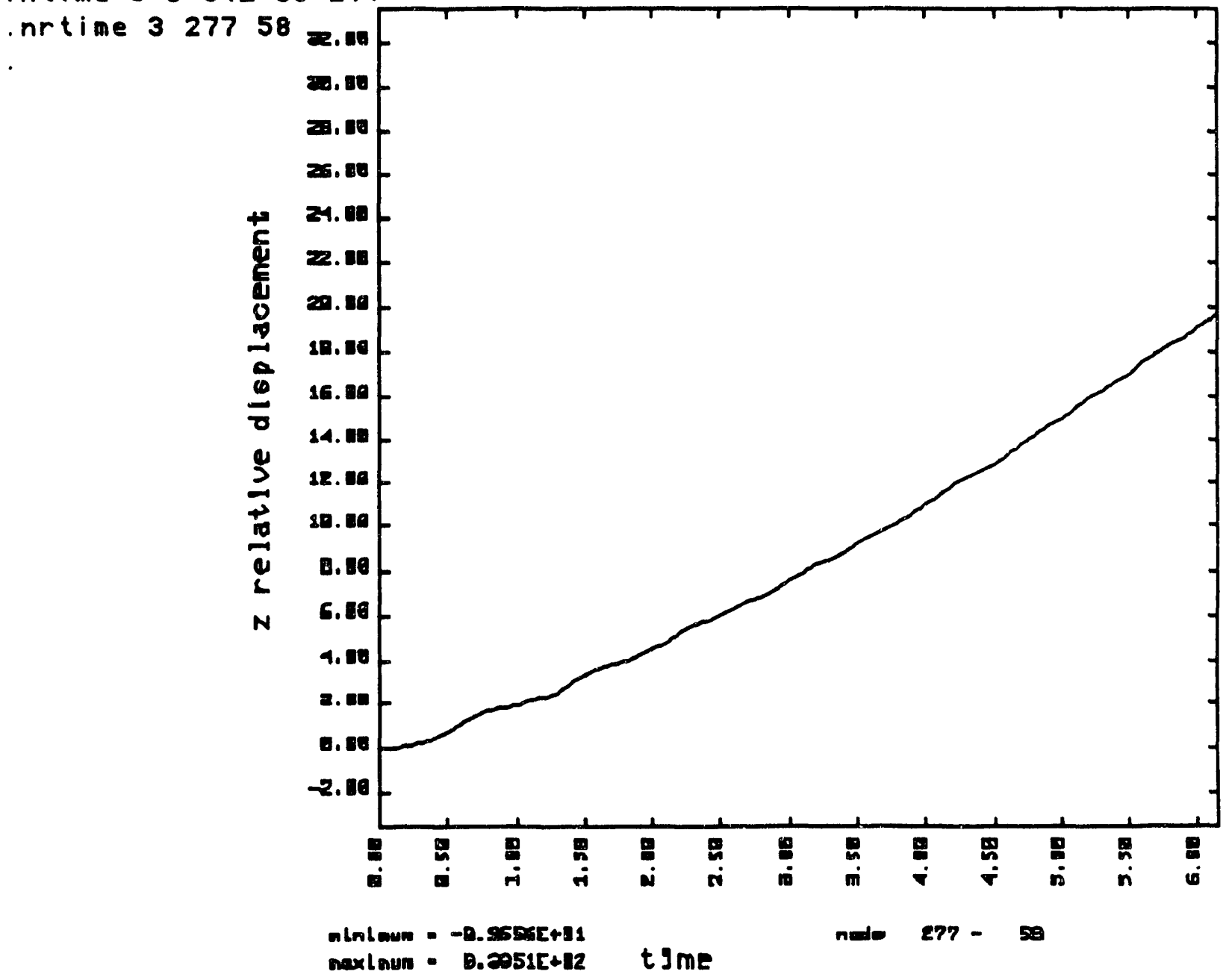



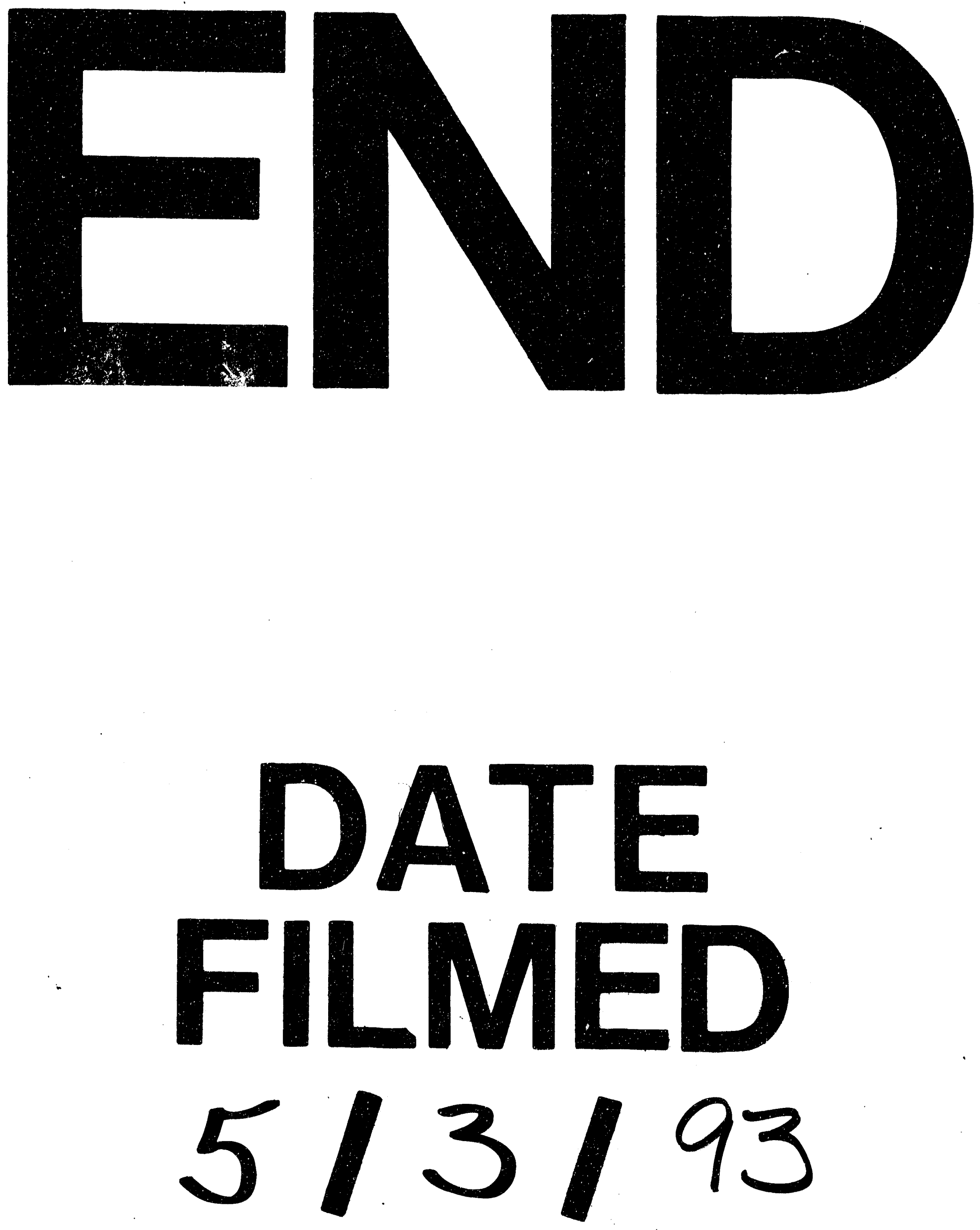
